

SISTEMAS Y SERVICIOS DE INFORMACIÓN DIGITAL 



\section{SISTEMAS Y SERVICIOS DE INFORMACIÓN DIGITAL}

Ernest Abadal Falgueras

EDICIONES TREA, S. L. 


\section{BIBLIOTECONOMÍA Y ADMINISTRACIÓN CULTURAL - 47}

(C) Ernest Abadal Falgueras, 2001

(C) de esta edición:

Ediciones Trea, S. L. y Edicions de la Universitat de Barcelona, S. L. U.

Ediciones TREA, S. L.

Donoso Cortés, 7, bajo. 33204 Gijón (Asturias)

Tel.: 9851334 52. Fax: 985131182

Edicions de la UniVERSITAT DE BARCElONA, S. L. U.

Balmes, 25, 2. ${ }^{\circ}, 2 .^{\text {a }} 08007$ Barcelona

Tel.: 9340355 30. Fax: 934035531

Cubiertas: Impreso Estudio (Oviedo)

Impresión: Gráficas Apel, s. L. (Gijón)

Encuadernación: Encuadernaciones Cimadevilla, s. L. (Gijón)

Depósito legal: As.-194-2001

ISBN: 84-95178-98-2 (Ediciones Trea)

ISBN: 84-8338-265-2 (Edicions de la Universitat de Barcelona)

Impreso en España - Printed in Spain

Todos los derechos reservados. No se permite la reproducción total o parcial de este libro, ni su incorporación a un sistema informático, ni su transmisión en cualquier forma o por cualquier medio, sea éste electrónico, mecánico, por fotocopia, por grabación u otros métodos, sin el permiso previo por escrito de Ediciones Trea, s. L. y Edicions de la Universitat de Barcelona, S. L. U. 


\section{SUMARIO}

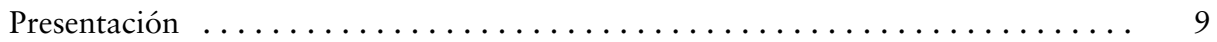

1. El documento y la transmisión del saber $\ldots \ldots \ldots \ldots \ldots \ldots \ldots \ldots \ldots \ldots \ldots$

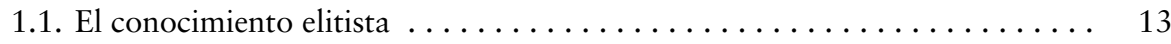

1.2. La reproducibilidad técnica de los documentos $\ldots \ldots \ldots \ldots \ldots \ldots . \ldots 14$

1.3. La distribución de la información en las redes $\ldots \ldots \ldots \ldots \ldots \ldots \ldots$

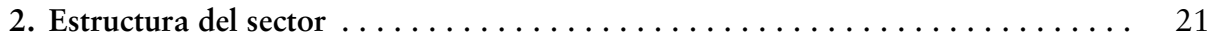

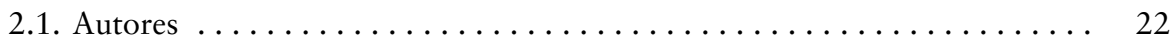

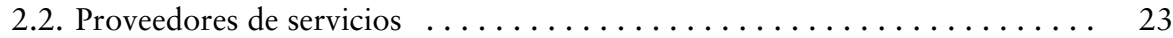

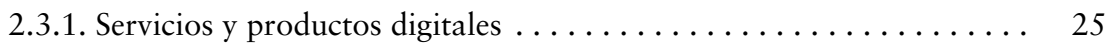

2.4. Distribuidores (o centros servidores) $\ldots \ldots \ldots \ldots \ldots \ldots \ldots \ldots \ldots .26$

2.4.1. Sistema de acceso y recuperación de la información $\ldots \ldots \ldots \ldots 27$

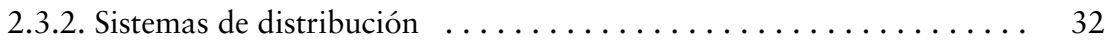

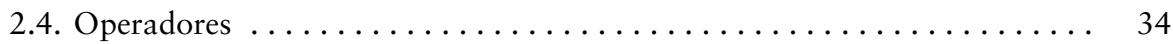

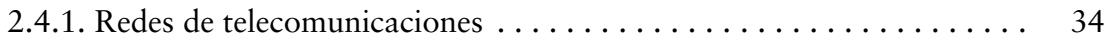

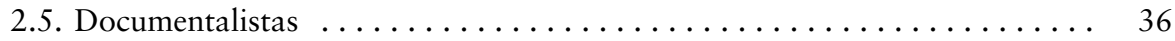

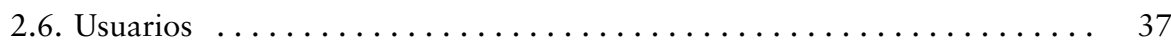

2.6.1. Equipos y programas informáticos $\ldots \ldots \ldots \ldots \ldots \ldots \ldots \ldots \ldots \ldots$

3. Los productos de información digital $\ldots \ldots \ldots \ldots \ldots \ldots \ldots \ldots \ldots \ldots, 41$

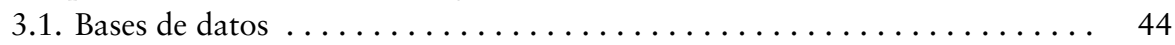

3.1.1. Bases de datos de ciencia y tecnología $\ldots \ldots \ldots \ldots \ldots \ldots \ldots .48$

3.1.2. Bases de datos de información económica y de negocios ........ 50

3.1.3. Bases de datos y servicios de información dirigidos al gran público .. 51

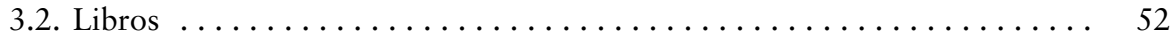

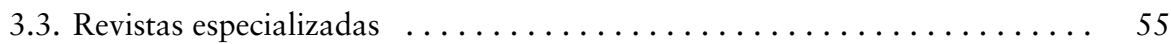

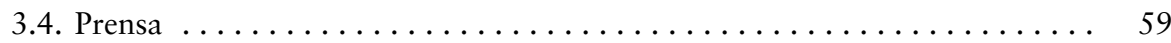

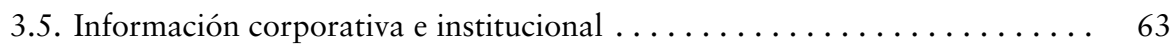

3.6. Problemas ................................. 64 


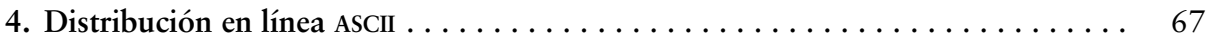

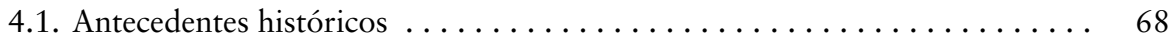

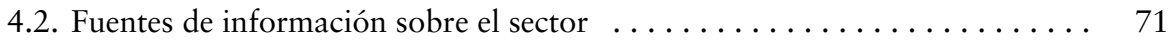

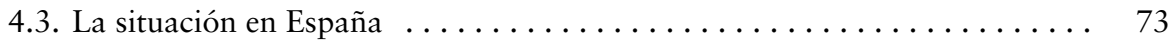

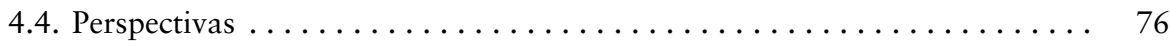

5. El Web, el nuevo estándar de distribución $\ldots \ldots \ldots \ldots \ldots \ldots \ldots$

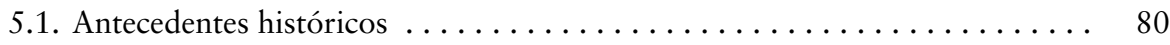

5.2. Fuentes de información sobre el sector: los localizadores de recursos $\ldots \ldots 84$

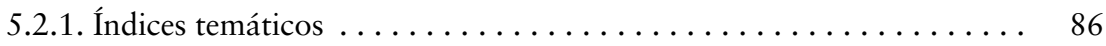

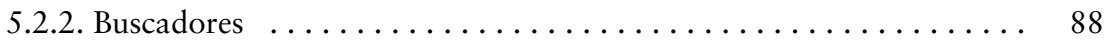

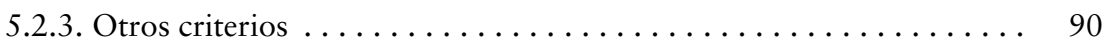

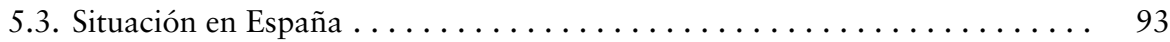

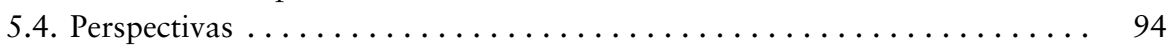

6. La edición óptica, el paso intermedio entre el papel y la Red . . . . . . . . 99

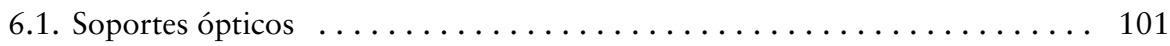

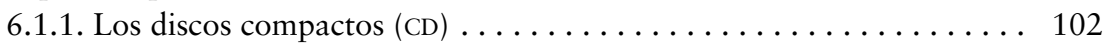

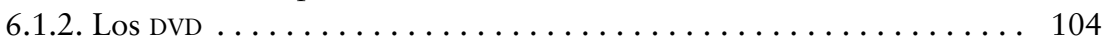

6.2. Fuentes de información sobre el sector $\ldots \ldots \ldots \ldots \ldots \ldots \ldots \ldots \ldots \ldots$

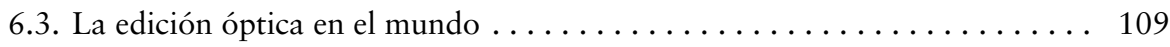

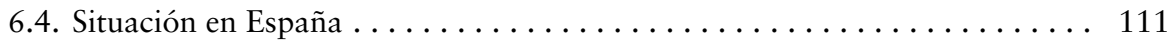

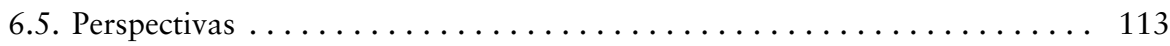

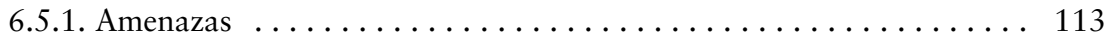

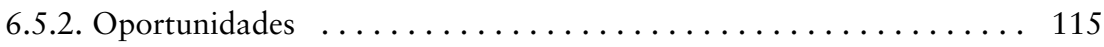

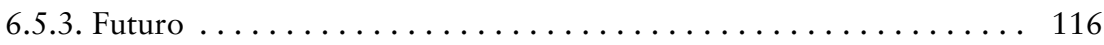

7. Economía y cultura en un mundo global . . . . . . . . . . . . . . . . 119

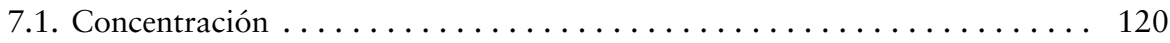

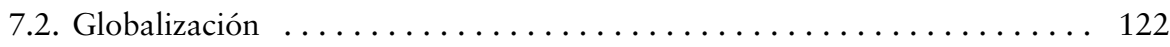

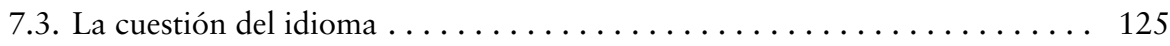

8. Las publicaciones del futuro y el futuro de las publicaciones . . . . . . . . 131

8.1. ¿Documento impreso o digital? La discusión sobre el soporte . . . . . . . . 131

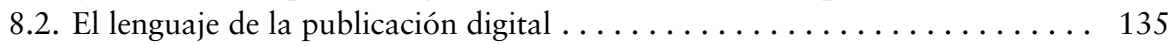

8.3. El tipo de información $\ldots \ldots \ldots \ldots \ldots \ldots \ldots \ldots \ldots \ldots \ldots \ldots \ldots \ldots \ldots$

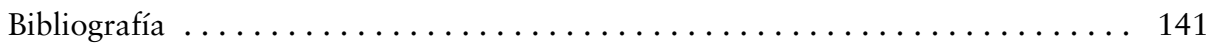

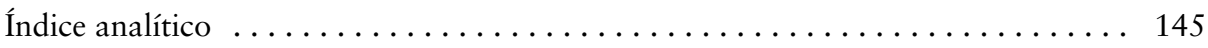




\section{PRESENTACIÓN}

El presente texto es la actualización y reescritura en español de Els serveis d'informació electrònica: què són i per a què serveixen, obra publicada en 1997 por Edicions de la UB. Aunque sólo han pasado cuatro años desde su publicación, se han tenido que revisar bastantes aspectos, pues el texto se centra en un ámbito en el que se han producido muchos cambios en poco tiempo.

A simple vista, una de las modificaciones más perceptibles se refleja en el mismo título de la obra. Si en 1997 adoptamos el término información electrónica para referirnos al sector, actualmente está plenamente consolidada y es más pertinente la denominación información digital. Por otro lado, comparando ambos sumarios se echa en falta, en la nueva edición, la inclusión de algunas formas de distribución que en aquel entonces aún tenían algún peso, como el videotexto -que ya iniciaba, no obstante, su declive imparable hacia la desaparición- u otras, como el audiotexto y el teletexto, que, aunque son sistemas de distribución en uso, se han descartado del presente análisis por su importancia secundaria y por el bajo nivel de interactividad que permiten.

En lo que respecta a los elementos analizados, hay que resaltar que el tratamiento de Internet y el Web son, sin ninguna duda, los que más han cambiado el libro. Y esto no atañe tan sólo al capítulo específico en el que se estudia el Web como forma de distribución, sino también a otros apartados de carácter más general, donde hay que apuntar la situación y las tendencias actuales del sector, así como al enorme cúmulo de direcciones web que se añaden para ayudar a conocer las últimas novedades sobre empresas y productos que aparecen citados por todo el libro.

El propósito general de este texto no es otro que el de explicar de forma clara cuáles son la estructura y las características del sector de la información digital, 
un ámbito que surge de la confluencia de los avances registrados en la tecnología informática, las telecomunicaciones y el almacenaje de la información (en especial los discos ópticos). La cuestión se aborda a un nivel introductorio y global, con el afán de situar el amplio contexto en el que se enmarca este sector.

Dentro de este enfoque general, los objetivos específicos son los siguientes:

- Mostrar los elementos y agentes que intervienen en el ciclo de producción y distribución de información digital.

- Describir cómo son los documentos y sistemas de información digitales: su tipología, su forma de consulta y los sistemas de distribución que utilizan.

- Presentar un análisis sobre la situación actual y las perspectivas de futuro respecto de la publicación digital.

El enfoque de la obra, de tipo divulgativo, le da un carácter introductorio que sirve para conocer las líneas generales de este sector. El público al cual se dirige es más bien universitario, en especial alumnos del ámbito de la Biblioteconomía y Documentación, o de asignaturas relacionadas con esta especialidad que se imparten en otras titulaciones. Ahora bien, también puede interesar y ser útil a todas aquellas personas que quieren disponer de una visión general de un sector tan emergente y de actualidad como el de la información digital.

Aunque el libro no está explícitamente dividido en partes, podríamos explicar su estructura y contenido agrupando los capítulos en cuatro grandes bloques.

En primer lugar, se encuentra un apartado introductorio que incluye el capítulo 1, «El documento y la transmisión del saber», que sitúa a la información digital en el contexto de la evolución histórica de las formas de transmisión del saber. La difusión del conocimiento se podría sintetizar en tres grandes etapas: la primera correspondería a la transmisión oral del saber, defendida por diferentes pensadores clásicos como una manera de llegar exclusivamente a las mentes preparadas; la segunda empezaría cuando el saber queda registrado en soportes documentales de difusión masiva —es decir, que se pueden reproducir en seriey se convierte en la forma básica de difusión de cultura; y, finalmente, la última etapa estaría marcada por la codificación binaria de la información y su distribución en formato digital, la creación de productos y servicios de información digital y su distribución a través de las autopistas de la información.

En segundo lugar aparece una caracterización general del sector, que comprende los capítulos 2 y 3 , en la que se describen la estructura y los principales pro- 
ductos del sector de la información digital. Así pues, en «Estructura del sector» se presenta, de forma general, a los principales agentes del sector (proveedores, distribuidores, operadores, usuarios), el objeto del que se ocupan (tipología de servicios, sistemas de distribución y de recuperación, tipos de redes y de equipos informáticos) y las funciones que cada uno realiza. Por su parte, el capítulo 3, «Los productos de información digital», se centra en describir los principales tipos de publicación digital: las bases de datos, los libros, las revistas especializadas, la prensa de masas y la información corporativa. En resumen, se trata de presentar y definir, en líneas generales, cuáles son los conceptos básicos que se necesitan para la comprensión del resto del texto.

El tercer bloque se centra en la descripción y análisis de los sistemas de distribución y abraza los capítulo 4, 5 y 6 . Tres son las formas básicas de distribución de información digital: el formato ASCII, que aún se utiliza en el mercado de bases de datos; el formato web y la edición óptica. A cada uno de estos sistemas se le destina un capítulo en el que se describen las principales características de cada una de las formas de distribución, sus antecedentes históricos, los principales directorios y fuentes de información para conocer la oferta existente en la actualidad, la situación en España y las perspectivas de futuro.

Finalmente, se presenta un cuarto bloque, desarrollado en los capítulos 7 y 8 , que tiene por objeto realizar un análisis sobre la situación actual del sector de la información digital. Así pues, en primer lugar, en «Economía y cultura en un mundo global» se ubica este sector dentro de lo que se han denominado industrias de la cultura y se analizan las actuales tendencias en este ámbito - la concentración empresarial y la globalización- y los peligros o problemas que se pueden derivar, en especial, de las cuestiones relacionadas con la identitad cultural. A continuación, en «Las publicaciones del futuro y el futuro de las publicaciones», se hacen una serie de reflexiones sobre el porvenir de la publicación digital, repasando diversas cuestiones como la competencia entre el papel y la distribución digital, las características de expresión de la publicación digital y la confrontación entre texto e imagen.

Las citas bibliográficas aparecen recogidas al final del texto y no son muy numerosas, pues se ha procurado limitar su número priorizándose la inclusión de textos de carácter básico y fundamental. Por otro lado, y en la medida de lo posible, se ha dado preferencia a la presencia de documentos escritos en castellano. 



\section{EL DOCUMENTO Y LA TRANSMISIÓN DEL SABER}

\subsection{EL CONOCIMIENTO ELITISTA}

A causa de la limitada difusión de la información conseguida por la comunicación oral, las sociedades humanas han optado por el registro de esta información sobre algún soporte material, ya sean tabletas de barro, papiros, pergaminos, papel o discos ópticos. Si todo el conocimiento se tuviera que transmitir exclusivamente de forma oral, probablemente en estos momentos no disfrutaríamos de muchas de las ventajas que han permitido los avances científicos y técnicos. Grabar la información asegura tanto su permanencia como la posibilidad de difundirla, constituyendo así una de las bases de la cultura.

Ahora bien, esta tendencia que nos parece de lo más normal chocó, en la antigüedad, con las reticencias de algunos de los pensadores más influyentes. Así, si nos remontamos a la Grecia clásica, podemos comprobar cómo se manifestó repetidamente, entre los círculos intelectuales de la época, un cierto temor hacia la palabra escrita, hacia el libro — aunque por aquel entonces no se presentase físicamente tal y como lo conocemos hoy-, porque se creía que era una forma de rebajar y encorsetar al auténtico saber.

Platón, por ejemplo, escribió el famoso pasaje de Fedro (Platón, 1981, 882-883) en el que se niega a la escritura la capacidad de transmitir ciencia. Según el filósofo griego, la información escrita tan sólo puede transmitir una sombra de sabiduría o de ciencia, porque, en el momento en que el lector interrogue un escrito, el texto no podrá defenderse, ni argumentar nada y, por lo tanto, no permitirá que el lector profundice en lo que allí se dice. El documento escrito, por tanto, sólo conserva las palabras, escapándosele el pensamiento, la situación vital de la cual éstas nacieron. El fragmento aludido constituye, así, una ferviente defensa de la 
dialéctica, de la palabra, como única forma viva de discurso, y de la obligatoriedad de inscribir forzosamente el pensamiento — que no puede fosilizarse en la letra impresa- en el espíritu del iniciado o del sabio.

Plutarco, en su Vida de Alejandro, nos recuerda una carta que el emperador macedonio escribió a su tutor Aristóteles en la que le recriminaba haber publicado (hecho públicas) sus enseñanzas. En el fondo, en estos dos textos, se palpa claramente una preocupación: el auténtico saber ha de ser forzosamente elitista, una ciencia para unos pocos iniciados. El miedo a la escritura es, en realidad, un temor a la vulgarización o extensión del saber.

Pierre Lévy (1998, 87-88) explica muy bien lo que supuso el paso de las culturas orales a las escritas. La escritura permite conocer mensajes de personas situadas a miles de kilómetros o a cientos de años de distancia, ya no es necesario compartir un mismo espacio y un mismo tiempo como pasa en la cultura oral. De esta forma, la información registrada (escrita) está "fuera de contexto", usando la expresión de Lévy, que constituye otra forma de hacer referencia al fenómeno al que aludía Platón en el fragmento antes citado.

Los textos comentados hacen especial referencia a la necesidad de privar del acceso al documento a todas aquellas personas que no son iniciadas. Los documentos tienen una especie de halo sagrado que los hacen incomprensibles a las masas. $\mathrm{La}$ figura del intérprete, de la persona que sabe relacionarse con los documentos y transmitirlos de forma inteligible, es fundamental en esta sociedad y constituye el eje sobre el que se asienta el conocimiento.

\subsection{LA REPRODUCIBILIDAD TÉCNICA DE LOS DOCUMENTOS}

A partir de la invención de la imprenta empieza a ser factible técnicamente la realización de copias múltiples de productos culturales de tipo textual. El documento impreso sobre papel se convirtió en la principal forma de difusión y expansión de la cultura, en detrimento de la comunicación oral reivindicada por algunos sabios. Con el paso del tiempo, este proceso de registro de la información fue afectando a otros ámbitos, como, por ejemplo, la música, que al ser grabada sobre un soporte podía conseguir una difusión muy superior a la de un concierto.

Así pues, en la edad contemporánea, los productos culturales pasan a convertirse en un objeto de consumo más debido a la facilidad para ser reproducidos. Por ello, la cultura ya no dispone del aura que parece invocar Platón al defender 
la transmisión oral del conocimiento, la cual, si acaso, estaría fragmentada en una multiplicidad de documentos grabados sobre una notable variedad de soportes materiales.

En el año 1935 José Ortega y Gasset dictó en Madrid el discurso inaugural del Congreso Internacional de Bibliotecas y Bibliografía. Esta conferencia, con el título "Misión del bibliotecario", fue publicada posteriormente y consiguió un importante eco, convirtiéndose en punto de constantes referencias. En este texto, Ortega describe con inusitada anticipación lo que será uno de los principales problemas relacionados con la producción de información. Es lo que él denomina selva de libros, término con el que quiere hacer referencia al exceso de producción editorial que dificulta la asimilación de todo aquello que el intelectual tendría que leer. Además, dentro de esta selva de libros, se encuentran montones de obras inútiles y muchas otras redundantes que obstaculizan todavía más la tarea del investigador. La misión que él propone para el bibliotecario es la de convertirse en guía o domador de libros para así orientar a los lectores entre el caos documental.

Este aumento cuantitativo de la producción impresa, que ya intuía Ortega pero que no llegó a su punto álgido hasta después de la segunda guerra mundial, es conocido con el nombre de explosión de la información, y es el responsable de haber complicado notablemente la tarea del investigador y del intelectual, que se han visto desbordados por la multiplicación cuantitativa y cualitativa de los documentos.

Derek de Solla Price, partiendo del análisis de abundante material estadístico, formuló en 1951 una ley general aplicable a la ciencia moderna —desde el siglo XVIII hasta la actualidad- que mostraba de forma precisa y rigurosa lo que era esta explosión de la información (Price, 1973, 37). Según su proposición, el crecimiento de la ciencia en el transcurrir del tiempo adopta una forma exponencial. De esta manera, cada diez o quince años se duplicaría el volumen de la literatura científica (de los títulos de publicaciones especializadas), con lo cual el crecimiento de la ciencia se podría representar mediante una curva exponencial. ${ }^{1}$

A título de ejemplo, se podría hacer referencia al crecimiento del número de publicaciones periódicas editadas en el mundo. La primera edición del Ulrich's periodicals directory (1932), ${ }^{2}$ la obra de referencia más consultada para conocer los títulos de revistas que se publican en el mundo, recogía tan sólo 6.000 publica-

\footnotetext{
${ }^{1}$ Posteriormente esto se corrigió, y se indicó que no podía ser una curva exponencial pura, sino que el crecimiento tenía que llegar a un límite o saturación.

${ }^{2}$ Puede consultarse en $<$ http://www.ulrichsweb.com>.
} 
ciones periódicas, mientras que actualmente contiene la descripción de más de 240.000 títulos, aunque el número total puede ser muy superior. Esto quiere decir que, si asignamos una media de 50 artículos por revista y año, actualmente se publican en el mundo unos 12 millones de artículos de revista (más de 30.000 artículos diarios, casi nada). No es extraño, por lo tanto, que al científico o al investigador les sea difícil controlar y conocer — no ya leer- todo lo que se publica en su área de especialización.

\subsection{LA DISTRIBUCIÓN DE LA INFORMACIÓN EN LAS REDES}

En la década de 1970 se produjo la llamada revolución telemática. Aparecieron los primeros sistemas de información que utilizaban la informática y las telecomunicaciones de forma conjunta y coordinada: las bases de datos en línea y el videotexto fueron los primeros exponentes de la era de la información digital.

Es a partir de este preciso momento cuando, además de un crecimiento cuantitativo de las fuentes de información, nos encontramos también frente a una disparidad cualitativa en relación al soporte material en que se registran, y cuando el papel empezará a perder la primacía como soporte portador de cultura y se producirá una notable diversificación de soportes documentales. La micrografía, los soportes magnéticos informáticos, los discos ópticos, etc., son las nuevas bases materiales sobre las cuales se podrá inscribir y distribuir la información.

Esta revolución telemática comporta la progresiva digitalización de la información. Anteriormente cualquier información, ya fuera textual (un libro cualquiera), sonora (un disco), gráfica (un cartel) o audiovisual (una película o vídeo) se grababa mediante procesos analógicos. La utilización de la informática implica la codificación binaria de la información: una nota musical, un gráfico o un texto no son otra cosa que una sucesión de ceros y unos. Aunque en un principio sólo se gestionaba digitalmente la información de tipo textual (la más fácil de almacenar y manipular) poco a poco se ha ido digitalizando también la información gráfica, la sonora y la audiovisual (la imagen en movimiento) y es posible, por lo tanto, gestionar y almacenar de forma conjunta cualquier tipo de información. La gestión del multimedia ha sido el último estadio de este proceso. 


\section{La telemática}

Dos famosos investigadores franceses, Simon Nora y Alain Minc, en su citadísimo informe La informatización de la sociedad (Nora, 1982), analizaron la revolución telemática desde un punto de vista sociológico y político. El texto de Nora y Minc tiene su origen en un informe solicitado por la presidencia de la República Francesa (en aquel momento representada por Valéry Giscard d'Estaing) con el fin de analizar y prever las posibles consecuencias políticas, sociales y económicas del desarrollo de las nuevas tecnologías. En él se define por primera vez telemática, uno de los términos más populares para hacer referencia a la nueva dimensión abierta por la conjunción de la informática y las telecomunicaciones.

Los autores, después de constatar que todas las evoluciones tecnológicas han provocado una reorganización de la economía y de la sociedad, centran su análisis en tres grandes ámbitos: la economía (con un previsible aumento del paro unido al crecimiento de la productividad), las relaciones de poder (analizan el conflicto entre centralización y descentralización que puede provocar la informatización) y la soberanía política. A esta última vertiente le dedican una buena dosis de reflexión, ya que se encuentran notablemente sensibilizados para intentar controlar el peso de algunas empresas transnacionales del sector de la informática y las telecomunicaciones, ${ }^{3}$ que disponen de una influencia que a veces va más allá de la capacidad de decisión de los poderes políticos.

Nora y Minc propusieron una serie de medidas que el Estado tendría que llevar a cabo para controlar al máximo estas variables y orientarlas hacia el bien de la sociedad. Estas recomendaciones eran el establecimiento de una política estatal de comunicaciones (normalización, creación y control de las redes de telecomunicaciones, etc.), la dotación de ayudas a los actores nacionales del sector telemático (es decir, las empresas francesas) y la informatización de la Administración pública.

El desarrollo y la amplia difusión del videotexto en Francia (llegó a contar con más de seis millones de usuarios, casi el $90 \%$ del total europeo), promocionado desde la Administración pública mediante la distribución gratuita de terminales y con la realización de notables mejoras en las redes de telecomunicaciones, así como la activa participación estatal en la empresa informática Bull y otras controladas por este grupo industrial, se explican más fácilmente desde la óptica de las conclusiones y recomendaciones del citado informe.

\footnotetext{
${ }^{3}$ IBM era en aquel momento el principal gigante del sector.
} 
El extraordinario interés mostrado por los poderes públicos hacia las repercusiones de la introducción de las nuevas tecnologías proviene, como es obvio, del hecho de que las telecomunicaciones no transportan una corriente inerte, como se cita textualmente en el informe, sino información, que es vista como generadora de poder. El dominio y control de la información pueden facilitar la colonización cultural y económica y éste era, y es todavía, uno de los principales temores de la administración francesa.

\section{Las autopistas de la información}

Unos quince años después de la realización del informe de Nora y Minc volvió a reavivarse la preocupación de los políticos por las redes de telecomunicaciones, acuñándose uno de los términos que más fortuna ha hecho en los últimos tiempos, las autopistas de la información, los antecedentes teóricos y políticos de las cuales hemos de ir a buscarlos en el proyecto «Infraestructura Nacional de la Información» (1993), presentado por el entonces presidente Bill Clinton, y en especial, su vicepresidente Al Gore - que ya defendió una iniciativa en esta línea en 1991, cuando era senador- La idea general incidía en la necesidad de construir las infraestructuras de la futura sociedad de la información para permitir que todas las empresas, escuelas, bibliotecas, hogares, etc., estuvieran interconectadas por estas nuevas redes y se dispusiera de un sistema que permitiera suministrar información a todos los ciudadanos cuándo y dónde ellos quisieran. Uno de los objetivos del gobierno de los Estados Unidos era preparar las condiciones - se habla de desregularización, de inversiones directas del sector público y de incentivos fiscales para la inversión privada- que estimulasen la inversión privada en el sector de las telecomunicaciones y constituyeran el motor para el despliegue del proyecto.

La réplica europea al plan norteamericano llegó en 1994 de la mano de Jacques Delors, el entonces presidente de la Comisión Europea. El texto "Crecimiento, competitividad y ocupación: retos y apuestas para entrar en el siglo XXI", también conocido como Informe Delors, exponía claramente la necesidad de crear las autopistas de la información y desarrollar sus servicios y aplicaciones.

Inspirado en el espíritu del informe Delors apareció poco después el famoso informe Bangemann, titulado Europa y la sociedad global de la información: recomendaciones al Consejo Europeo (1994), el cual, además de incidir en la impor- 
tancia de las infraestructuras de telecomunicaciones, también recomendaba el fomento del desarrollo de servicios y la creación de la demanda como condiciones de base para estimular el uso de las redes, adjudicando a los gobiernos y a la industria un papel de liderazgo para desarrollar al máximo las posibilidades de revolución tecnológica que lleva a la creación de una sociedad de la información. ${ }^{4}$

Algunas de las principales recomendaciones que allí se expresaron hacían referencia a la necesidad de abrir mercados a la competencia y desregularizar aquellos servicios e infraestructuras que están todavía en régimen de monopolio, es decir, liberalizar las telecomunicaciones; de estimular las infraestructuras de comunicaciones y el mercado de servicios; de avanzar en el proceso de normalización; de reducir las tarifas de telecomunicaciones para igualarlas a los Estados Unidos; de establecer normativas comunes para la propiedad intelectual, intimidad y seguridad; y de aplicar eficazmente las normas de competencia.

La comisión adoptó los principios de este informe, fijando un calendario para cada área. El modelo de referencia de estas autopistas es Internet, así como lo son también las redes de cable. Detrás de la estela de los Estados Unidos y de Europa, el resto de países industrializados (Japón o Canadá, por poner dos ejemplos) han realizado propuestas similares. Incluso el G-7, el grupo que reúne a los siete países más industrializados, incluyó el tema en la agenda de varias de sus reuniones de trabajo.

Queda muy claro, pues, que la sociedad del futuro basará su estructura y sus relaciones en las redes de telecomunicaciones. No sólo servirán para la distribución de información o de contenidos, en general, sino que también serán la base para el comercio, la enseñanza, el trabajo, etc. Estos cambios, aunque en un primer momento implicaban tan sólo a sectores especializados, han llegado a un punto tan amplio de difusión que involucran a toda la sociedad, al menos en el primer mundo.

La popularización y el alto grado de utilización de las redes de telecomunicaciones supone un nuevo problema. En estos momentos, una de las preocupaciones más importantes para los promotores de la interconectividad y de las autopistas de la información es, precisamente, llenarlas de contenidos. No hay suficiente con disponer de calles limpias y bien alquitranadas, sino que es necesario llenarlas de tiendas, plazas, parques y buenos jardines para que los ciudadanos se pa-

\footnotetext{
${ }^{4}$ Asdrad Torrès $(1998,183-184)$ critica a Bangemann el hecho de haberse rodeado de los patronos de las grandes empresas para formar parte del grupo de trabajo y también le recrimina que sea, según él, un «declarado partidario de la mercantilización cultural y de la competitividad como paradigma de progreso».
} 
seen por ellas. Esta necesidad ha empujado al establecimiento de relaciones entre el mundo del audiovisual (televisión, cine, vídeo) y el de la informática y las telecomunicaciones. Microsoft es un buen ejemplo de esta ampliación de intereses hacia las redes de información y el audiovisual, y la prueba la tenemos en Microsoft Network, su red de servicios en línea, y también en el intento de compra de la cadena de televisión CBS. Otros ejemplos que ratifican este matrimonio pueden ser la fusión de AOL (Internet e informática) con Time-Warner (audiovisual), o la constitución de la empresa DreamWorks Interactive, una sociedad participada por Microsoft y por la productora cinematográfica de Steven Spielberg. Todas estas iniciativas, y muchas otras, surgen de la necesidad de llenar de contenidos a las autopistas de la información.

La implicación directa de los más altos niveles de los gobiernos en el desarrollo de las tecnologías de la información y la comunicación se explica por el hecho de que estén siendo utilizadas como un camino muy rápido para conseguir crecimiento económico. El mayor problema puede darse si este progreso económico no hace sino ahondar en los ya enormes desequilibrios que existen actualmente en el mundo.

\section{Situación actual}

En el contexto del ciberespacio, así como en el de la explosión de la información, ya no hay intérprete que valga. El saber ya no está concentrado en unos pocos documentos difíciles de interpretar pero, al fin y al cabo, abarcables, sino que se han desparramado en una inmensidad de pequeñas piezas hipertextuales interrelacionadas entre sí y que cada persona puede leer a su manera. El problema reside ahora más bien en diseñar sistemas que permitan organizar este cosmos y establecer procedimientos destinados a facilitar el acceso a las personas que lo deseen.

A partir de ahora, después de describir la evolución de la difusión del saber como un camino que va desde la transmisión oral hasta la información digital, pasando por la reproducción masiva en soportes analógicos, nos vamos a centrar en perfilar las características y tipología del sector de la información digital, que emerge como uno de los pilares fundamentales de la nueva sociedad de la información. 


\section{ESTRUCTURA DEL SECTOR}

La industria de la información digital (o electrónica) se ocupa de la producción y distribución de información por medio de un soporte digital, ya sea magnético u óptico. ${ }^{5}$ Sus orígenes se remontan a la década de 1970 en los Estados Unidos, y unos diez años más tarde empieza a extenderse en Europa. Desde entonces, y de modo progresivo, se ha ido consolidando como complemento o alternativa, según los casos, a la información registrada sobre papel.

El sector de la información digital presenta un ciclo de producción y distribución más complejo y diversificado que el existente en la industria editorial tradicional porque incluye algunos agentes que no existen en el ámbito de la edición impresa y se ve alterado el papel ejercido por otros. La tabla que se presenta a continuación intenta sintetizar cuáles son los actores que forman parte de esta cadena, los objetos de los que se ocupan y las funciones que realizan.

Tabla 2.1. El ciclo de producción y distribución de la información digital

\begin{tabular}{|c|c|c|}
\hline Actor & Objeto o servicio & Función \\
\hline Autor & $\begin{array}{l}\text { Documentos científico-técnicos y } \\
\text { culturales: libros, artículos de } \\
\text { revista, informes, patentes, etc. }\end{array}$ & - Creación intelectual de originales. \\
\hline $\begin{array}{l}\text { Proveedor de } \\
\text { servicios } \\
\text { (productor de } \\
\text { bases de } \\
\text { datos, etc.) }\end{array}$ & $\begin{array}{l}\text { Servicios y productos digitales: } \\
\text { - información (publicaciones } \\
\text { digitales); } \\
\text { - comunicación; } \\
\text { - transacciones; } \\
\text { - entretenimiento. }\end{array}$ & $\begin{array}{l}\text { - Diseño del producto del servicio digital. } \\
\text { - Selección, análisis, presentación y elaboración } \\
\text { de la información. } \\
\text { - Inclusión de información de valor añadido: } \\
\text { resúmenes, descriptores, clasificaciones. }\end{array}$ \\
\hline
\end{tabular}

${ }^{5} \mathrm{Al}$ tratarse de soportes digitales, el usuario necesita un sistema de descodificación y visualización, que suele consistir en la combinación de un aparato de lectura, un ordenador y unos periféricos de salida (normalmente monitor e impresora). 
Tabla 2.1. El ciclo de producción y distribución de la información digital (continuación)

\begin{tabular}{|c|c|c|}
\hline Actor & Objeto o servicio & Función \\
\hline $\begin{array}{l}\text { Distribuidor (host, } \\
\text { centro servidor, } \\
\text { servidor web, etc.) }\end{array}$ & $\begin{array}{l}\text { Sistema de acceso y de } \\
\text { recuperación de la } \\
\text { información: } \\
\text { - navegación jerárquica; } \\
\text { - navegación hipertextual; } \\
\text { - lenguaje de búsqueda. } \\
\text { Sistema de distribución: } \\
\text { - en línea (básicamente, } \\
\text { Internet); } \\
\text { - soporte óptico (cederrón, y } \\
\text { DVD, fundamentalmente). }\end{array}$ & $\begin{array}{l}\text { Acceso, recuperación y distribución de la } \\
\text { información en línea. } \\
\text { - Distribución de la información en otros } \\
\text { soportes (papel, soporte magnético, soporte } \\
\text { óptico). } \\
\text { - Creación de servicios añadidos: difusión } \\
\text { selectiva de la información, elaboración de } \\
\text { dossieres temáticos, elaboración de } \\
\text { bibliografías, etc. } \\
\text { - Comercialización (análisis de mercado, } \\
\text { promoción, venta, asistencia técnica, } \\
\text { asistencia post-venta, etc.). }\end{array}$ \\
\hline $\begin{array}{l}\text { Operador de } \\
\text { telecomunicaciones }\end{array}$ & $\begin{array}{l}\text { Redes de telecomunicaciones } \\
\text { para la transmisión de la } \\
\text { información. }\end{array}$ & $\begin{array}{l}\text { - Gestión de las infraestructuras de } \\
\text { transmisión de la información. } \\
\text { - Facturación de la información en } \\
\text { determinados casos (p. e., servicios de } \\
\text { información telefónicos o audiotexto). }{ }^{6}\end{array}$ \\
\hline Documentalista & $\begin{array}{l}\text { Formulación de estrategias de } \\
\text { búsqueda. }\end{array}$ & $\begin{array}{l}\text { - Identificación y selección de las fuentes de } \\
\text { información más relevantes. } \\
\text { - Realización de la consulta. }\end{array}$ \\
\hline Usuario & $\begin{array}{l}\text { Equipos y programas } \\
\text { informáticos. }\end{array}$ & $\begin{array}{l}\text { - Explotación y utilización de la información. } \\
\text { - Pago de la información. }\end{array}$ \\
\hline
\end{tabular}

En los apartados siguientes se profundizará en la descripción de los objetivos, servicios y funciones de cada uno de los agentes que se toman en consideración.

\subsection{AUTORES}

El primer actor de la cadena o del ciclo de la información digital es, naturalmente, el autor de la información, y su función no es otra sino la creación y elaboración de originales. Los componentes de este grupo son científicos, profesores de universidad, periodistas, técnicos, ingenieros, expertos en legislación o en economía, etc., y, en general, miembros de lo que se ha dado en llamar «trabajadores del conocimiento" (knowledge workers).

La tipología de documentos que elaboran y que serán seleccionados para formar parte de las bases de datos documentales es la siguiente:

${ }^{6}$ El audiotexto es el término técnico que se utiliza para hacer referencia a los servicios de información y ocio que se distribuyen por teléfono, y que aparecen en Europa a principios de la década de 1990. El sistema ofrece información de tipo sonoro y sólo necesita como equipo el aparato de teléfono. 
- Artículos de revistas científicas (p. e., revistas editadas por departamentos de universidad, institutos de investigación o sociedades científicas).

- Artículos de revistas técnicas (por ejemplo, revistas comerciales sobre informática, economía o medicina).

- Noticias de prensa (artículos, reportajes, entrevistas, etc., publicados por la prensa diaria escrita o por la prensa semanal, mensual, etc., con predominio, generalmente, de la información económica).

- Transcripciones de conferencias, debates o entrevistas emitidos por radio y televisión (éste es un sector con poca presencia en nuestro país, pero con una amplia tradición en el mundo anglosajón, donde hay varias empresas y diversas bases de datos especializadas en esta clase de informaciones).

- Actas de congresos científicos y profesionales.

- Tesis doctorales.

- Patentes.

- Disposiciones y textos legales.

Los actuales sistemas de producción y distribución están permitiendo que los autores se ocupen no sólo de la creación de originales, sino que empiecen a abordar también seriamente el proceso de producción y distribución de sus textos. Cada vez es más frecuente el caso de autores que editan y distribuyen sus publicaciones en la Red.

\subsection{PROVEEDORES DE SERVICIOS}

Se trata de empresas, organizaciones o instituciones que disponen de alguna información o servicio que quieren ofrecer telemáticamente al público de forma gratuita o a cambio de alguna compensación económica. Los primeros proveedores solían ofrecer exclusivamente servicios de información (es decir, no ofrecían servicios de comunicaciones ni de transacciones). Así pues, se dedicaban a recopilar y analizar información en algún ámbito especializado (la biomedicina, la química, las artes y la cultura, etc.) o también información de carácter general (p. e., información ciudadana). Dentro de esta categoría de proveedor se pueden encontrar empresas u organismos de sectores diversos, como, por ejemplo: 
- Empresas de análisis y tratamiento documental de la información.

Seleccionan y analizan las publicaciones más importantes de cada campo del conocimiento y producen información de valor añadido, generalmente una descripción bibliográfica normalizada que facilita el acceso a la información, más una representación del contenido temático del documento, también normalizada, y compuesta por lo general por un resumen, un conjunto de descriptores o palabras clave y la asignación a una o más categorías de un cuadro de clasificación. Estas empresas tienen un grado de especialización bastante elevado, porque han sido creadas ex profeso para gestionar, organizar y distribuir la información digital. Muchas tienen sus orígenes en la confección de boletines de resúmenes (p. e., Chemical Abstracts). Sus productos típicos son las bases de datos documentales y los boletines de resúmenes, tanto en papel como en soporte digital.

- Administración pública.

El sector público ha dispuesto tradicionalmente de una presencia notable (en algunos países más que en otros) en el sector de la información digital. La intervención pública en este ámbito viene motivada por dos objetivos primordiales: por un lado, ayudar a la dinamización de este nuevo sector y, por otro, consolidarlo como una nueva forma de hacer llegar información de carácter general a una amplia mayoría de ciudadanos.

- Industria editorial.

La mayoría de las grandes empresas editoriales está dedicando considerables recursos para la difusión de sus productos tradicionales, especialmente grandes obras de consulta como enciclopedias o diccionarios, en soportes materiales que no son el papel. De esta forma, diversifican su oferta hacia mercados complementarios. Esta clase de empresas suele generar bases de datos de texto completo con su producción propia. Por ejemplo, la Agencia EFE (http://www.efe.es) produce, y además distribuye, una base de datos de texto completo que contiene todos sus despachos de noticias desde hace varias décadas. Otro ejemplo podría ser la Enciclopedia Catalana (http://www.grec.net) o la Enciclopedia Británica (http://www.britannica.com), que han producido y distribuido a través de Internet una versión digital de estas obras, consultables en forma de bases de datos.

No obstante, debido a que la oferta actual de servicios ya no es únicamente informativa, nos podemos encontrar empresas de cualquier sector económico que 
aprovechan las facilidades de la publicación en Internet para promocionar (y vender) sus productos. Lo mismo se puede decir de la Administración pública (ayuntamientos de toda clase, escuelas, etc.) e incluso de algunos particulares, que se han constituido también como proveedores de servicios telemáticos (no se puede olvidar que el continuado descenso de precios de los equipos informáticos y de telecomunicaciones propician que cualquier persona pueda llegar a ser, fácilmente, proveedor de servicios telemáticos).

\subsubsection{Servicios y productos digitales}

Los múltiples servicios que ofrecen los productores podrían agruparse, según su orientación, de la siguiente forma:

- Información.

Una buena parte de los servicios y productos telemáticos consiste en ofrecer, normalmente a través de bases de datos documentales, la posibilidad de acceder a grandes volúmenes de información retrospectiva o en tiempo real de todos los ámbitos del conocimiento y de todas las actividades sociales. En el capítulo 3 se presenta una detallada descripción de los principales productos de información digital que existen en la actualidad.

- Comunicación.

La gran mayoría de proveedores permite que sus usuarios puedan comunicarse entre ellos, principalment mediante el correo electrónico. Las posibilidades de comunicación son variadas: interpersonal (con buzones privados), estableciendo grupos de discusión que intercambian mensajes, o accediendo a tableros de avisos electrónicos. Se trata de un servicio muy utilizado y en continuo crecimiento que, probablemente en pocos años, adquirirá carácter de servicio universal.

- Transacciones.

La tercera aplicación básica consiste en la posibilidad de autorizar diversos pagos o transacciones a través del sistema. En este sentido, podemos encontrar diversos proveedores especializados en gestión de cuentas bancarias (telebanca); otros, que permiten comprar todo tipo de productos que son cargados a la cuenta del cliente (telecompra), y otros, que permiten hacer reservas de espectáculos, 
ferrocarriles, líneas aéreas, restaurantes, etc. Se trata del ámbito con mayores perspectivas de crecimiento a corto plazo.

- Entretenimiento.

En este apartado se incluirían aquellos servicios que no tienen ninguna otra pretensión que distraer (juegos, imágenes de entretenimiento, etc.). Es una de las vertientes con más oferta desde el momento en que el gran público ha empezado a ser usuario principal de los servicios y productos electrónicos.

Estas orientaciones no se encuentran nunca aisladas, sino que es frecuente que un determinado servicio especializado en ofrecer productos de información (p. e., La Vanguardia Digital (http://www.vanguardia.es), incluya prestaciones para el comercio electrónico (transacciones), la comunicación o el entretenimiento. Los famosos portales de Internet (p. e., Terra o eresMas, en España, o Yahoo! ${ }^{7}$ y AOL en Estados Unidos) son servicios que incluyen un poco de todo: información, transacciones, comunicación y entretenimiento. Su objetivo no es otro que convertirse en el centro de recursos donde el usuario pueda encontrar todo aquello que necesita para resolver sus problemas básicos.

La diversidad de productos y servicios del sector hace necesario acotar bien el ámbito al que se va a prestar especial atención. En particular, nos centraremos en el sector de la información que está formado por la oferta de bienes y servicios relacionados con el procesamiento de contenidos (típicamente, la selección y descripción de documentos e informaciones y la creación de información de valor añadido) y la oferta de facilidades para su acceso a través de bases de datos documentales, dejando de lado los servicios relacionados con la comunicación, las transacciones o el entretenimiento. A partir de ahora, si no se indica lo contrario, cuando se haga mención al sector de la información digital nos referiremos al ámbito señalado.

\subsection{DISTRIBUIDORES (O CENTROS SERVIDORES)}

Las empresas que adoptan el rol de distribuidores realizan operaciones de tipo técnico y otras comerciales. Las operaciones técnicas consisten principalmente en

\footnotetext{
${ }^{7}$ Se trata del portal más visitado, con más de 30 millones de personas que se conectan mensualmente a su Web.
} 
cargar las bases de datos (creadas por los productores) en sus ordenadores, y dotarles de facilidades para la consulta y recuperación de la información. El objetivo de estas operaciones técnicas es ofrecer al público grandes bases de datos que pueden ser consultadas en forma remota (actualmente casi exclusivamente a través de Internet) y por un gran número de usuarios concurrentes. Los distribuidores, al igual que las grandes superficies en el sector de la alimentación, tienden a presentar una amplia oferta de bases de datos con el fin de ganar la mayor cuota de mercado posible.

Por otro lado, las operaciones comerciales consisten en la distribución y venta de productos de información digital utilizando las redes de telecomunicaciones o mediante soporte magnético u óptico, así como de la gestión administrativa de la relación con los usuarios (contratos, información comercial, etc.). ${ }^{8}$ Así pues, las empresas distribuidoras se dedican a comercializar la información creada por los productores o proveedores, de forma similar a lo que se hace en todos los sectores económicos (podemos pensar en los distribuidores editoriales, por citar un ejemplo próximo, que actúan de intermediarios entre las librerías y las editoriales).

\subsubsection{Sistema de acceso y recuperación de la información}

Cualquier fuente de información digital ha de proponer a los usuarios instrumentos de consulta, navegación y recuperación de información adecuados para que no se sientan disuadidos de seguir utilizando el servicio, es decir, para que puedan convertir con la mayor facilidad posible sus necesidades de información en modos de búsqueda y navegación que les proprocionen informaciones relevantes.

El distribuidor acostumbra a ser el encargado de resolver el problema de la localización y el acceso a la información. El problema no es trivial, porque los distribuidores de información digital se ven obligados a afrontar el siguiente dilema: por un lado, con el fin de ganar cuota de mercado, deben ofrecer la máxima cantidad y variedad de información posible; ahora bien, cuantos más documentos o mensajes contenga una fuente de información, más difícil es encontrar la información relevante para cada necesidad de información particular. Dicho de otro

\footnotetext{
${ }^{8}$ Si el usuario tuviera que contactar directamente con cada uno de los productores de recursos de información (p. e., bases de datos) que le pudieran interesar, tendría que realizar muchas gestiones de tipo administrativo que se le ahorran contratando los servicios del distribuidor.
} 
modo, serviría de poco tener acceso a millones de documentos si no dispusiéramos de sistemas para recuperar selectivamente aquellos que nos pueden interesar en un momento determinado.

El acceso y la recuperación de la información descansa sobre sistemas informáticos, básicamente sistemas de gestión de bases de datos, complementados con sistemas de navegación hipertextuales. La unidad elemental de información es la página, que no debe necesariamente coincidir con una pantalla, y que puede contener elementos textuales junto con otros icónicos y/o sonoros.

Las principales herramientas para facilitar el acceso y la recuperación de la información son las siguientes:

- Sistemas de navegación de tipo jerárquico (menús).

En este caso, la información se estructura jerárquicamente en clases y subclases y el usuario debe ir indicando cuál de las opciones propuestas quiere para poder llegar a los documentos o a la información que le interesen.

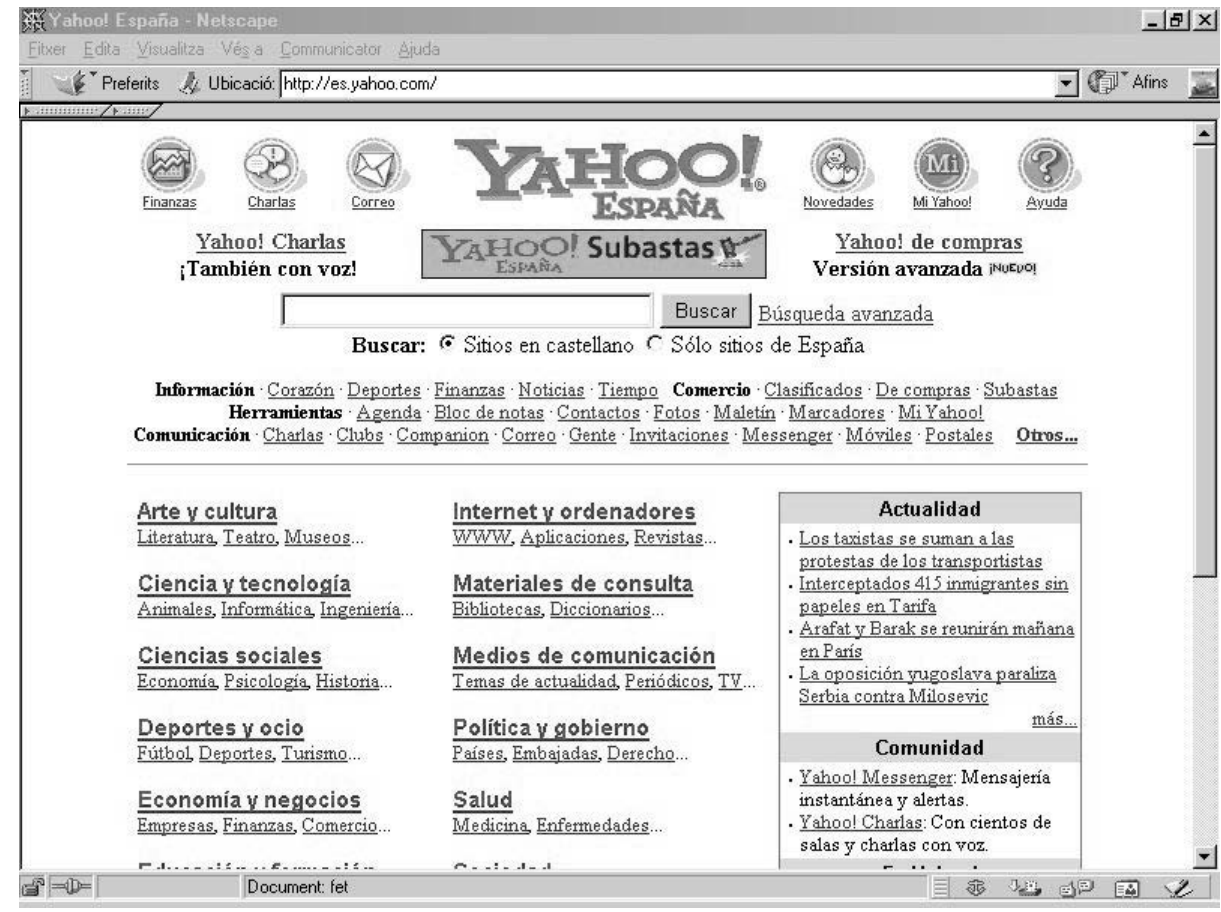

Fig. 2.1. Ejemplo de navegación: menús de Yahoo! 
Un buen sistema de estas características no tendría que superar un determinado número de opciones, para que puedan ser fácilmente asimilables por el usuario. ${ }^{9}$ Por otro lado, también se recomienda disponer los menús en forma vertical, porque son más fáciles de captar que los horizontales. Debido a ello es importante que las opciones se agrupen de forma lógica y coherente por niveles jerárquicos, porque de esta manera se facilita el aprendizaje y se aumenta la velocidad de uso del sistema.

- Sistemas de navegación hipertextuales.

La consulta hipertextual, utilizada especialmente por el Web, permite que el usuario pueda ir «saltando» de un documento a otros documentos relacionados si activa los vínculos que previamente se han establecido, y que suelen estar resaltados de forma visible. Estos vínculos pueden transportar a documentos que no se encuentran en el ordenador al que se está conectado, lo cual quiere decir que el usuario puede ir viajando, sin darse cuenta, de país en país siguiendo las uniones hipertex-

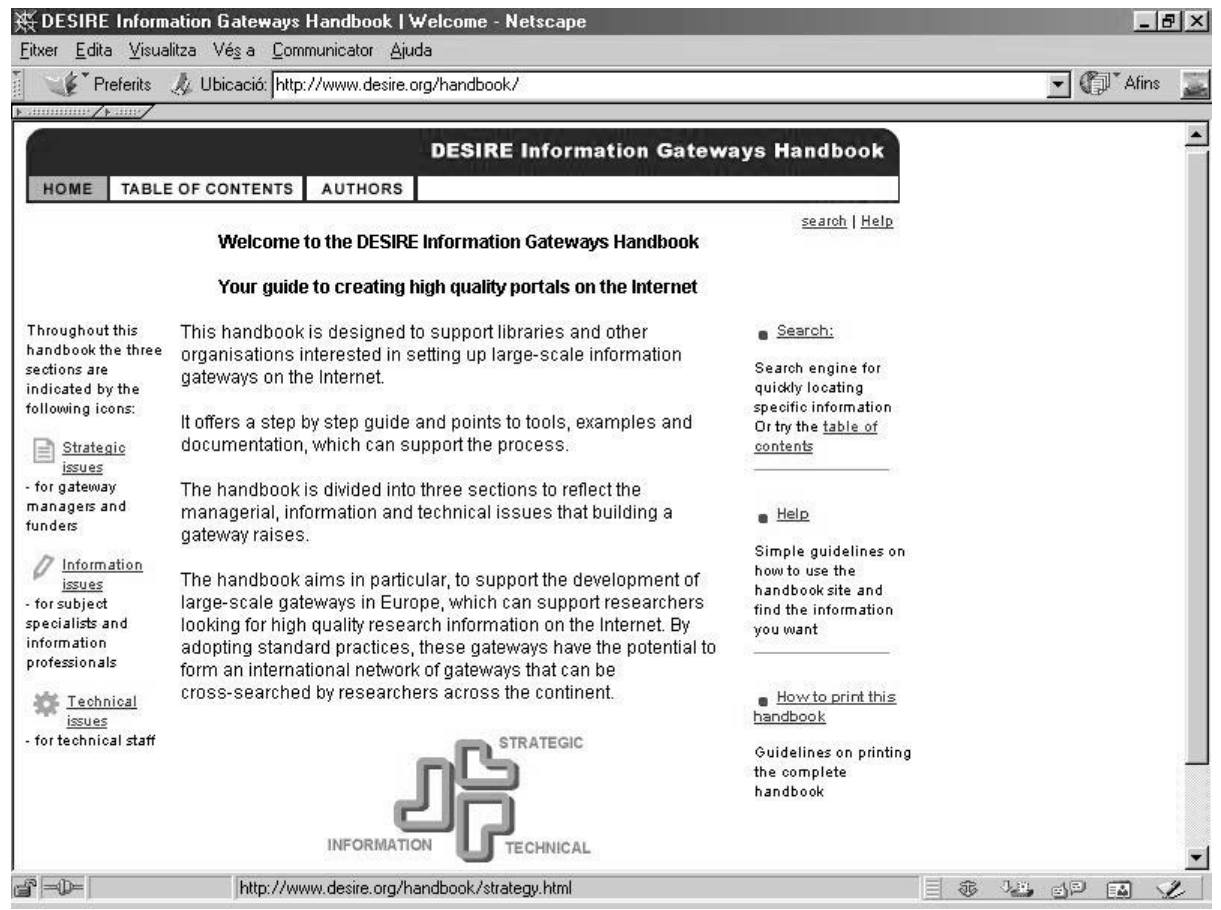

Fig. 2.2. Ejemplos de enlaces: página de inicio del manual del proyecto Desire

\footnotetext{
${ }^{9}$ Un usuario adulto está preparado para asimilar entre cinco y nueve opciones a la vez.
} 
tuales. El documento hipertextual está formado, pues, por unos bloques o partes interrelacionadas entre sí que se pueden recorrer en muchas direcciones y siguiendo órdenes diversos. El hipertexto da un papel más activo al lector, porque es él quién selecciona el camino de la compleja red que ha tejido el autor del documento.

La consulta hipertextual, cuyos fundamentos teóricos se atribuyen al famoso artículo «As we may think» escrito por Vannevar Bush en 1945, permiten al usuario que pueda moverse dentro de un documento siguiendo la libre asociación de ideas. Para mostrar más gráficamente este concepto se acostumbra a contraponer la consulta hipertextual (ejemplificada con la lectura de una enciclopedia, en la que vamos saltando hacia adelante y hacia atrás) a la lectura lineal o secuencial (el caso de una novela, por ejemplo). El «desbordamiento cognitivo», la facilidad para perderse en un exceso de información, es la crítica que se acostumbra a hacer al hipertexto. Este inconveniente ha de ser suplido con un buen diseño, o con una gran habilidad del lector.

- Sistemas de recuperación de información.

En lugar de proceder por navegación, como en los dos casos anteriores, el usuario indica uno o varios términos que pueden combinarse por medio de un conjunto de operadores e instrucciones que servirán para representar su necesidad de información. La base de la recuperación de la información en la mayoría de sistemas informáticos es el álgebra booleana (la unión, intersección y negación de conjuntos), aunque cada vez son más los sistemas que permiten realizar búsquedas semánticas ${ }^{10}$ y búsquedas patronales. ${ }^{11} \mathrm{~A}$ diferencia de la consulta jerárquica (menús) o hipertextual, que prácticamente no requieren ningún conocimiento previo, se hace difícil poder realizar consultas complejas utilizando un lenguaje de interrogación ${ }^{12} \sin$ disponer de un cierto grado de entrenamiento.

\footnotetext{
${ }^{10}$ El objetivo de las búsquedas semánticas, o por conceptos, es poder ampliar la consulta de un término a todos aquellos que estén relacionados de alguna manera con él (derivaciones morfológicas, sinonimia, antonimia, términos generales, específicos, etc.). El sistema permite, pues, consultar la base de datos utilizando tesauros o diccionarios especializados previamente elaborados que indiquen cuáles son las relaciones entre los términos.

${ }^{11}$ La búsqueda por patrones, o por reconocimiento de forma, permite localizar no sólo el término exacto que se introduce en la consulta, sino todos aquellos términos que comparten el mismo patrón, que tienen un parecido con el que ha indicado el usuario. La recuperación se realiza por aproximación a partir de unas reglas internas que rigen el proceso de comparación, y que incorporan elementos de la lógica difusa.

${ }^{12}$ El lenguaje de interrogación es un conjunto de instrucciones y operadores que permite poner en contacto las consultas de los usuarios (formuladas en lenguaje natural y, por tanto, ininteligibles hasta el momento para el sistema informático) con la lógica interna de almacenamiento del programa. El usuario tiene que estar entrenado, por lo tanto, en el conocimiento y manejo de los recursos de este complejo lenguaje de interrogación o, en caso contrario, delegar al documentalista la realización de su consulta.
} 


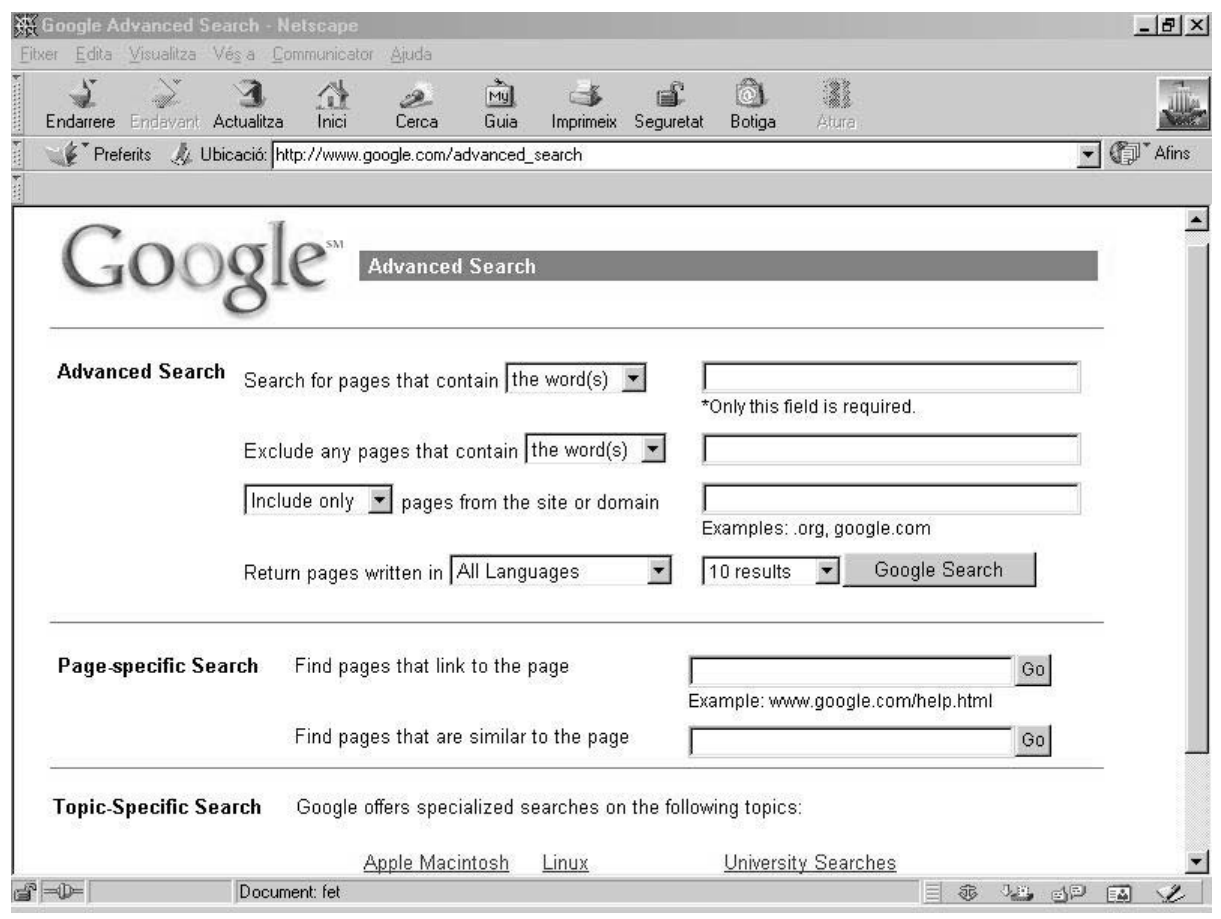

Fig. 2.3 Ejemplo de consulta a una base de datos

Consultar bases de datos en línea no es un proceso simple. El usuario suele expresar su demanda de información en lenguaje natural, el mismo que utiliza para comunicarse. No obstante, los documentos no están organizados según este lenguaje natural, sino según un determinado lenguaje documental (artificial) que se ha usado en la indización. Por este motivo, hay que traducir la consulta documental expresada en lenguaje natural a lo que se denomina ecuación de búsque$d a$, una frase o formulación que combina los descriptores utilizados para analizar los documentos mediante unos determinados operadores (unión, intersección y negación, en la mayoría de los casos). El documentalista especializado en información digital (v. 2.5) ha sido tradicionalmente el encargado de realizar la función de convertir consultas complejas de usuarios en ecuaciones de búsqueda inteligibles para los sistemas de recuperación de información.

Un inconveniente del lenguaje de interrogación, aparte de que es poco intuitivo, reside en el hecho de que no existe una formulación universal y que se utilizan, por tanto, una infinidad de lenguajes de interrogación diferentes. Cada dis- 
tribuidor dispone de su propio lenguaje de interrogación, ya sea Dialog, Yahoo! o Altavista, el cual, aunque comparte unos fundamentos teóricos comunes, asigna a cada operador o instrucción (unión, intersección, negación, búsqueda en campo concreto, etc.) una formulación diferente..$^{13}$

\subsubsection{Sistemas de distribución}

Actualmente una fuente de información digital (una base de datos, una publicación electrónica, etc.) puede ser distribuida de diversas formas sin necesidad de tener que cambiar sus contenidos ni estructura interna. Las formas básicas son dos, aunque ambas puedan subdividirse en algunas más:

- En línea (online) o vía telemática, que a su vez puede adoptar las siguientes variaciones:

- En formato web o html, que es la forma mayoritaria.

- En formato ASCI puro, que se encuentra en vías de desaparición.

— En formato videotexto, prácticamente ya desaparecido. ${ }^{14}$

- Fuera de línea o en un soporte material:

- Disco óptico, ya sea cederrón o DVD.

- Discos o cintas magnéticas (en vías de desaparición).

${ }^{13}$ Así, p. e., la intersección de conjuntos podría representarse, según el lenguaje de que se tratara, de diversas maneras: Y, ET, AND, *, \&, etc.

${ }^{14}$ El videotexto se quiso enmarcar en lo que algunos llamaron telemática de consumo. Su objetivo prioritario era facilitar el acceso al gran público a servicios de información electrónica, y por lo tanto la mayor parte de la información que se distribuía tenía un carácter muy general. Se podían encontrar noticias de actualidad, actos culturales y espectáculos, guías de restaurantes, programas de cine, hoteles, turismo, información ciudadana, etc. De forma similar a lo que actualmente permite Internet, el videotexto era un sistema que ofrecía una gran variedad de servicios a sus usuarios. No sólo podían realizarse consultas de información, sino que también era posible la comunicación por medio del correo electrónico, las transacciones (comprar y vender). Las bases de datos videotexto utilizaban una norma de codificación específica (norma V23), con un aspecto visual muy similar al del teletexto, con el que compartía sistema de codificación. Se disponía de una pantalla con sólo 40 columnas (y no las 80 estándar), con caracteres de dimensiones superiores al texto ASCII y, además, se podían combinar gráficos con texto y exhibir una utilización muy variada del color. La consulta se hacía a través de un sistema de menús y no necesitaba (excepto en aplicaciones especiales) el concurso de complejos lenguajes de interrogación. Una gran aportación innovadora del videotexto fue la instauración de un sistema de pago que no exigía suscripción previa, lo que se denominó sistema quiosco. El operador de la red de telecomunicaciones se encargaba de registrar y facturar a cada usuario por la utilización de la red de telecomunicaciones y también por el consumo de información de la base de datos, en el caso de que ésta no fuera gratuita. Posteriormente, el operador liquidaba a los proveedores de servicios la parte que les correspondía de la factura pagada por el usuario. 
Tal y como ya se ha adelantado, no hay duda respecto a que los principales sistemas que se utilizan son la distribución por medio del Web y en soporte óptico. El formato ASCII, que aún emplean algunas bases de datos especializadas, es consultado por un número muy reducido de usuarios. Finalmente, el videotexto y el soporte magnético se puede decir que prácticamente están ya en desuso.

La siguiente tabla intenta sintetizar las principales características de cada una de las tres principales formas de distribución de información digital.

Tabla 2.2. Características básicas de los principales sistemas de distribución

\begin{tabular}{|c|c|c|c|}
\hline Parámetro & Formato web & En linea ASCII & Edición óptica \\
\hline $\begin{array}{l}\text { Tipo de } \\
\text { información }\end{array}$ & $\begin{array}{l}\text { Texto, sonido, gráficos, ima- } \\
\text { gen fija, imagen animada. }\end{array}$ & $\begin{array}{l}\text { Texto y gráficos muy senci- } \\
\text { llos. }\end{array}$ & $\begin{array}{l}\text { Texto, sonido, gráficos, ima- } \\
\text { gen fija, imagen animada. }\end{array}$ \\
\hline $\begin{array}{l}\text { Forma de } \\
\text { difusión }\end{array}$ & Red de transmisión de datos. & Red de transmisión de datos. & $\begin{array}{l}\text { Autonomía respecto de las } \\
\text { redes de telecomunicacio- } \\
\text { nes. }\end{array}$ \\
\hline Usuarios & $\begin{array}{l}\text { Gran público, sectores espe- } \\
\text { cializados y profesionales. }\end{array}$ & $\begin{array}{l}\text { Sectores muy especializados } \\
\text { (investigación, negocios y fi- } \\
\text { nanzas, etc.). }\end{array}$ & $\begin{array}{l}\text { Gran público, sectores es- } \\
\text { pecializados y profesiona- } \\
\text { les. }\end{array}$ \\
\hline $\begin{array}{l}\text { Forma de } \\
\text { consulta }\end{array}$ & $\begin{array}{l}\text { Lenguaje de interrogación } \\
\text { simple. Menús, enlaces hi- } \\
\text { pertextuales. }\end{array}$ & $\begin{array}{l}\text { Lenguaje de interrogación } \\
\text { complejo. }\end{array}$ & $\begin{array}{l}\text { Lenguaje de interrogación } \\
\text { avanzado, menús, enlaces } \\
\text { hipertextuales. }\end{array}$ \\
\hline $\begin{array}{l}\text { Variables de } \\
\text { facturación }\end{array}$ & $\begin{array}{l}\text { Muchos servicios gratuitos. } \\
\text { En algunos casos, tiempo de } \\
\text { uso o número de documen- } \\
\text { tos consultados. }\end{array}$ & $\begin{array}{l}\text { Tiempo de uso, e informa- } \\
\text { ción consultada. }\end{array}$ & $\begin{array}{l}\text { Precio fijo, independiente } \\
\text { del uso. }\end{array}$ \\
\hline Forma de pago & $\begin{array}{l}\text { Facturación del proveedor de } \\
\text { acceso a Internet según tiem- } \\
\text { po de utilización, y, cuando } \\
\text { procede, facturación del ser- } \\
\text { vicio de información. }\end{array}$ & $\begin{array}{l}\text { Factura del proveedor del ser- } \\
\text { vicio (previo contrato). }\end{array}$ & $\begin{array}{l}\text { Suscripción o precio por } \\
\text { unidad (compra al núme- } \\
\text { ro). }\end{array}$ \\
\hline $\begin{array}{l}\text { Equipos } \\
\text { necesarios }\end{array}$ & $\begin{array}{l}\text { Microordenador, módem, lí- } \\
\text { nea telefónica y acceso a In- } \\
\text { ternet. }\end{array}$ & $\begin{array}{l}\text { Microordenador, módem, lí- } \\
\text { nea telefónica y acceso a red } \\
\text { de datos. }\end{array}$ & $\begin{array}{l}\text { Microordenador y lector de } \\
\text { discos ópticos. }\end{array}$ \\
\hline $\begin{array}{l}\text { Fecha de } \\
\text { aparición }\end{array}$ & $\begin{array}{l}\text { Principios de la década de } \\
1990 .\end{array}$ & $\begin{array}{l}\text { Principios de la década de } \\
1970 .\end{array}$ & 1985 (cederrón). \\
\hline
\end{tabular}

El productor o el distribuidor son los encargados de decidir por cuál o cuáles de estas vías les será más adecuado difundir sus obras entre el público. En muchos casos, se opta por más de un sistema de distribución para llegar a mercados distintos y complementarios. 


\subsection{OPERADORES}

Las empresas de telecomunicaciones o PTT (por Poste Telephone and Telegraph) se ocupan del transporte de la información entre el distribuidor de bases de datos (v. 2.3) y los terminales de los usuarios (v. 2.6). Actualmente, este proceso se realiza casi siempre a través de Internet, de manera que el distribuidor suele ser un servidor web y el terminal del usuario un cliente web sobre un microordenador. Entre ambos extremos (el servidor y el cliente web) operan una serie de compañías de telecomunicaciones, como pueden ser, en el caso de España, Telefónica, Retevisión, Uni2, Jazztel u otras, que se ocupan de asegurar el funcionamiento de la infraestructura básica (las redes) y que, en algunos casos (videotexto o audiotexto), se han llegado a hacer cargo también de la gestión del cobro de los servicios.

A pesar de que, últimamente, los distribuidores se habían independizado parcialmente de los transportistas distribuyendo sus bases de datos por medio de discos ópticos, el protagonismo de los operadores ha vuelto a renacer debido sobre todo a dos factores: la liberalización del sector ${ }^{15}$ y el auge de las autopistas de la información. Esto ha llevado a que las compañías de telecomunicaciones hayan conseguido unas cotizaciones en bolsa inimaginables hace tan sólo unos años.

\subsubsection{Redes de telecomunicaciones}

Los notables avances conseguidos en este campo han propiciado el gran desarrollo experimentado por la información digital en los últimos veinte años. Gracias a las redes de telecomunicaciones resulta rápido y simple poder acceder a depósitos de información que se encuentren en cualquier parte del mundo. Intentar hacer una breve caracterización técnica de las redes de telecomunicaciones impli-

${ }^{15}$ El Libro verde de las telecomunicaciones (Green paper on the development of a common market for equipments and services), una directiva europea aprobada en 1987, significó el disparo de salida de un proceso de desregularización progresiva del sector de las telecomunicaciones. Estos cambios han sido forzados por diversos factores, entre los cuales podríamos destacar las presiones de las grandes corporaciones, que quieren tener la oportunidad de hacer negocio en un sector en plena expansión económica, la complejidad y variedad de los servicios existentes, difíciles de explotar en régimen de monopolio, o la presión de los consumidores. Estados Unidos ya inició este proceso en 1956 y lo completó en 1982. Japón hizo lo mismo en 1985 privatizando la NTT (Nipon Telephone and Telegraph). En el Consejo de Ministros de Telecomunicaciones de la Unión Europea celebrado en junio de 1993, se decidió liberalizar la telefonía vocal de forma progresiva y gradual, en un plazo flexible que se adaptase a las particularidades de cada país. El plazo medio que se previó era de cinco años (1998), y la mayoría de los países de la Unión Europea (entre ellos, España) llegaron a esta fecha habiendo liberalizado casi totalmente el sector de las telecomunicaciones (la telefonía móvil en primer lugar, el satélite, el cable y, finalmente, la telefonía vocal). 
ca describir su tipología básica. Si seguimos un orden cronológico y de importancia, esto equivale a hablar de las siguientes redes:

- RTB (Red Telefónica Básica).

También se conoce como Red Telefónica Conmutada (RTC) y aún es la red más extendida. Funciona basándose en un cable que contiene hilos de cobre en su interior. Las líneas están unidas entre sí por centralitas y se van ramificando hasta llegar a los domicilios de los usuarios. Es analógica porque transmite en forma de impulsos eléctricos las vibraciones de nuestra voz. Aunque sus orígenes y desarrollo van íntimamente ligados a la transmisión de voz, también es posible enviar datos, es decir, comunicar entre sí dos ordenadores, lo que se consiguió a mediados de la década de 1950. En este caso es necesario el concurso de un módem ${ }^{16}$ que se ocupa de convertir la señal analógica en digital y viceversa.

- RTD (Red de Transmisión de Datos).

A partir de la década de 1970, la mayoría de los países occidentales comenzó a crear redes específicas para la transmisión de datos (RTD, Redes de Transmisión de Datos) que funcionan con el sistema de conmutación de paquetes. ${ }^{17}$ Hasta este momento, la red telefónica era la más importante y utilizada. Las RTD están pensadas para gestionar la circulación de la información de tipo alfanumérico (p. e., la contenida en la mayoría de bases de datos en línea) y, en muchos casos, se comunican con las redes de telefonía tradicionales que actúan de puente entre los usuarios de los servicios de información electrónica y la red de transmisión de datos.

- RDSI (Red Digital de Servicios Integrales).

La red digital de servicios integrados (RDSI o ISDN, Integrated Services Digital Network) trabaja también sobre la base de cables de cobre (aunque en este caso el cableado es más grueso), pero con la capacidad de enviar y recibir datos a mayor velocidad (velocidad de conexión de hasta $128 \mathrm{Kbps}$ ) y, además, las centralitas son totalmente digitales. Por este motivo no son necesarios aparatos conver-

\footnotetext{
${ }^{16}$ Un módem es un equipo de comunicaciones que transforma señales digitales en analógicas y al revés, para permitir que un ordenador pueda enviar y recibir información a través de las líneas telefónicas y utilizando los mismos circuitos de la red básica de transmisión de voz. El problema es que los ordenadores utilizan información en formato digital, minetras que las líneas telefónicas solamente aceptan información en formato analógico. La función del módem es modular la información digital en forma analógica, o desmodularla desde el formato analógico al formato digital.

${ }^{17}$ La red de transmisión de datos española recibe el nombre de Iberpac.
} 
sores, aunque se tenga que usar un adaptador especial conectado al equipo informático y a la línea RDSI. ${ }^{18}$

En un futuro muy cercano, las redes digitales de servicios integrados de banda estrecha servirán de soporte no sólo a todos los sistemas de información digital, sino también al resto de servicios tradicionales (télex, telefonía, etc.), así como a todos aquellos que puedan ir surgiendo. Actualmente, estas RDSI ya funcionan de forma parcial en todos los países occidentales.

Ahora bien, la RSDI no es la última estación en el desarrollo de las telecomunicaciones, sino que ya se está experimentando con las redes digitales integradas de banda ancha, que estarán preparadas para la transmisión de servicios multimedia avanzados: videoconferencias, videoteléfono, transmisión de imágenes fijas y animadas, etc. Si la RDSI es capaz de transportar datos a una velocidad de un máximo de $64 \mathrm{Kbps}$ (muy superior a la de las líneas analógicas), la RSDI de banda ancha, según los expertos, no se podrá implantar hasta dentro de un mínimo de diez años y, al ser compatible con la banda estrecha, la podrá ir sustituyendo de forma gradual.

De cara al futuro no podemos olvidar la conexión mediante fibra óptica, comúnmente llamada cable, ni el satélite, centrados por el momento de forma casi exclusiva en el sector del ocio y la televisión. Estas infraestructuras, no obstante, no tardarán demasiado en disponer de un papel más importante respecto a la distribución de información electrónica y documentos digitales.

\subsection{DOCUMENTALISTAS}

Entre el usuario final que busca una información y esa información suele existir una figura que nosotros hemos identificado como el documentalista y que a veces se denomina también intermediario o broker.

Este intermediario suele ser un profesional de la documentación que conoce bien:

a) Uno o varios ámbitos temáticos, por ejemplo, la economía, el derecho, la medicina, el cine, la historia, etc., de manera que está especializado en el lenguaje y los conceptos básicos de esa(s) disciplina(s).

\footnotetext{
${ }^{18}$ A estos dispositivos que realizan las funciones de interfaz entre el ordenador y la red se les denomina, de manera un poco inadecuada, módems digitales.
} 
b) Cuáles son las mejores y más importantes fuentes de información digitales de uno o varios campos del conocimiento, así como cuáles son las formas de utilización de esas fuentes (lenguajes de interrogación, instrucciones y formas de acceso, etc.).

c) La metodología y los procedimientos generales para transformar necesidades de información expresadas en lenguaje natural en ecuaciones de búsqueda. ${ }^{19}$

Con estas tres habilidades y los conocimientos señalados, los profesionales de la documentación están en condiciones de ayudar a resolver con eficacia y economía de medios las necesidades de información de los usuarios finales. Al menos, de aquellos usuarios finales que trabajan en organismos que disponen de servicios de documentación, como pueden ser las universidades, los institutos de investigación, y también las empresas que disponen de departamentos de I+D.

\subsection{USUARIOS}

Finalmente, ¿quién es el usuario típico de estos servicios? En un primer momento, el sector de la información digital se dirigió, de forma casi exclusiva, hacia el ámbito profesional y científico-técnico. Así pues, una buena parte de los usuarios de los servicios de información digital forman parte de los mismos colectivos sociales que ejercen de autores (profesores de universidad, investigadores, periodistas, ingenieros, técnicos, etc.), a los que hay que añadir de manera destacada - y cada vez más - a ejecutivos de empresa y técnicos y directivos de la Administración pública. No obstante, poco a poco se fueron desarrollando dos nuevas líneas de expansión.

${ }^{19}$ Los pasos que hay que efectuar para convertir una consulta en una ecuación de búsqueda son los siguientes:

- Formular la consulta en lenguaje natural.

P. e.: «Querría saber cuáles son las obras escritas por Josep Pla sobre gastronomía en el período comprendido entre los años 1953 y 1967».

- Analizar la consulta para determinar cuáles son los conceptos básicos a los que hace referencia. P. e.: Josep Pla / gastronomía / 1953-1967.

- Traducir los conceptos al lenguaje de indización (tesauros) utilizado en la base de datos. P. e.: Utilizan gastronomía, arte culinario, o cocina?

- Establecer las relaciones sintácticas entre los términos de indización (utilizando los operadores y otros recursos del lenguaje de interrogación) para poder formular la ecuación de búsqueda.

P. e.: «AU = Josep Pla AND gastronomía AND 1953-1967».

A partir de esta última formulación, el programa es capaz de encontrar todos los registros que responden a las condiciones estipuladas. 
En primer lugar, adquirieron mucha importancia los servicios profesionales especializados sobre información económica y financiera (datos comerciales y económicos de compañías, estudios de mercado, valores de bolsa, etc.), que llegaron a ser los más utilizados en el subsector de las bases de datos en línea.

En segundo lugar, se intentó abrir un nuevo frente desarrollando servicios de información digital dirigidos específicamente al gran público. Ésta era una apuesta clara y decidida en pro de la ampliación del mercado. A pesar de ello, era necesario conseguir una serie de requisitos previos centrados básicamente en el campo de las infraestructuras: hacía falta popularizar y disminuir los costes de los equipos informáticos, y se necesitaba una red de telecomunicaciones preparada para soportar el aumento en el tráfico de datos.

Estas condiciones empezaron a cristalizar a partir de la segunda mitad de la década de 1980, especialmente en Francia con el videotexto, un sistema que se orientó desde un principio hacia el gran público. También la edición en disco óptico, con títulos de carácter general, como enciclopedias o diccionarios, y obras de entretenimiento, empezó a potenciar una línea de productos de gran consumo. Ahora bien, la popularización definitiva de los sistemas de información digital no ha llegado hasta la consolidación de los recursos y servicios en Internet y, en especial, del Web.

\subsubsection{Equipos y programas informáticos}

Con el fin de poder utilizar los sistemas de información digital, al usuario le es imprescindible disponer de un conjunto de equipos específicos cuya configuración más habitual estará formada por un microordenador multimedia, un módem y un lector de discos ópticos junto con una serie de aplicaciones informáticas básicas (programas de comunicaciones, visualizador de recursos Internet, etc.). ${ }^{20}$ Finalmente, será necesaria una conexión a la red de telecomunicaciones y, en muchos casos, además, estar dado de alta como usuario de algún distribuidor de servicios telemáticos.

La popularización de la microinformática y la simplicidad de uso de los equipos y de los programas han facilitado el aumento de los usuarios potenciales de

\footnotetext{
${ }^{20}$ Los programas informáticos han ido ganando en simplicidad para permitir así una fácil utilización, y también han ido introduciendo unas interfaces de usuario cada vez más intuitivas y amigables, o userfriendly, como les gusta llamarles a los anglosajones.
} 
documentos y de servicios de información digitales. Gracias a los bajos precios, actualmente, un microordenador multimedia con módem puede considerarse, casi, como un electrodoméstico más, mientras que, anteriormente, al disponerse de pocos equipos informáticos, las consultas a servicios de información electrónica sólo podían realizarse en centros públicos o privados dedicados a estas funciones, lo cual constituía un obstáculo para su expansión.

La extensión del acceso al Web a través de teléfono móvil o desde el televisor constituirá una pequeña revolución en los sistemas de acceso a la información. Con la tecnología WAP (Wireless Application Protocol) el teléfono móvil podrá romper el monopolio del ordenador en lo que se refiere a acceso al Web y a Internet y, aunque le será muy difícil sustituir al PC, sí que podrá realizar algunas de sus funciones, como pueden ser la recepción de información no muy extensa, correo electrónico, etc. Lo mismo puede decirse del televisor.

De hecho, los expertos ya vaticinan una convergencia entre estos tres aparatos que, en distintas épocas, han presidido la escena de la comunicación y la información. Las interrelaciones y confluencias que se pueden establecer entre ellos empiezan a hacer variar sustancialmente el panorama de la comunicación social y de la distribución de información. 



\section{LOS PRODUCTOS DE INFORMACIÓN DIGITAL}

En sus inicios, en la década de 1970, los productos de información digital, aunque eran complementarios, estaban nítidamente diferenciados de los impresos. En primer lugar, el sector de la edición tradicional se ocupaba de elaborar documentos «originales» de todo tipo (libros, revistas, etc.) y la industria de la información digital era más bien un servicio de transformación que actuaba sobre los documentos confeccionando referencias que pasarían a formar parte de bases de datos.

En segundo lugar, el sector de la información digital facilitaba el acceso a información retrospectiva, pero no publicaba información de actualidad ni otros productos culturales como libros o revistas, un tipo de documentos que quedaban reservados al mundo analógico del papel y de las emisiones audiovisuales. En este momento, pues, los documentos digitales estaban formados, sobre todo, por aplicaciones de tipo secundario que contenían información exclusivamente textual (bibliografías, catálogos de bibliotecas, bases de datos, etc.) y que iban dirigidas a un público especializado y, por tanto, minoritario.

A finales de la década de 1980 y principios de la de 1990 se empezaron a editar fuentes de información digital de primera mano. Las obras de consulta (enciclopedias, diccionarios, etc.), un tipo de textos que no exige una lectura continuada, sino sólo consultas esporádicas, y las bases de datos de texto completo (en el campo de la legislación o la prensa diaria) constituyeron las primeras aplicaciones. Por otro lado, poco después, la técnica permitió crear productos que incluían, además del texto, imagen fija, en movimiento y sonido. Es entonces cuando empieza a hablarse de multimedia o de multimedia interactivo, de un tipo de obras que permiten difundir contenidos más orientados hacia el ocio y el entretenimiento y que suponen, por tanto, un giro importante hacia el gran público. 
Actualmente pues, el sector de la información digital es un ámbito del cual forman parte no sólo aquellas empresas dedicadas a facilitar el acceso a información secundaria de tipo retrospectivo, sino también empresas dedicadas a la publicación de libros, revistas y diarios destinados a ser leídos mediante un ordenador de propósito general, o mediante un aparato informático ad hoc más o menos especializado.

De momento, la primera oleada de estas nuevas publicaciones digitales ha consistido en la correspondiente versión digital de algunas publicaciones analógicas preexistentes y basadas en la letra impresa, con la utilización ocasional de imágenes, y que se pueden identificar con productos clásicos de la cultura, como libros, diarios y revistas. Ahora bien, según todas las previsiones, una segunda oleada corresponderá a los medios audiovisuales, tales como las emisiones de radio y televisión. En este momento, todo el espectro de géneros y de productos de la comunicación social estará disponible en formato digital. En este futuro escenario, las diferencias entre los géneros propios de la letra impresa y los géneros propios del audiovisual se podrán mezclar y se crearan géneros nuevos. En el apartado 8.2, «El lenguaje de la publicación digital», se presentan unas reflexiones sobre estas cuestiones.

El brillante éxito de Internet y la tecnología web, así como la progresiva consolidación de la edición óptica han vuelto a reavivar el debate sobre el futuro de la edición y su relación con los soportes documentales tradicionales (el papel). Esta discusión renace cíclicamente cada vez que se desarrolla una nueva tecnología para la distribución de información. Diez años atrás parecía que el videotexto era uno de los llamados a ganar esta batalla. A la hora de la verdad, sin embargo, las limitaciones técnicas del sistema le impidieron dejar de ser más que una buena promesa. Esta vez, no obstante, parece que la cuestión se aborda con mucha más consistencia. Los datos que se presentan en la tabla 3.1, aunque se trata de una prospección, indican claramente que en el año 2000 entre un 10 y un $20 \%$ del volumen del negocio generado por libros, revistas, periódicos y edición corporativa provendría de productos digitales.

En este sentido, Brigitte Chaintreau, vicepresidenta del MIDEM, entidad organizadora de MILIA, manifestó que estaba convencida de que en un plazo de diez o quince años todas las enciclopedias, diccionarios, libros técnicos, de arte, etc., estarían de forma casi exclusiva en soporte digital. También dejarían de publicarse en papel los catálogos de empresas (muchos de los cuales ya se distribuyen en disquetes y en disco óptico), así como los manuales técnicos de funcionamiento de 
Tabla 3.1. Mercado de edición electrónica (año 2000)

\begin{tabular}{lc}
\hline Sector & Volumen total de negocio \\
Libros & $8-18 \%$ \\
Revistas & $5-15 \%$ \\
Prensa & $5-10 \%$ \\
Edición corporativa & $10-25 \%$ \\
\hline
\end{tabular}

Fuente: Consulting Tust GmbH

equipos y aparatos muy diversos (las grandes empresas automovilísticas, p. e., Renault, o aeronáuticas, p. e., McDonnell Douglas, ya no editan sus voluminosos manuales en incontables volúmenes de papel, sino en soporte óptico, más pequeño y fácil de manejar).

Por otro lado, otros estudios prospectivos (v. tabla 3.2) indican que el consumo de papel aún crecerá, al menos hasta el año 2005, aunque su cuota de mercado irá disminuyendo. Esto se explica porque el volumen total de información se incrementará de forma espectacular. En el apartado 8.1, «¿Documento impreso o digital? La discusión sobre el soporte», se analizará con más profundidad esta cuestión.

Tabla 3.2. Mercado global de impresión (en billones de ptas.)

\begin{tabular}{lcc}
\hline Año & Papel & Digital \\
1994 & $60(57 \%)$ & $40(43 \%)$ \\
2005 & $80(34 \%)$ & $150(66 \%)$ \\
\hline
\end{tabular}

[Fuente: KBA, citada por Alonso, 2000]

Aunque aún no hemos descrito con detalle algunas características de la edición en Internet ni de la edición óptica (v. 5 y 6), analizaremos a continuación la situación actual de los principales productos de información digital: las bases de datos, las monografías, las revistas especializadas y la prensa de masas. También incluiremos una breve referencia a la información corporativa e institucional y una visión panorámica de los principales problemas que afectan a los documentos digitales. 


\subsection{BASES DE DATOS}

Como veremos más adelante (v. 4), las bases de datos han constituido el primer producto de información electrónica y disponen de una presencia en el mercado que supera ya los treinta años. Normalmente están relacionadas con la información de carácter retrospectivo, ya que la información actual se distribuye por otros canales, ya sean monografías o publicaciones periódicas. Aunque en los siguientes apartados trataremos de forma separada estos tipos de documento, no hay que olvidar que lo que sería información retrospectiva de prensa, revistas, etc., se consulta en forma de base de datos.

Una base de datos es un conjunto de información estructurada, con un contenido básicamente textual o alfanumérico, que ha sido grabada en soporte digital y que dispone, además, de un programa informático que nos facilita su recuperación. El tipo de programa que se ocupa de la gestión automatizada de estos grandes volúmenes de información se conoce técnicamente con el nombre de sistema de gestión de bases de datos (SGBD, o Data Base Management System). Estos programas permiten la creación, explotación y consulta a las bases de datos y se utilizan en la mayor parte de servicios de información digital. Algunas de estas bases de datos permiten el acceso público a través de las redes de telecomunicaciones (y entonces se habla de bases de datos en línea), aunque también se pueden distribuir, como ya hemos visto en el capítulo anterior, por otras vías (en papel y en soporte magnético u óptico, p. e.).

Las bases de datos pueden clasificarse atendiendo a diversos criterios: el carácter primario o secundario de la información que contienen (referenciales o fuente), la materia que tratan (economía, medicina, etc.), el tipo de productor que las crea (público, privado), o el idioma.

Siguiendo el primero de los criterios, se acostumbra a hacer una doble distinción entre bases de datos referenciales, que contienen información de tipo secundario, es decir, que no disponen de la información final y remiten al usuario a otra fuente de información para resolver totalmente la consulta, y bases de datos de tipo fuente cuyo contenido son documentos primarios, es decir, que proporcionan directamente la información final. En la tabla 3.3 hacemos constar, también, una subtipología.

El mercado de las bases de datos cuenta con tres grandes subsectores diferenciados: las bases de datos cientifico-técnicas de tipo retrospectivo (mercado clási$c o$ ), los servicios de información económica y de negocios (distribuidos en tiem- 
Tabla 3.3. Tipología de las bases de datos

(según el carácter primario o secundario de la información)

\section{Bibliográficas}

Contienen referencias documentales, y remiten a otros documentos: libros, artículos, etc.

\section{Referenciales Directorio}

Contienen datos domiciliarios, biográficos o curriculares que remiten a organizaciones, instituciones, empresas o personas, o descripciones de objetos (p. e., obras de arte).

\section{Textuales}

Contienen textos completos de documentos (con la incorporación, en muchos casos, de recursos gráficos de presentación).

Fuente

\section{Numéricas}

Contienen datos estadísticos o factuales.

\section{Multimedia}

Contienen documentos en los que podemos encontrar no sólo texto, sino también sonido, imagen fija e imagen en movimiento.

\begin{tabular}{|c|c|c|c|}
\hline \multicolumn{3}{|c|}{ buscar1-Netscape } & $x$ \\
\hline Eveferits & 1. Ubicació: http://pci204.cindoc.csic.es/cgi-bin/wwwi32.exe/(in=cindoc/tesis.in]/\#2 & 7 Pins & 网 \\
\hline \multicolumn{4}{|l|}{ 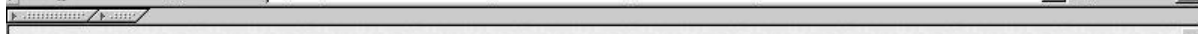 } \\
\hline \multicolumn{4}{|c|}{$\begin{array}{l}\text { Resultado de la búsqueda: } 14 \text { registros encontrados en la base ALPE } \\
\qquad \text { mostrando del } \mathbf{1} \text { al } \mathbf{1 4} \text { de } \mathbf{1 4}\end{array}$} \\
\hline $1 / 14$ & marcar: $\Gamma$ & D] 000 & \\
\hline Título & Dudas sobre el tráfico de armas a Colombia revelado por Fujimori & & \\
\hline Periódico & El País & & \\
\hline Fecha & 25 agosto 2000 & & \\
\hline Tipo de noticia & crónica & & \\
\hline Descriptores & Tráfico de armas; servicios secretos; presidente de gobierno; conflictos armados; guerrilla & & \\
\hline Identificadores & Fuerzas Armadas Revolucionarias de Colombia; Fujimori, Alberto; Montesinos, Vladimiro & & \\
\hline Topónimos & Colombia; Perú; Lima & & \\
\hline $2 / 14$ & marcar: $\Gamma$ & D 200 & \\
\hline Título & El jefe del espionaje de Fujimori sale a la luz para acusar a las FARC & & \\
\hline Periódico & El País & & \\
\hline Fecha & 23 agosto 2000 & & \\
\hline Tipo de noticia & crónica & & \\
\hline Descriptores & Tráfico de armas; servicios secretos; presidente de gobierno; conflictos armados; guerrilla & & \\
\hline Identificadores & Fuerzas Armadas Revolucionarias de Colombia; Fujimori, Alberto; Montesinos, Vladimiro & & \\
\hline Topónimos & Colombia; Perú; Lima & & \\
\hline $\mathrm{d}^{\mathrm{N}}=0=$ & Document: fet & 7 舟 & \\
\hline
\end{tabular}

Figura 3.1. Ejemplo de registros de una base de datos bibliográfica: ALPE (América Latina en los Periódicos Españoles) 


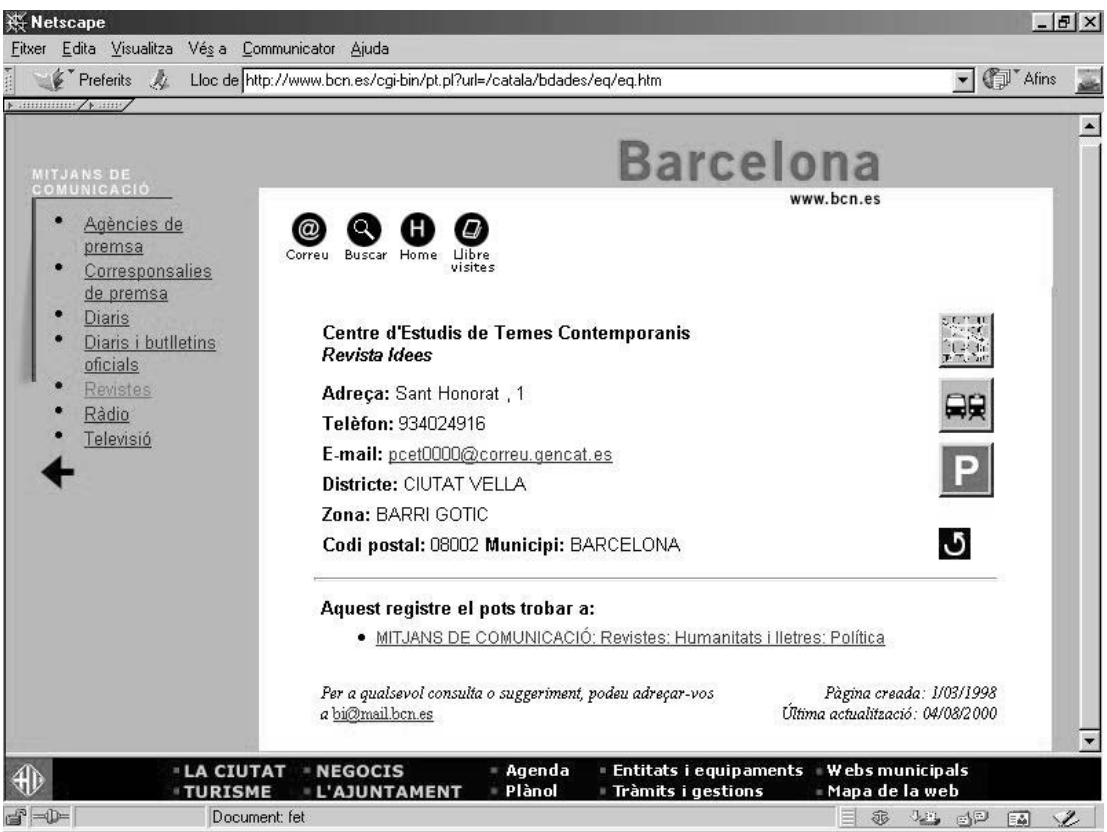

Figura 3.2. Ejemplo de registro de una base de datos directorio: directorio del Ajuntament de Barcelona

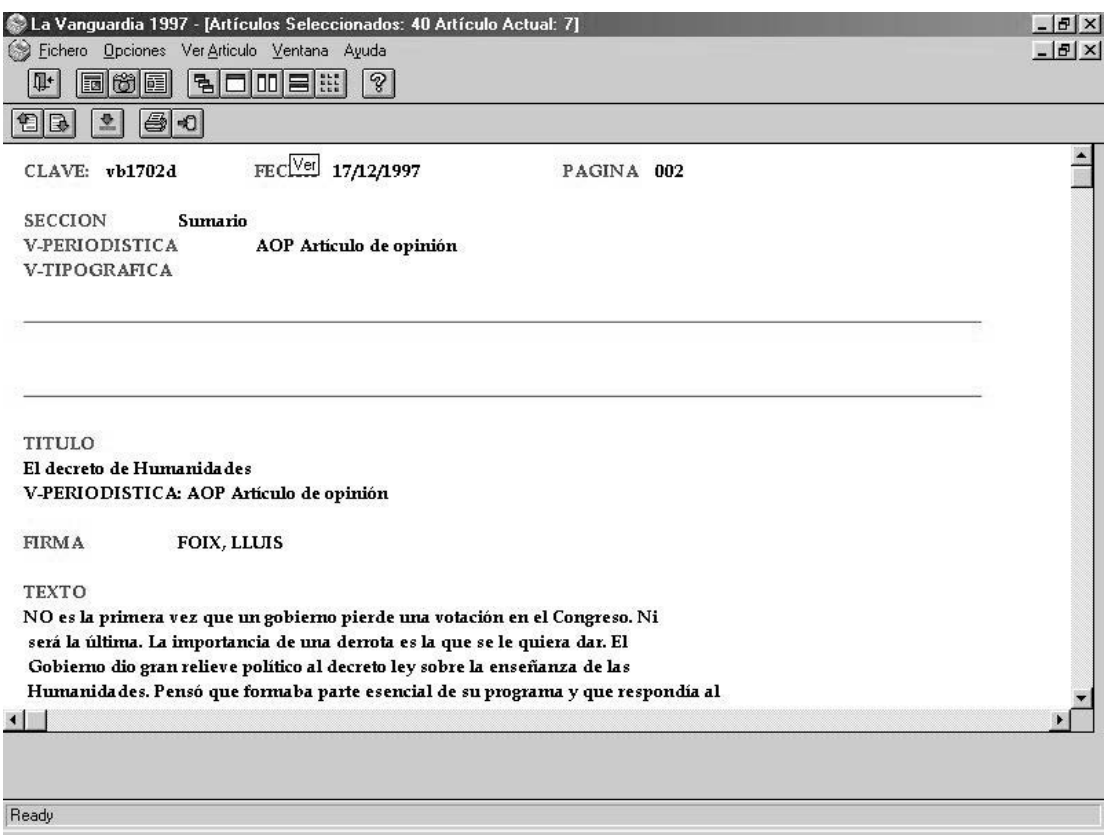

Figura 3.3. Parte de un registro de una base de datos textual: La Vanguardia 


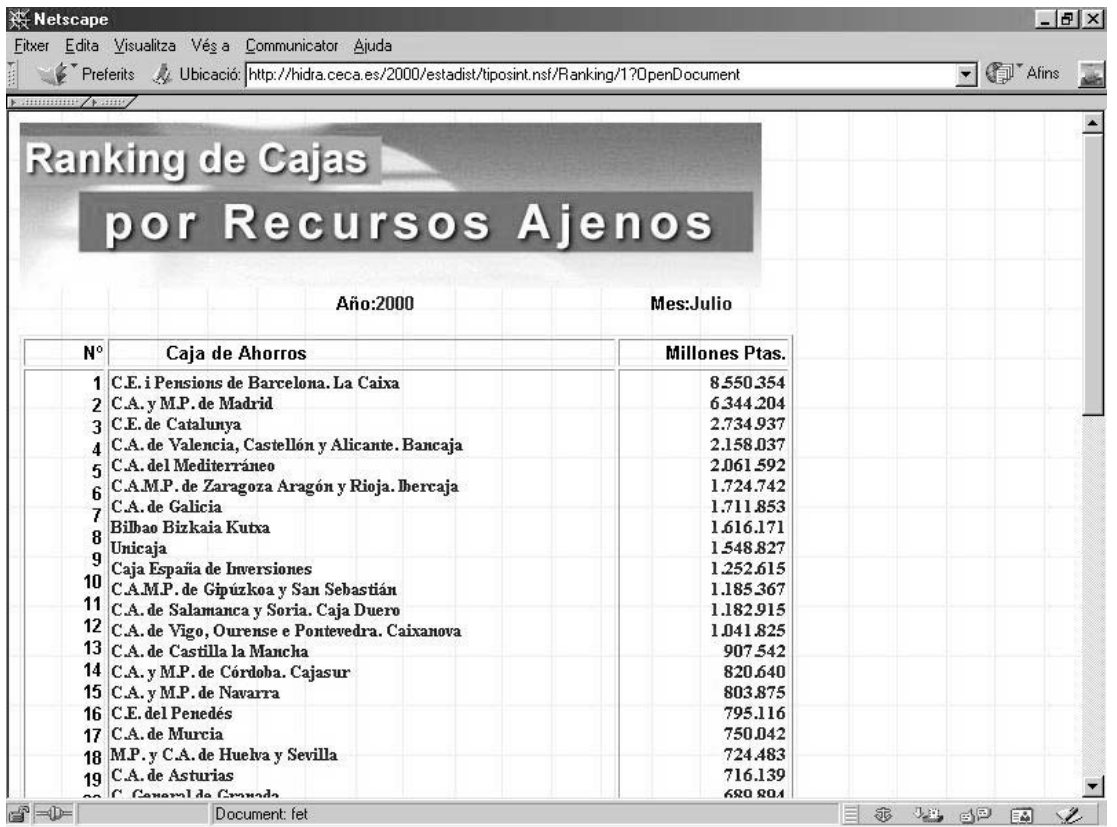

Figura 3.4. Ejemplo de registro de una base de datos numérica:

Confederación Española de Cajas de Ahorro

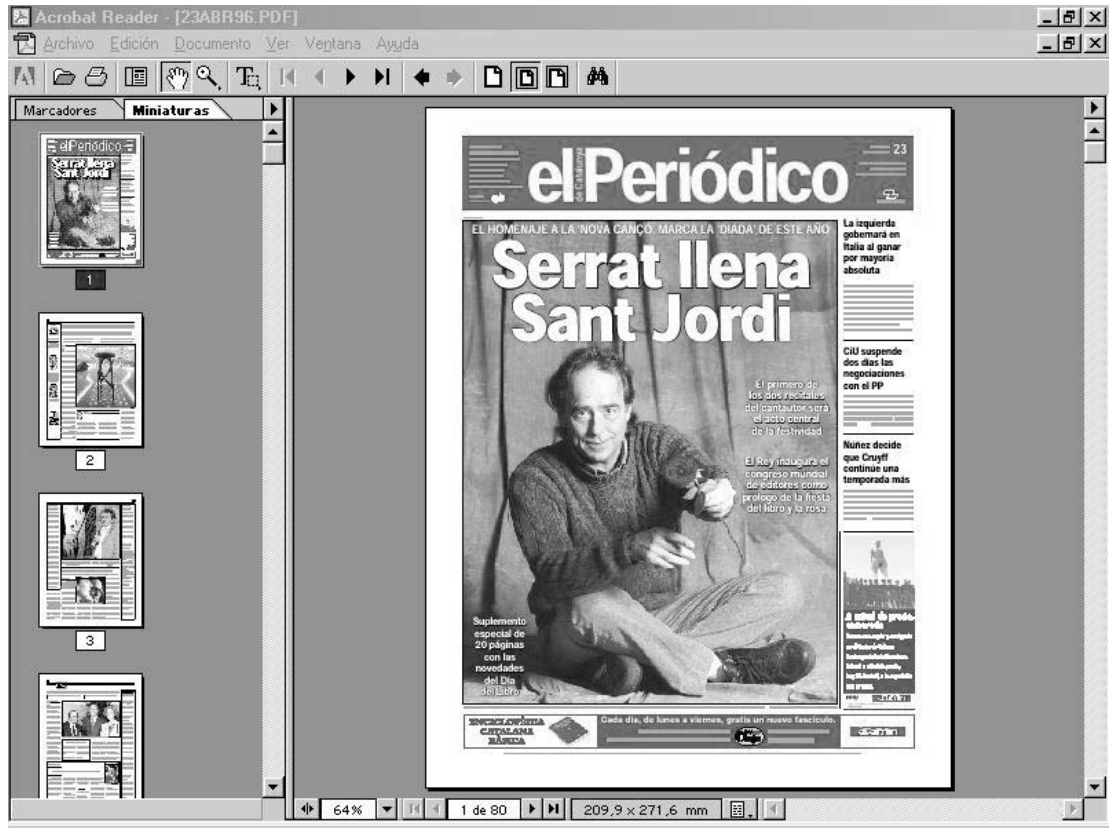

Figura 3.5. Ejemplo de registro de una base de datos textual con compaginación original: El Periódico de Cataluña (en cederrón) 


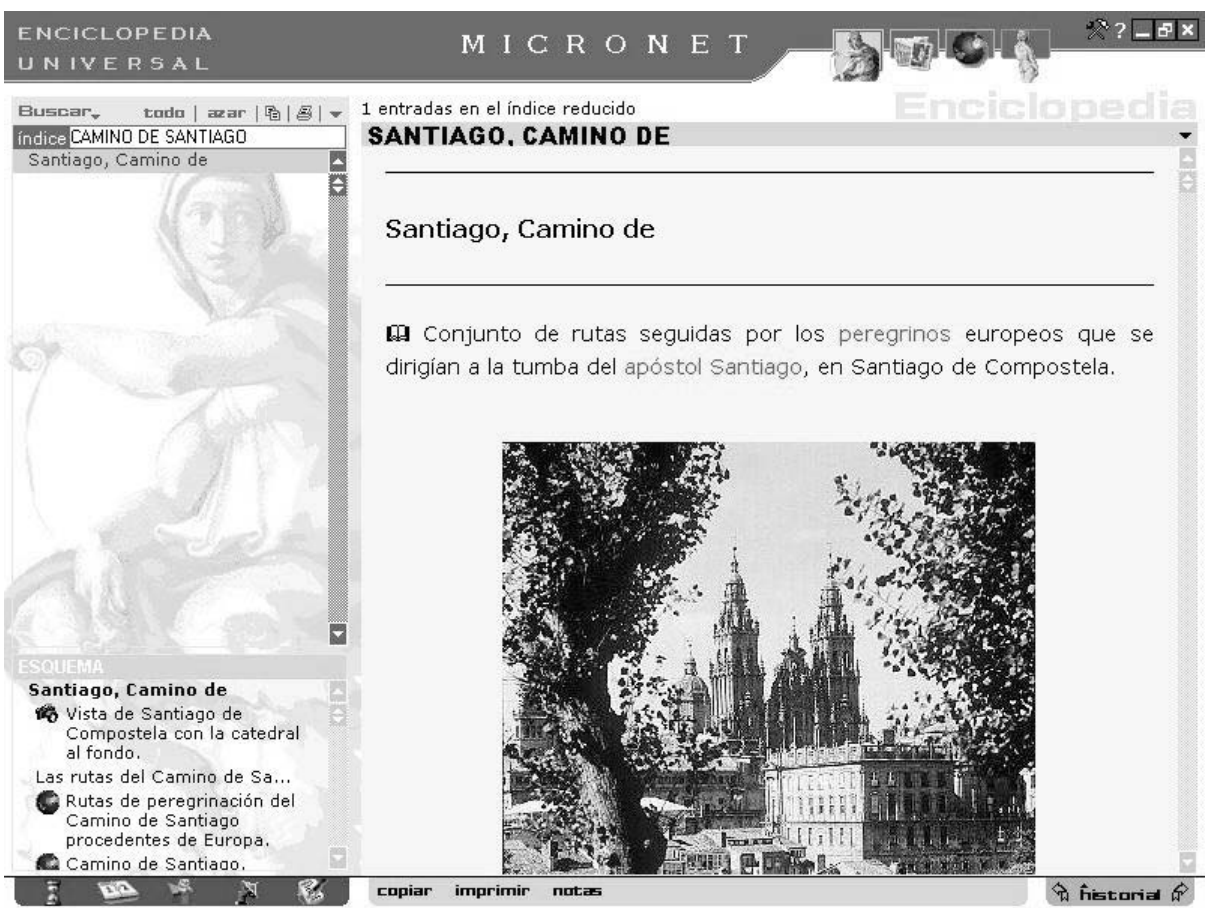

Figura 3.6. Ejemplo de registro de una base de datos multimedia: Enciclopedia Micronet

po real), y las bases de datos de información general. Los dos primeros subsectores son de tipo profesional y van dirigidos a la investigación y a la gestión financiera, respectivamente. El tercero, en cambio, se orienta básicamente hacia el gran público, y es el que ha registrado un crecimiento más importante en los últimos años. A continuación, presentamos una breve descripción de cada uno de ellos.

\subsubsection{Bases de datos de ciencia y tecnología}

El contenido de estas bases de datos es de carácter especializado y sus principales usuarios son los departamentos de investigación y desarrollo (I+D) de las empresas, las universidades, los organismos públicos de investigación y, también, los centros de documentación y las bibliotecas especializadas (y, en especial, las universitarias). La presencia de usuarios personales no es relevante en este subsector. 
El mercado de la información científico-técnica está dominado por los distribuidores americanos (especialmente Nexis-Lexis y The Dialog Corporation, dos de los gigantes del sector), que son los que disponen de unas infraestructuras técnicas y comerciales más desarrolladas. La presencia europea en este ámbito es bastante reducida y tiene en Questel (Francia) y Dimdi (Alemania) sus principales baluartes. Precisamente, uno de los host europeos más desarrollados, el suizo Data-Star, fue adquirido hace años por The Dialog Corporation.

The Dialog CORPORATION <HTTP://WWw.DIALOG.COM>

Es la denominación comercial del consorcio formado por tres distribuidores de bases de datos Dialog (California), Data-Star (Suiza) y Profound. Dialog, que dispone actualmente de unas 600 bases de datos especializadas, tiene el honor de ser uno de los primeros distribuidores que aparecieron en el mercado. Tiene unos 20.000 clientes corporativos en más de 120 países. En un principio dependía de la empresa aeronáutica Lockheed. Después de la grave crisis que sufrió esta empresa, a raíz de unos casos de soborno en Italia, la división de información en línea se independizó de la antigua casa madre. En 1991 Knight Ridder, una empresa del sector de la información, compró Dia$\log$ y, posteriormente, también Data-Star, que era el principal distribuidor europeo y que cuenta con unas 300 bases de datos. En noviembre de 1997 el grupo Maid compró Knight-Ridder Information y constituyó The Dialog Corporation, que es la actual denominación del grupo. Finalmente, en mayo de 2000, pasó a manos de Thomson, una importante empresa del sector de la información.

A principios de la década de 1970, cuando nacen los primeros servicios en línea, las bases de datos científico-técnicas (información para la aeronáutica, biomedicina, química, etc.) eran las más consultadas. A principios de la década de 1980 ya empezaron a ser superadas por la información económica y financiera y, poco después, también por las bases de datos dirigidas al gran público. Es decir, que su crecimiento en los últimos años ha sido muy escaso si lo comparamos con el que han registrado los otros dos subsectores. Tan sólo hay que comparar los 20.000 clientes de Dialog con los 23 millones de usuarios de AOL (v. 3.1.3), aunque no podemos olvidar que los conceptos y productos son distintos, ya que en el primer caso son clientes corporativos y de pago, mientras que, en el segundo, son personales y los servicios son prácticamente gratuitos. 


\subsubsection{Bases de datos de información económica y de negocios}

Se trata de bases de datos que contienen información económica, comercial o de negocios dirigida principalmente a las empresas - y, en especial, a las que tienen importantes volúmenes de facturación y departamentos financieros- y procedente, en muchos casos, de publicaciones periodísticas. Podríamos distinguir dos tipos de orientación:

- Información financiera.

Se trata de bases de datos que se ocupan de registrar valores de fluctuación constante: índices de bolsa, mercado de futuros, divisas, etc. Es un tipo de información que va actualizándose constantemente, lo que se denomina distribución en tiempo real. Éste es un aspecto clave en el sector de la información financiera: se han de poder registrar todas las variaciones de los datos (p. e., cotizaciones de bolsa) aunque se produzcan a cada segundo. Los principales distribuidores son Reuters, Telerate, Quotron, etc., y acostumbran a utilizar terminales, tecnología y redes propias.

- Análisis e investigaciones de mercado.

Contienen otras informaciones de negocio útiles para las empresas: créditos, directorios económicos y empresariales, memorias y balances de empresas, etc. Su distribución no es en tiempo real, aunque se actualicen diariamente. Algunos ejemplos: Dow Jones, Dun\&Bradstreet (uno de los distribuidores de información de negocios con una facturación más alta), Informa (España), FT Profile, Maid, etc.

Los servicios en línea de información económica están adquiriendo una notoriedad cada vez más grande y llegan a representar la parte más importante del total del negocio generado por las bases de datos en línea (unas diez veces el subsector científico-técnico). Los precios de este tipo de servicio son bastante elevados.

El mercado más desarrollado para esta clase de productos es Estados Unidos, seguidos por Europa y Japón. Como en el caso anterior, hay también una diferencia considerable en el número de abonados en este tipo de bases de datos respecto a las de gran público (Reuters dispone de poco más de medio millón de abonados). 


\section{REUTERS < $<$ HTP://WWW.REUTERS.COM>}

Se trata de una de las empresas líder en el campo de la información digital. Compila y distribuye servicios de información en línea para unos 520.000 usuarios del sector financiero, de negocios y también para los medios de comunicación (agencias de noticias, prensa, radio y televisión) de más de 150 países. Utiliza una red propia de telecomunicaciones (una de las redes privadas más grandes) y un programa de comunicaciones específico.

Se trata de una empresa con más de cientocuarenta años de historia que proviene del sector periodístico, de la información de actualidad. Hace unos años creó un servicio de información para negocios que ha registrado un éxito tan importante que ha pasado a constituir la actividad principal de la empresa, muy por encima de su dedicación tradicional a la información de actualidad. Tiene su sede en Londres.

Aparte de los servicios en tiempo real dispone también de bases de datos retrospectivas. Así, p. e., Reuter:file es un conjunto de bases de datos especializadas en finanzas, economía, energía, aeronáutica y noticias económicas y de empresas, con documentos desde 1980. Otra base de datos importante es Reuter Business Briefing, que contiene noticias e informes financieros de mercado y que incluye información procedente de los principales periódicos económicos españoles.

\subsubsection{Bases de datos y servicios de información dirigidos al gran público}

Con posterioridad a los tipos de servicios descritos, aparecieron también bases de datos y servicios de información digitales dirigidos al gran público. Su principal atractivo era el acceso a fuentes de información no especializada (p. e., meteorología, deportes, espectáculos, etc.) y la provisión de otra clase de servicios telemáticos (en especial el correo electrónico, los foros de discusión, la transferencia de ficheros, etc.). Se trata, pues, de una oferta de servicios de carácter general que se dirige en especial hacia el gran público y no a sectores profesionales o especializados, como sería el caso de los subsectores precedentes.

En un primer momento estas bases de datos se distribuían en línea en formato ASCII y eran de pago previa suscripción. Los distribuidores que adquirieron mayor renombre fueron CompuServe - uno de los pioneros y de los más conocidos-, America Online - con un crecimiento espectacular en los últimos años-, Prodigy, o Microsoft Network. Estos distribuidores tenían la necesidad de captar un alto número de usuarios para poder rentabilizar las grandes inversiones que efec- 
tuaban (ofrecían en exclusiva servicios de información de actualidad procedentes de agencias de noticias o de prensa diaria). La expansión y consolidación de Internet provocó un trasvase hacia el Web y, actualmente, los que quedan se encuentran en Internet y acostumbran a ser gratuitos. De todos los mencionados anteriormente, los que han sobrevivido a la revolución de Internet son America Online, ahora más conocido como AOL, y Microsoft Network.

\section{AMERICA ONLINE (AOL) <HTTP://WW W.AOL.COM>}

Es una de las mayores empresas de servicios de información digital. Fue fundada en 1985 y tiene su sede en Virginia (EUA). En el año 2000 contaba con unos 23 millones de usuarios a los que se ofrecen servicios de información sobre finanzas, entretenimiento, noticias de actualidad, etc., juntamente con el acceso a Internet y muchos otros servicios (mensajería, chats, productos comerciales, etc.). En enero de 1998 adquirieron CompuServe, uno de los distribuidores más antiguos del sector (se creó en 1979), que cuenta con unos 2,8 millones de usuarios y que, a pesar de formar parte del mismo grupo, sigue en el mercado como marca independiente de America Online. Últimamente ha vuelto a saltar a la palestra con motivo de la alianza con Sun para el desarrollo de aplicaciones para Internet, por la compra de Netscape (1998) y, especialmente, por la fusión con Time Warner, una de las compañías de información y entretenimiento más importante del mundo (enero 2000).

También tendríamos que considerar como parte de este gran grupo a los grandes localizadores de recursos web (véase 5.2), ya se trate de directorios temáticos al estilo Yahoo! o de buscadores como Altavista. En este caso no es necesario formalizar ninguna suscripción porque se trata de servicios gratuitos que se financian con la publicidad y que constituyen, como es bien sabido, los sitios web más visitados por los internautas.

\subsection{LIBROS}

El libro está considerado como el medio por excelencia para la difusión de la cultura. Su implantación y arraigo es muy grande y van muy unidos al papel, el soporte material de impresión más utilizado hasta el momento (v. 8.1). Aun así, es posible encontrar, cada vez más, un mayor número de libros digitales, o e-books, como los llaman los anglosajones, y que se distribuyen de diversas maneras: 
- En disco óptico.

En este caso, tal y como se detallará más adelante (v. 6), los principales tipos de título que se editan son las obras de referencia, libro infantil y libros de conocimientos, entre otros. Un aspecto importante que debe reseñarse es la notable presencia de editores profesionales. Actualmente, una buena parte de lo que se llaman obras de consulta (enciclopedias, diccionarios, etc.) se están editando, en una proporción considerable, en soporte óptico. Por el momento, se trata de títulos más elaborados en cuanto a presentación que los que se pueden encontrar en las redes, que disponen de interfaces más bien austeros, con pocos elementos multimedia.

- Impresión a demanda.

Esta opción se utiliza para ediciones que ya se han agotado y de las cuales no es rentable hacer una reimpresión. El contenido del libro está almacenado en un sistema que dispone de impresoras de alta calidad, encuadernadora y guillotina, que pueden generar una copia impresa a la carta en menos de quince minutos. La librería Catalonia, en Barcelona, dispone desde finales de 1999 de un equipo de estas características.

- Consulta en línea.

El libro se encuentra en una dirección web donde se puede consultar de forma gratuita o previo pago de una cantidad determinada.

- Descarga a un microordenador.

El libro digital está contenido en un fichero que el usuario ha de descargar en su PC, de la misma forma que se hace en el Web para otro tipo de ficheros. El principal inconveniente reside en el hecho de que se trata de un proceso lento con los equipos y redes que existen actualmente. Edicions de la UOC y Edicions Virtuals UPC son dos ejemplos de editoriales que suministran documentos por este sistema, normalmente en formato pdf. También se podría citar a netLibrary <http://www.netlibrary.com>, que ofrece más de 20.000 libros digitales a particulares y organizaciones, unos 4.000 de los cuales son gratuitos.

- Descarga a un lector de libro digital.

En este caso el proceso es idéntico al anterior, pero se dispone de un equipo especial, mucho más transportable que el ordenador. El lector de libro digital es un 
potente ordenador de pequeñas dimensiones con pantalla de cristal líquido y conexión por módem a la sede del editor para poder descargar los libros. Aunque la transportabilidad está resuelta, hay otros aspectos ergonómicos que aún pueden mejorar, especialmente la calidad de la visualización.

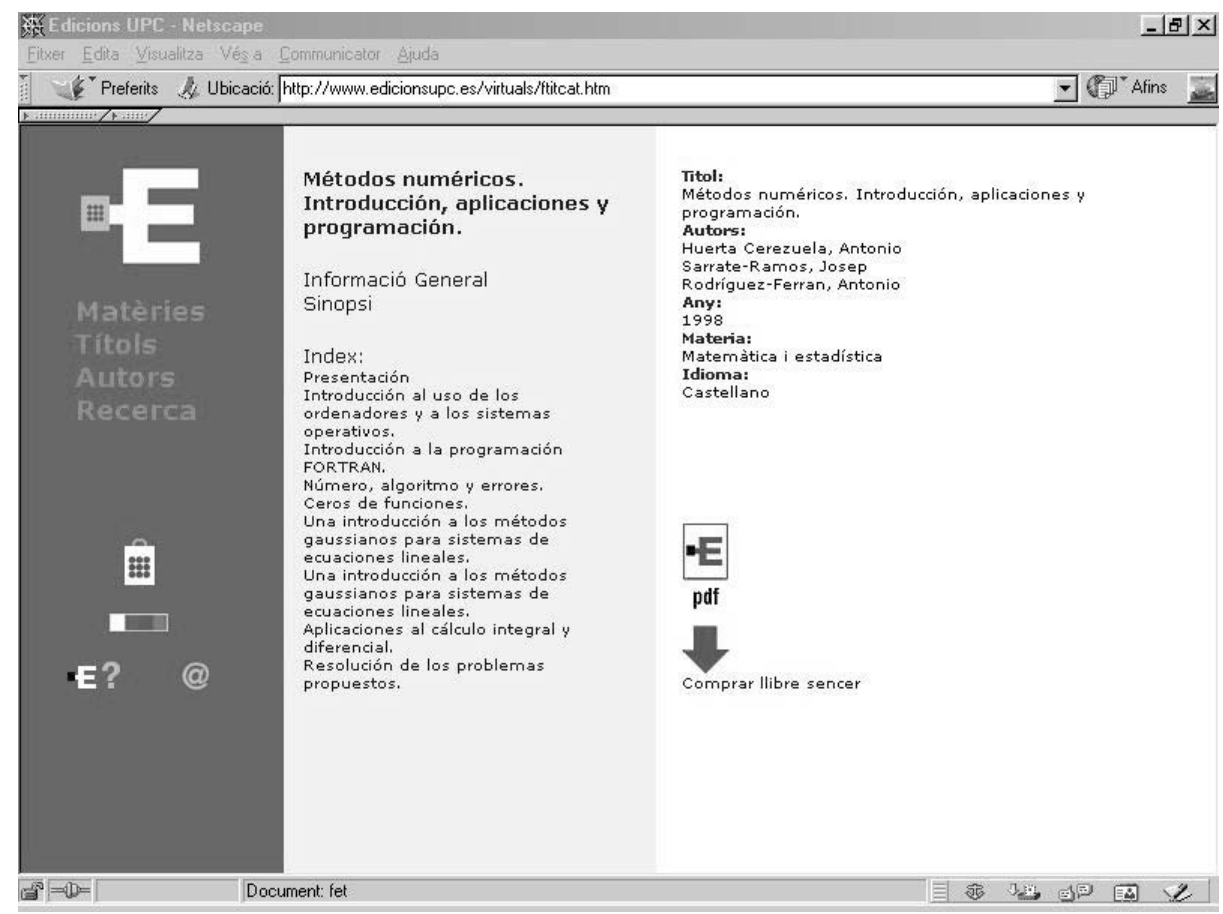

Fig. 3.7. Ejemplo de venta por descarga de libros digitales: Edicions Virtuals UPC

Hay diversos prototipos, como SoftBook (SoftBook) o Rocket eBook (Nuovo Media), y no existe aún un formato estándar, aunque se ha constituido un consorcio, The Open eBook Initiative, que agrupa a los principales industriales del sector $^{21}$ y que está trabajando en esta línea. En septiembre de 1999 apareció el primer borrador del estándar Open Electronic Book (OEB), que se basará en html y xml, y que pretende asegurar que la lectura será posible desde cualquier plataforma.

Aunque actualmente la oferta en la red está formada más bien por contenidos dirigidos a un público especializado (informes técnicos, obras de literatura con de-

\footnotetext{
${ }^{21}$ Entre otros, hay que destacar a los siguientes: IBM, Microsoft, SoftBooks, Nuovo Media, Adobe Systems, etc.
} 
rechos de autor ya caducados, textos académicos, etc.), las grandes editoriales están digitalizando sus fondos para poder distribuirlos por alguna de las vías antes expuestas, en especial la descarga a ordenador y también la impresión a demanda.

Tabla 3.4. Directorios y portales de libros digitales en la red

Nombre

Alex Catalog of e-Texts

Ebook Network

E-books.org

Internet Public Library

Open Directory
Dirección

http://sunsite.berkeley.edu/alex/

http://www.ebooknet.com

http://www.e-books.org

http://www.ipl.org/reading/books/index.html

http://www.dmoz.org/Computers/E-Books/

Por ahora, los libros digitales son un instrumento muy útil para hacer consultas concretas, como las que se puedan realizar a una enciclopedia, ya que ocupan menos espacio, su coste es menor, y permiten un acceso más rico y complejo al contenido de la información que el de la edición tradicional. También se utilizan para distribuir documentos ya agotados en la edición impresa o cuyos contenidos van dirigidos al público especializado. Ahora bien, los libros dirigidos al gran público, con tiradas muy elevadas, siguen editándose por el sistema tradicional. No obstante, ya existen experiencias de distribución de algún superventas por medio del web. Es el caso del relato Riding the bullet, de Stephen King, que se distribuyó en exclusiva en la red (los lectores podían descargar en su ordenador previo pago de unas quinientas pesetas) y que tuvo muy buena acogida, ya que en dos semanas había sido vendida a 500.000 lectores. ${ }^{22}$ Arturo Pérez Reverte siguió la misma estela y colocó en Internet El oro del rey — la última entrega del personaje Alatriste- un mes antes de llegar a las librerías.

\subsection{REVISTAS ESPECIALIZADAS}

Las publicaciones periódicas científico-técnicas se caracterizan por disponer de un mercado global, por realizar unas tiradas más bien cortas, y por la rápida pér-

${ }^{22}$ A pesar de ello, tuvo problemas en otro proyecto suyo de novela por entregas en el cual las dificultades para copiar los diversos capítulos que iban apareciendo y el progresivo descenso del número de clientes le llevó a abandonar la edición de la obra en Internet. 
dida de vigencia de buena parte de sus contenidos. Dos son los principales problemas que afectan a sus ediciones: por un lado, son el sector más perjudicado por la piratería de los derechos de autor (las fotocopias), lo que les provoca un descenso paulatino de las ventas y un aumento de los precios en una espiral interminable y, por otro lado, el excesivo tiempo transcurrido entre la recepción de originales para la publicación y su distribución entre los lectores provoca un considerable retraso en el acceso a la información. Este segundo obstáculo es especialmente grave en el ámbito científico-técnico, en el cual existe una gran pugna para publicar resultados o descubrimientos antes que los competidores. Frente a los dos problemas, los editores han ingeniado nuevas estrategias, en sintonía con los nuevos tiempos que corren, y aprovechando al máximo las actuales posibilidades tecnológicas.

Aunque se pueden encontrar algunos ejemplos de revistas en soporte óptico (el disco Adonis ${ }^{23}$ es el ejemplo que suele citarse en estas ocasiones), el recurso a las redes de telecomunicaciones, Internet en especial, es la forma de distribución mayoritaria por la que han optado los editores. Así pues, cada vez es mayor el número de editores tradicionales que distribuyen también una versión electrónica de sus publicaciones, normalmente en formato pdf. Es el caso de Academic Press, ${ }^{24}$ Elsevier ${ }^{25}$ o Springer Verlag, ${ }^{26}$ que ofrecen a sus suscriptores la posibilidad de disponer también de la versión electrónica de sus títulos. Por otro lado, también podemos encontrar un número cada vez mayor de boletines y revistas electrónicas sin un referente previo sobre papel, que tratan de los más diversos y variados temas: astronomía, turismo, química, arte, medicina, filosofía, etc., y que son accesibles conectándose al Web. Su estructura es idéntica a la de una publicación convencional: tienen su director, un equipo de colaboradores, un editor, aparecen con una determinada periodicidad, disponen de secciones fijas, etc.

Tal y como pasa con otros tipos de publicaciones digitales, conocer el número de revistas especializadas digitales que existen en el mundo es una tarea de imposible resolución debido a que no existen directorios que cubran de forma exhaustiva este ámbito. De todas formas, para tener una referencia podemos citar el Direc-

\footnotetext{
${ }^{23}$ Contiene el texto completo de varios centenares de revistas especializadas en biomedicina.

${ }^{24}$ Dispone del servicio International Digital Electronic Access Library (Ideal), que ofrece unas 200 revistas. $<$ http://www.idealibrary.com>.

${ }^{25}$ El servicio EES (Elsevier Electronic Subscription) permite el acceso a más de 1.200 títulos de revista. En algunos casos se trata de títulos totalmente digitales, sin referente en el ámbito impreso. <http://www.elsevier.com>.

${ }^{26}$ Se trata de una de las primeras empresas editoriales que dispuso de servicios digitales para sus suscriptores. <http://www.springer.de>. Su servicio Link ofrece unos 180 títulos.
} 
tory of electronic journals, newsletters and academic discussion lists, ${ }^{27}$ elaborado por la ARL (Association of Research Libraries) que en su edición de 1997, la última consultable por el momento, repertoriaba unas 8.000 entradas de las cuales 1.465 correspondían a revistas académicas. Hay que destacar, por otra parte, que casi el $75 \%$ de estos títulos realizan procesos de revisión de los artículos (peer review). También se puede consultar el directorio NewJour <http://gort.ucsd.edu/newjour/>, que está más actualizado que el anterior.

Las publicaciones académicas especializadas han sido uno de los primeros ámbitos en los que han aparecido títulos digitales y versiones digitales de cabeceras impresas. Algunos de los motivos que explican el porqué son los siguientes:

- Se dirigen a un tipo de público especialmente preparado.

Disponer de equipos informáticos y saber cómo utilizarlos acostumbra a ser el inconveniente más citado por muchos editores de documentos electrónicos para explicar las dificultades de crecimiento en que se encuentran este tipo de ediciones. En cambio, las características del tipo de lector de revista especializada -nivel de formación alto, conocimiento de idiomas, con equipos informáticos conectados a las redes de telecomunicaciones, y entrenados en el uso de las nuevas tecnologías- les facilita enormemente la consulta de ediciones digitales.

- Los costes de producción son mínimos.

Las publicaciones académicas se dirigen a un público especializado y, por lo tanto, sus tiradas son notablemente reducidas. Por otro lado, la facilidad con la que se dispone de fotocopias de artículos de este tipo de revista hace que todavía disminuyan más las ventas y, por lo tanto, se tengan que subir constantemente los precios. Las ediciones digitales, al no seguir los procesos habituales de impresión y distribución, tienen unos costes materiales menores.

- La distribución es muy rápida y barata.

La distribución es otro problema de las ediciones sobre papel. Sus costes son elevados (envíos por correo, repartos en los puntos de venta, gestión de las devoluciones, etc.) y, además, es un sistema lento porque transcurre un notable lapso de tiempo desde que la revista se imprime hasta que llega a sus lectores. En el caso que nos ocupa, el acceso al contenido de la publicación puede ser prácticamente inmediato.

\footnotetext{
${ }^{27}$ Consultable en: <http://www.arl.org/scomm/edir/index.html>.
} 


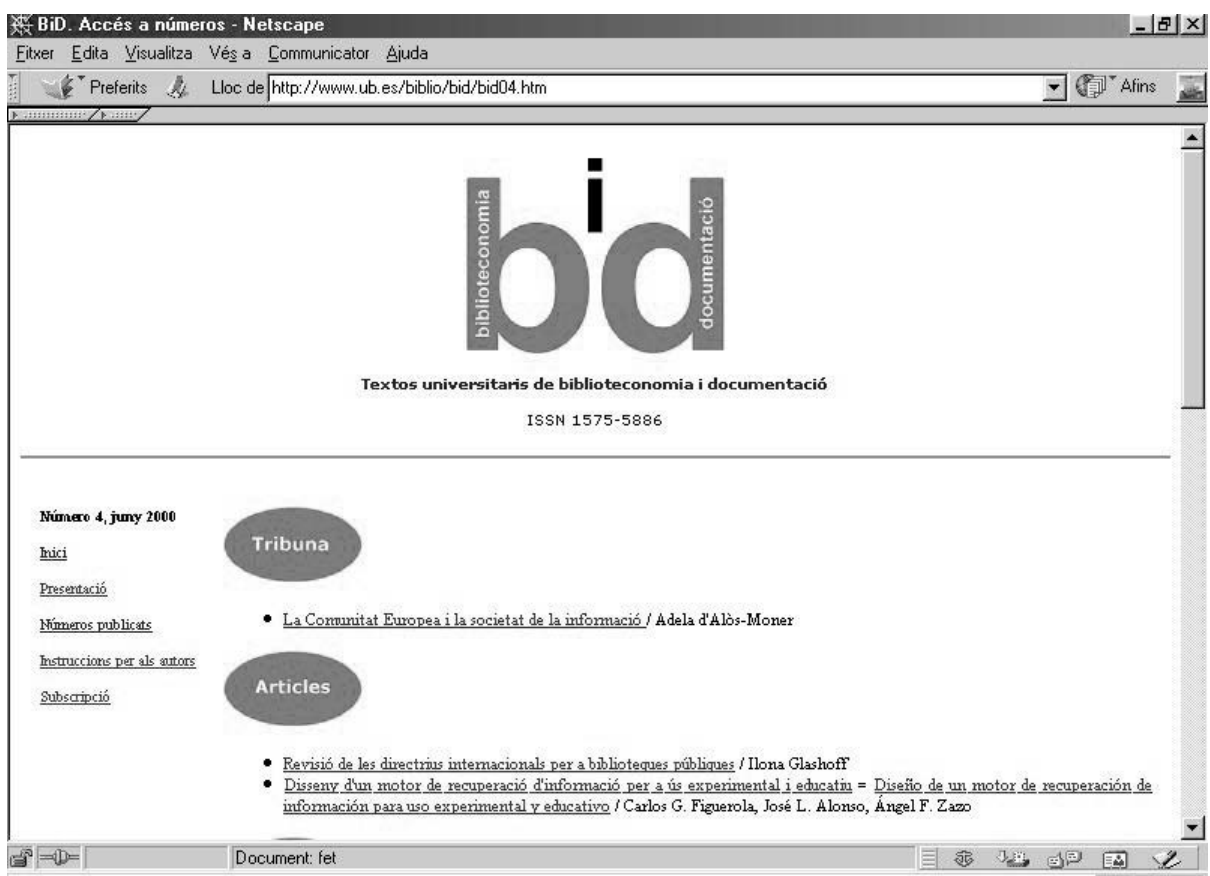

Fig. 3.8. Ejemplo de revista digital: $B i D$

- Es bastante sencillo llegar a ser editores de información digital.

Editar una revista de tipo académico en papel sólo se encuentra al alcance de editores especializados o de universidades y centros de investigación tan potentes como para disponer de una buena infraestructura de edición y de distribución. Como ya hemos visto, en el caso de disponer sólo de versión digital, se simplifican enormemente los procesos de edición y de distribución, y es posible ampliar considerablemente el número de agentes susceptibles de llegar a ser editores (cualquier universidad, asociación científica, o, incluso, grupos de científicos).

- Posibilidad de incluir documentos complementarios.

Los artículos de las revistas digitales pueden ir acompañados de material complementario de mucha utilidad que sería imposible incluir en una edición impresa: imágenes en movimeinto, sonido, programas informáticos, etc.

Algunas cuestiones que quedan pendientes de resolución hacen referencia al prestigio intrínseco del medio, una cualidad que está aún asociada en gran medida a la 
publicación impresa en papel y no tanto al entorno digital. El impacto de las revistas digitales es mucho menor que el de las tradicionales. Ahora bien, no podemos olvidar que empiezan a ser muchas las revistas digitales que disponen de una estructura idéntica a las impresas: consejo editorial, revisión de artículos, inclusión en bases de datos, etc. Todo esto, junto con la progresiva extensión de los títulos y el aumento de las consultas permitirá ir superando este inconveniente.

Tampoco se pueden olvidar los problemas relativos a los derechos de autor, ni a la conservación y almacenaje de las publicaciones digitales. En el medio impreso, el suscriptor era propietario de una copia del título que conservaba tanto tiempo como quería, que podía leer siempre que quería sin costes adicionales, y que podía dejar en préstamo a otras personas, etc. Esta situación ya no se reproduce en el medio digital, en el cual el modelo que quieren imponer los editores se asemeja al del "pago por visión": hemos de conectarnos a la sede de la revista y pagar (si es el caso) para consultarla.

\subsection{PRENSA}

La prensa es uno de los sectores que está utilizando con mayor profusión y éxito la distribución digital de sus contenidos. Aparte de pequeñas experiencias en videotexto, la tendencia actual de las ediciones electrónicas corrientes de prensa de masas se orienta a la distribución en línea en el Web, tomando como base las mismas noticias que los periodistas han elaborado y que se han publicado en la edición impresa a las cuales se añaden diversas singularidades: actualización diversas veces al día, presencia de publicidad interactiva (posibilidad de indicar criterios de selección con tal de recuperar la información que al usuario le interesa), existencia de conexiones hipertextuales dentro del mismo periódico, lo que significa que las noticias contendrán botones que conectarán ciertas palabras con otros documentos que ampliarán o contextualizarán las explicaciones, etc.

Casi todos los grandes periódicos del mundo disponen de versiones en línea a través de Internet del número corriente. Las experiencias en este sentido no son nuevas. Diversos medios y agencias norteamericanas ya hace años que permiten la consulta en formato texto al periódico del mismo día. Ahora bien, desde 1994 se ha producido un vuelco espectacular. La popularización del Web ha propiciado que muchas empresas de comunicación se hayan decidido a distribuir su contenido en formato electrónico. 


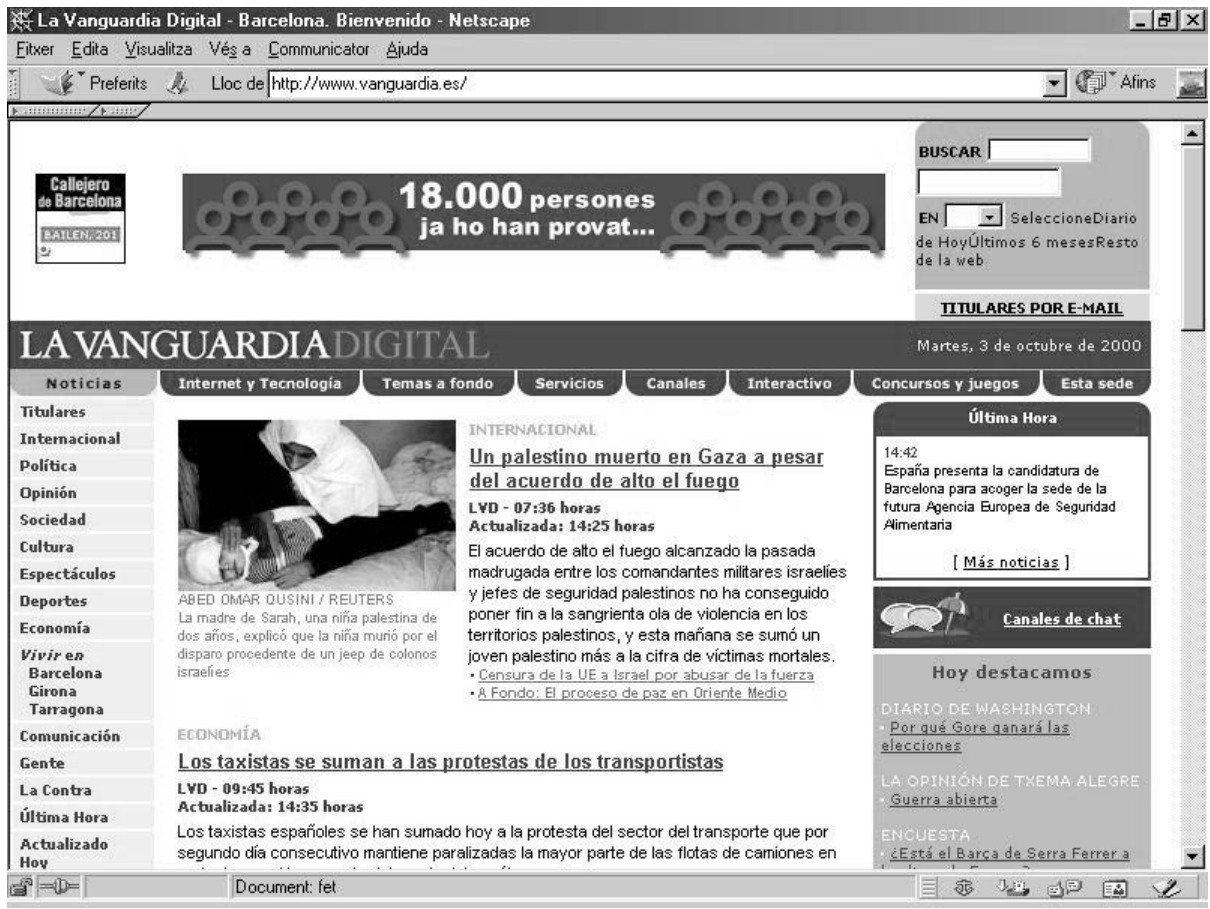

Fig. 3.9. Ejemplo de diario digital: La Vanguardia Digital

Los medios de comunicación españoles, que no disponían de ninguna experiencia previa de distribución en línea, se han implicado bastante a fondo en esta nueva etapa. Esto explica el hecho de que, en estos momentos, podamos encontrar decenas de cabeceras de prensa estatal, y también muchos títulos regionales y locales, y que su consulta por parte de los usuarios sea destacable. Según los datos de la tercera encuesta sobre Internet (octubre-diciembre de 1999), llevada a cabo por la Asociación para la Investigación de los Medios de Comunicación $<$ http://www.aimc.es>, de las primeras diez webs más visitadas, tres correspondían a prensa escrita, concretamente a El País, Marca y El Mundo.

Las características comunes de estas ediciones son las siguientes:

- Proporcionan acceso al texto íntegro y a informaciones complementarias.

La consulta a una cabecera digital permite acceder no sólo a los textos completos de las ediciones impresas, sino que, en muchos casos, incluye material 
no publicado que complementa o amplía las informaciones del periódico en papel.

- Se actualizan diversas veces al día.

La edición digital, que puede consultarse al mismo tiempo e incluso antes que la edición impresa, dispone de la facilidad de ir actualizando la información, lo que constituye, sin ninguna duda, un interesante atractivo para los usuarios, y es una de las bazas más importantes de la edición digital respecto de la impresa.

- Disponen de servicios complementarios.

Aunque en algunos casos nos encontramos ante unos documentos que son muy parecidos a las versiones impresas sobre papel, se está generalizando el hecho de incluir diversas opciones encaminadas a enriquecer la consulta del periódico digital y a singularizarlo respecto de la versión en papel. Nos estamos refiriendo a la existencia de hemeroteca, consultas de anuncios clasificados, atención al suscriptor, ventas, foros de debate, etc.

- Permiten la consulta y recuperación de ediciones anteriores (archivo de prensa). Algunas cabeceras están incluyendo motores de recuperación que permiten consultar el texto completo de la edición del día e incluso de un período más amplio que puede llegar hasta los ocho días. Es cada vez más frecuente encontrar medios de comunicación que permiten el acceso a una buena parte de su archivo de prensa, aunque normalmente se trate de un servicio de pago.

- El acceso es gratuito, excepto al fondo retrospectivo.

De momento, la gran mayoría de títulos se pueden consultar gratuitamente. Por ahora, pues, la prensa en Internet no es una apuesta para sacar una rentabilidad económica inmediata por la venta del producto, sino que es una opción de futuro (quién sabe si a corto, medio o largo plazo). Por ello la mayoría de cabeceras están invirtiendo notables recursos económicos sin ninguna otra contraprestación directa que no sean beneficios de imagen o publicitarios. Ofrecer estos servicios libres de peaje persigue, obviamente, la creación de un mercado de lectores que se interesen por el producto y, en un futuro, puedan estar dispuestos a pagar para consultarlo, y también pretende crear nuevos productos y servicios como pueden ser la consulta retrospectiva de la colección del periódico, o la explotación de los pequeños anuncios. 
- La consulta se realiza por sistema de navegación.

Normalmente, la forma de consulta es idéntica a la versión tradicional sobre papel: hay un sumario en el que constan las secciones del periódico (opinión, internacional, deportes, etc.) y, dentro de cada una, los titulares de las informaciones que contienen. El lector va moviéndose arriba y abajo en esta estructura jerárquica de menús con el fin de ir accediendo a las diferentes partes del periódico. En algunos casos, se pueden encontrar algunos botones que permiten ir arriba y abajo dentro de una sección, saltar de sección, o volver al menú principal.

La distribución de prensa en soporte óptico se utiliza exclusivamente para ediciones retrospectivas. Es difícil salvar los problemas inherentes a la edición óptica: tiempo de producción y estampación, costes de distribución, etc., para que puedan convertirse en un soporte adecuado para ediciones corrientes. En España llegaron a aparecer unos cuantos números de una revista mensual de información cultural que se editaba en cederrón, pero no tuvo continuidad ni tampoco fue imitada por otras experiencias.

La mayor parte de títulos de prensa diaria internacional dispone de ediciones de este estilo, lo que ha tenido como consecuencia más inmediata la progresiva desaparición de las antiguas ediciones en microfilm y microficha. En España podemos encontrar también diferentes ejemplos, aunque no son tan numerosos, ni por asomo, como la oferta de títulos en Internet. Se pueden destacar las ediciones de El Mundo, El Periódico, La Vanguardia o el suplemento cultural de ABC.

Como hemos visto, aunque la idea que preside la gran mayoría de proyectos y realizaciones actuales en este ámbito es la complementación de ediciones, particularmente en el seno de las grandes corporaciones de prensa, han aparecido ya numerosos proyectos en todo el mundo de prensa genuina y exclusivamente digital. Algunos ejemplos relevantes, en el sector de la información general, podrían ser publicaciones como La Estrella Digital <http:www.estrelladigital.es>, Vilaweb $<$ http://www.vilaweb.com> o, incluso, CNN, que, aunque tiene una contrapartida en un canal de televisión, se ha proyecto en el medio web como una oferta independiente <http:www.cnn.com; http://www.cnnenespanol.com>. Otros ejemplos de publicaciones de sectores específicos pueden ser Salon <http://www.salon.com>, sobre arte y cultura, o Film <http.//www.film.com>, sobre cine. 


\subsection{INFORMACIÓN CORPORATIVA E INSTITUCIONAL}

Finalmente, queremos hacer referencia a un tipo de documento menor y de carácter efímero: los trípticos o folletos de información corporativa de empresas e instituciones. Antes de la aparición de la red, este material, que incluye información muy útil sobre las organizaciones (su estructura interna, servicios, actividades, etc.), no se tomaba en consideración y actualmente es muy apreciado por todos los internautas porque permite conocer informaciones concretas sobre las organizaciones de forma rápida y actualizada.

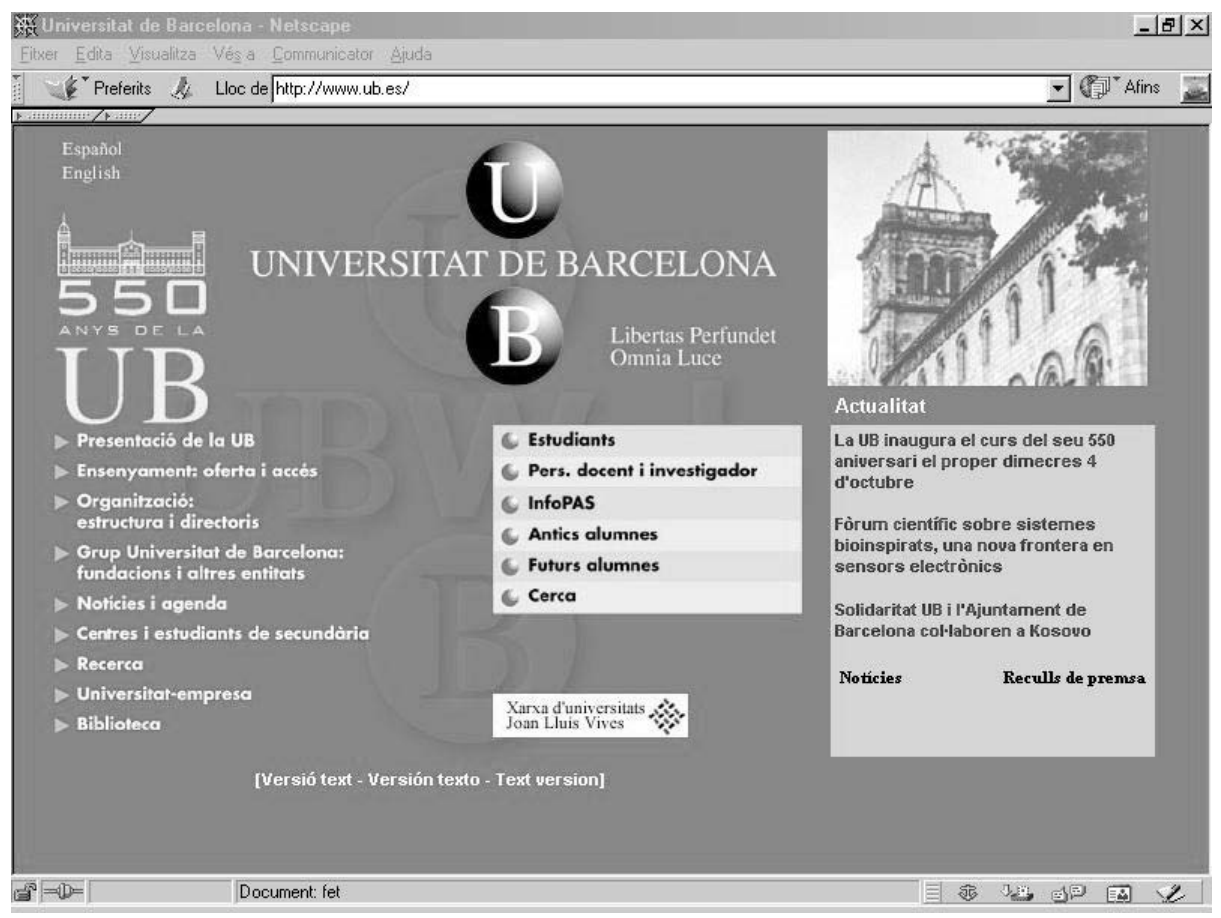

Fig. 3.10. Ejemplo de información corporativa: Universitat de Barcelona

Los principales productores de este tipo de información son las administraciones públicas (p. e., ayuntamientos, diputaciones, gobiernos autónomos, ministerios, etc.), organismos sin ánimo de lucro (p. e., partidos políticos, fundaciones, ONG, etc.) y también el sector privado (la mayoría de empresas, grandes y pequeñas, ya disponen de presencia en el Web). Los objetivos perseguidos son, por un 
lado, acercarse a los ciudadanos y ofrecerles información o, por otro lado, dar a conocer la empresa y sus productos a los consumidores para persuadirles en sus acciones de compra. Internet ha invertido la dinámica comunicativa existente hasta hace poco, que consistía en costosos envíos masivos o selectivos de información a los usuarios, para instaurar el «Aquí estamos, venid a vernos», con las consiguientes disminuciones de costos que esto comporta.

Los problemas de este tipo de documento están relacionados con el interés que puedan tener, su grado de actualización y también con los mismos inconvenientes de la propia Internet: lentitud, dificultades de localización de la información, disparidad en el valor e interés de los contenidos, etc. Ahora bien, es cierto que, desde el punto de vista del usuario de información, es muy práctico poder consultar datos concretos sobre una empresa o institución sin tener que depender de estar incluido en un mailing. Por otra parte, las organizaciones han de competir entre ellas para atraer el interés de los usuarios ofreciéndoles información atractiva, actualizada y, también, servicios complementarios.

\subsection{PROBLEMAS}

Quizá el coste de los documentos y el control de los derechos de autor sea el principal problema que afecta por ahora el ámbito de las publicaciones digitales que tienen un carácter editorial. En el entorno impreso existe un modelo de funcionamiento muy claro y consolidado que considera que el usuario que ha adquirido un documento es propietario de esta reproducción y, además, le concede el derecho a utilizarla tantas veces como quiera. La legislación, obviamente, comprende muchos otros aspectos como la preservación de los derechos de autor (económicos y morales) sobre la obra, la copia para uso particular con fines educativos o de investigación y la compensación por esta copia al autor, etc., que acaban de establecer el sistema de funcionamiento en este ámbito.

En el entorno digital, en cambio, aún no existe una legislación establecida, aunque se está en vías de llegar a unos primeros acuerdos. La Unión Europea está elaborando una directiva sobre la cuestión y otros países occidentales también se mueven por el mismo camino. En estas discusiones aparecen muy claras dos posturas un tanto divergentes. Por un lado, los usuarios, que no quieren que se varíe el modelo que rige en la edición impresa y que consideran que tan sólo es necesario una adaptación de la legislación al medio digital y, por otro lado, los edito- 
res, que quieren construir un nuevo marco legislativo para proteger la gestión de los derechos de autor. Este nuevo marco se fundamenta en el pago de los documentos digitales en función de su uso, lo que supone un cambio radical respecto a lo que constituía el derecho de autor en el entorno impreso, ya que el usuario deja de ser "propietario» de una copia que puede utilizar tantas veces como quiera y se convierte en un abonado a un servicio por el que ha de pagar tantas veces como lo utilice. Se trata, de hecho, del modelo que ya impera en los canales de televisión de cable o codificados, lo que se denomina pago por visión. Los editores quieren una legislación muy restrictiva y controlada porque les parece que, de otro modo, los actuales sistemas de copia y reproducción les pueden arruinar, ya que puede ser imposible obtener la compensación económica para el acto de creación intelectual de originales. Por su parte los usuarios temen que este nuevo modelo sea un escollo que dificulte aún más la difusión de la cultura y el acceso a la información para una gran parte de la población.

Aparte de esto, también hay que terminar de desarrollar sistemas de micropago seguros, en especial a través de Internet, para que las publicaciones que actualmente se distribuyen sólo en versión impresa o en disco óptico también sean accesibles en línea. En el apartado 5.4 se incluyen algunas consideraciones sobre la situación actual de esta cuestión. 



\section{DISTRIBUCIÓN EN LÍNEA ASCII}

Vamos a referirnos al primer sistema de distribución de información digital, al formato ASCII, el acceso en línea clásico, lo cual quiere decir que vamos a hacer un poco de historia para narrar los orígenes de la información digital. No se puede entender bien el fenómeno de Internet y del Web como sistema mundial de difusión de información sin conocer las características y estructura de sus precedentes. Esta presentación nos permitirá comprobar cómo ha ido evolucionando el sector hasta llegar a la convergencia de distribución por el Web.

Aunque actualmente esta forma de distribución se encuentra ya en horas bajas, no hay que olvidar que agrupa un mercado, el de las bases de datos especializadas, que seguirá manteniendo sus signos de identidad aunque el sistema de distribución que pase a utilizarse en breve sea, de forma exclusiva, el Web. Este mercado ha sido descrito con anterioridad cuando se han analizado sus productos: las bases de datos científico-técnicas (v. 3.1.1.) y las de información económica (v. 3.1.2). El Web y los discos ópticos (los otros dos sistemas de distribución que se analizarán en los próximos capítulos) se utilizan para la difusión de todo tipo de publicaciones digitales, ya sean monografías, publicaciones periódicas e información corporativa, y no sólo de bases de datos, como es el caso del formato ASCII.

Las bases de datos en línea suministran la información carácter a carácter y no tanto página por página o pantalla por pantalla, como podría ser el caso del Web o del videotexto. Por otro lado, aunque hay algunas excepciones, la información que distribuyen es básicamente textual, sin gráficos, ni tampoco imágenes ni sonidos de ninguna clase (como las que puede incorporar el Web).

En lo que se refiere a los costes, seguramente se trata del subsector con unos precios más elevados, lo que nada tiene que ver con la forma de distribución de 
la información, sino más bien, con el carácter especializado de la información que ofrecen. Para acceder al contenido de las bases de datos se tiene que haber establecido previamente un contrato específico con su distribuidor; a partir de aquí, el usuario recibe las claves de acceso al sistema e indica la forma de cobro que desea. Las facturaciones suelen ser mensuales y, normalmente, dependen de la utilización que se haya hecho de las bases de datos. En un principio, el tiempo de consulta (el taxímetro, como lo llamaban algunos) era la única variable de la cual dependían los costes, pero, actualmente, se han añadido otros parámetros, especialmente la cantidad de información consultada, para no hacer depender excesivamente la factura del tiempo de conexión. ${ }^{28}$

A causa de la existencia de un mercado reducido, la rentabilidad de una base de datos pasa, la mayoría de las veces, por su comercialización a escala mundial. ${ }^{29}$ Para que esto sea factible, la lengua constituye un elemento clave. En este sentido, la difusión de bases de datos en idiomas de conocimiento masivo (es decir, en inglés) es la única vía, por el momento, para llegar a un espectro de mercado más amplio. Más adelante (v. 7.3) analizaremos con más detalle cuáles son los idiomas predominantes en los servicios de información digital, entre los cuales el castellano tiene una presencia muy baja. Este obstáculo aún es mucho más determinante en el caso de las bases de datos en catalán.

\subsection{ANTECEDENTES HISTÓRICOS}

Los orígenes de las bases de datos en línea se sitúan en la década de 1960, cuando las empresas productoras de boletines de resúmenes empezaron a utilizar la informática para almacenar y gestionar de forma automatizada su información, convirtiendo sus enormes ficheros bibliográficos manuales en formatos legibles por

\footnotetext{
${ }^{28}$ En 1987 Chemical Abstracts introdujo un primer cambio al reducir el coste de la variable tiempo a la vez que aumentaba la tarifa por los resultados obtenidos. Dos años más tarde, el distribuidor europeo ESA llevó a cabo un cambio todavía más drástico que implicaba la eliminación de la variable tiempo de conexión. Dialog ha aplicado el mismo sistema desde junio de 1998: sólo cobra por el uso del sistema y por la información extraída. De esta forma, sólo se paga por la información obtenida y no por el lapso de tiempo utilizado para conseguirla. Poco a poco, el resto de grandes distribuidores se han ido alineando con esta opción, intentando afrontar con más éxito la competencia de otros servicios de información electrónica, en especial de los discos ópticos. Las reformas, pues, van en la línea de hacer recaer más el coste de las sesiones en la información recuperada y no tanto en el tiempo utilizado para realizar la consulta.

${ }^{29}$ Las principales empresas distribuidoras de bases de datos tienen un ámbito internacional, es decir, que tienen clientes repartidos por todo el mundo.
} 
máquina. ${ }^{30}$ De esta forma, disponían no sólo de las versiones en papel, sino también de copias en soporte magnético con unas facilidades de consulta mucho más grandes.

Posteriormente, a principios de la década de 1970, se produjeron importantes avances en las redes de telecomunicaciones: aparecieron las primeras redes de transmisión de datos y, en poco tiempo, fue posible no sólo la transmisión de voz, sino también de datos (información alfanumérica). A partir de este momento, nace la telemática y empieza a dibujarse una nueva era de los servicios de información, caracterizada por la posibilidad de enviar y acceder a distancia al contenido de grandes volúmenes de documentos.

Estados Unidos fue la cuna de las bases de datos y constituye, todavía hoy, el mercado más avanzado. Allí, a principios de la década de 1970, se produjeron las primeras experiencias y desarrollos. Una década más tarde, este mismo proceso se repitió en Europa occidental, que pasó a convertirse en la segunda área más desarrollada. En España, como se verá con un poco más de detalle, no se puede empezar a hablar de la existencia de bases de datos propias hasta la segunda mitad de la década de 1980.

Después de unas primeras experiencias iniciales en las que participaron algunos de los más conocidos distribuidores y productores de bases de datos (p. e., Dialog, The New York Times, Dow Jones News Retrieval, etc.) se fueron creando nuevas y variadas bases de datos, que pusieron su información al alcance de cualquier persona en cualquier lugar del mundo. Así pues, desde el punto de vista cuantitativo, el número de bases de datos en el mundo no ha dejado de aumentar, aunque moderadamente, hasta 1996, año en que se estanca el crecimiento y se empieza a percibir una recesión cuyas dimensiones se tendrán que analizar cuando se tenga más perspectiva. Quizá haya sido la década de 1980 el momento en que se han registrado aumentos porcentuales más notorios. Observemos especialmente el crecimiento producido entre 1981 y 1984, que llega a ser casi del $50 \%$ anual, en lo que respecta al número de bases de datos (tabla 4.1).

Actualmente, tal y como puede comprobarse en la tabla 4.2, los dos grandes mercados mundiales de bases de datos están formados por Estados Unidos (con más del $60 \%$ del total de bases de datos existentes) y Europa occidental (casi un $30 \%$ ), y se mantiene, por tanto, la preeminencia de los mercados de información

\footnotetext{
${ }^{30}$ Este proceso lo llevaron a cabo la NASA y la National Library of Medicine en el año 1964, y Chemical Abstracts, en 1968.
} 
Tabla 4.1. El crecimiento de las bases de datos en línea en el mundo

\begin{tabular}{cccc}
\hline Año & Bases de datos & Productores & Distribuidores \\
1979 & 300 & 221 & 59 \\
\hline 1980 & 411 & 269 & 71 \\
\hline 1982 & 919 & 612 & 189 \\
\hline 1984 & 1807 & 1069 & 327 \\
\hline 1986 & 2369 & 1379 & 454 \\
\hline 1988 & 3135 & 1685 & 555 \\
\hline 1990 & 3943 & 1950 & 645 \\
\hline 1992 & 4447 & 2033 & 772 \\
\hline 1994 & 5300 & 2232 & 822 \\
\hline 1996 & 5511 & 2255 & 860 \\
\hline 1998 & 5561 & 2124 & 1070 \\
\hline 1999 & 5497 & 2107 & 1076 \\
\hline
\end{tabular}

[Fuente: Gale directory of databases]

digital que se consolidaron en primer lugar (Estados Unidos y Europa occidental). Por otro lado, la distinción norte-sur (desarrollo-subdesarrollo) que se utiliza en los análisis sociales, políticos y económicos también es válida en el ámbito de las bases de datos. La presencia de los países subdesarrollados es prácticamente inexistente en este sector, entre otros motivos, por el bajo nivel de infraestructuras en telecomunicaciones e informática, y por la inexistencia de demanda de información especializada.

Tabla 4.2. Distribución geográfica de las bases de datos (1998)

\begin{tabular}{lc}
\hline Área geográfica & Porcentaje \\
África & $<1 \%$ \\
\hline Asia & $4 \%$ \\
\hline Australia & $2 \%$ \\
\hline Europa oriental & $2 \%$ \\
\hline Europa occidental & $29 \%$ \\
\hline América del Norte & $63 \%$ \\
\hline América del Sur & $<1 \%$ \\
\hline
\end{tabular}

[Fuente: Martha E. Williams] 
En Europa no existe una situación homogénea, sino que encontramos algunos países mucho más avanzados, como Gran Bretaña (con más de 600 bases de datos, cifra bastante superior al resto de países europeos, explicable, en parte, por la estratégica posición de la City como centro de operaciones financieras internacionales, lo que ha permitido el desarrollo de un significativo mercado de servicios de información financiera en tiempo real), Alemania (que dispone de un notable nivel de producción en el área científica y tecnológica, con unas 350 bases de datos) y Francia (unas 250 bases de datos). La consolidación, en los próximos años, del Mercado Único Europeo tendrá, sin duda, repercusiones positivas para aumentar el desarrollo de la industria europea de la información digital.

Una de las principales ventajas de la industria americana respecto de la europea reside en el hecho de disponer de un mercado interno mucho más homogéneo, pues que en Europa no se puede hablar de la existencia de un mercado global de la información, sino de muchos mercados nacionales fragmentados y heterogéneos (tan sólo la Unión Europea supera la decena de lenguas oficiales y todavía tiene otras tantas minoritarias). Por otro lado, los contenidos de la mayoría de las bases de datos europeas tienen una cobertura geográfica de carácter doméstico con poca presencia de datos de otros países. Este factor explica por qué su comercialización se concentra básicamente en mercados nacionales y dispone, por lo tanto, de un grado de internacionalización bastante bajo.

Las optimistas previsiones que sobre el uso de la información en línea se formularon en los primeros años no se han llegado a cumplir plenamente. A pesar de que se ha constatado un crecimiento continuado de la demanda, ésta no ha llegado a las cotas que desearían muchos proveedores. ${ }^{31}$ Últimamente, además, este crecimiento se ha visto ralentizado por la fuerte competencia que suponía la popularización del cederrón y de Internet como forma de distribución de bases de datos.

\subsection{FUENTES DE INFORMACIÓN SOBRE EL SECTOR}

A cualquier persona que quiera hacer uso de las bases de datos le es imprescindible conocer cuáles son las que están a su alcance y las que le pueden ayudar a resolver sus problemas de información, así como la forma de acceder, los cos-

\footnotetext{
${ }^{31}$ El número de clientes de los principales distribuidores no ha aumentado prácticamente desde 1996.
} 
tes, etc. El número de bases de datos, como hemos visto, no ha dejado de crecer desde sus inicios, y esto quiere decir que es muy difícil tenerlas todas controladas. Por ello resulta casi imprescindible disponer de directorios de alcance internacional y estatal, que describan y recojan las bases de datos accesibles en línea. A continuación se hace referencia al principal directorio de cobertura internacional, y a otro de ámbito español del cual, lamentablemente, ya no se dispone de nuevas actualizaciones.

Gale directory of databases. Jan. 1993-. Detroit [etc.] : Gale Research Inc., 1993-. v. ; 28 cm. Semestral. Vol. 1: Online databases.

Se trata del directorio internacional de más prestigio y que constituye un punto de referencia entre los usuarios de las bases de datos. Es el resultado de la fusión de dos de los directorios más importantes del sector: el Directory of line databases (del cual era editorCarlos Cuadra y que fue fundado en 1979), y el Computer-readable databases (fundado en 1975 por Martha Williams). La editorial Gale compró el Williams en 1987 y el Cuadra en 1991, y en 1993 publicó este nuevo directorio cuya versión impresa aparece semestralmente dividida en dos volúmenes, y que puede consultarse también en línea o en cederrón.

El directorio contiene las descripciones de unas 6.000 bases de datos accesibles en línea, ordenadas alfabéticamente por su nombre. Algunos de los datos que se incluyen son los siguientes: nombre, productor, tipo (referencial, textual, etc.), contenidos, ámbito temático, lengua, ámbito geográfico, tiempo de cobertura, actualización, distribuidores y otras formas de distribución.

Para facilitar el acceso a la información desde otros puntos de vista, también dispone de un índice geográfico; uno, temático y uno global, que incluye todas las bases de datos y los organismos incluidos en su descripción (productores, distribuidores, etc.).

En lo referente a la información sobre bases de datos producidas en España, lamentablemente, no podemos traer a colación ningún directorio similar al anterior. Hemos de remontarnos a 1994 para hacer referencia a la última edición del Catálogo de servicios españoles de información electrónica, ${ }^{32}$ patrocinado desde 1984 por la Fundación para el Fomento de la Información Automatizada (Fuinca). Los datos que ofrecía constituyen una inestimable fuente de conocimiento de

${ }^{32}$ Catálogo de servicios españoles de información electrónica ASCII: 1994. Edición de Beatriz Ruiz. 7. ${ }^{\text {a }}$ ed. Madrid: Fuinca, 1994. 408 pp. (Los libros de Fuinca, 3). 
la situación de los servicios españoles de información electrónica, en especial de las bases de datos ASCII y los cederrones, hasta 1994. Analizadas en conjunto todas las ediciones se pueden obtener las líneas maestras de evolución del sector en España (crecimiento cuantitativo, tipos de productores y distribuidores, temática, etc.) durante el período señalado.

La reorganización empresarial de Telefónica, consecuencia del proceso de privatización de la compañía, afectó directamente a Fundesco y Fuinca, dos fundaciones que se ocupaban de promover y publicar estudios sobre el sector de la información digital. La desaparición de Fuinca, la entidad que promovía la edición del catálogo, ha supuesto también la desaparición de esta obra, ya que nadie se ha ocupado de su mantenimiento y actualización.

\subsection{LA SITUACIÓN EN ESPAÑA}

Tomás Baiget, en un excelente artículo recopilatorio titulado « 25 años de teledocumentación en España» (Baiget, 1998), hace un repaso histórico del uso y de la producción de bases de datos en línea en España. Para ello, toma como fecha de partida 1973, año en que se instaló, en la sede del INTA (Instituto Nacional de Técnica Aerospacial) de Torrejón de Ardoz (Madrid), el primer terminal de consulta en línea de España. Poco después se instaló otro en Barcelona en el ya desaparecido Consorci d'Informació i Documentació de Catalunya (CIDC). A partir de aquí, empezó a desarrollarse el incipiente mercado español.

Las primeras bases de datos españolas no comenzaron a despuntar y darse a conocer hasta mediada la década de 1980. Una visión de su crecimiento cuantitativo en España (ver tabla 4.3) nos la proporcionan los datos del directorio Fuinca, al cual se ha hecho alusión en el epígrafe anterior. ${ }^{33}$ Ahora bien, debemos co-

Tabla 4.3. La industria de las bases de datos en España

\begin{tabular}{lcccccccc} 
& 1983 & 1984 & 1985 & 1986 & 1987 & 1988 & 1991 & 1993 \\
\cline { 2 - 9 } Bases de datos & 23 & 52 & 70 & 85 & 106 & 168 & 172 & 158 \\
\hline
\end{tabular}

[Fuente: Fuinca]

\footnotetext{
${ }^{33}$ Lamentablemente, desde la desaparición del citado directorio, ya no disponemos de datos estadísticos sobre el sector.
} 
rregir a la baja las cifras que aparecen en el directorio porque en él constaban bases de datos que no eran accesibles en línea; otras, tenían un bajo nivel de desarrollo y, además, la inmensa mayoría no disponían ni de manual de usuario para consulta (que explique el lenguaje de interrogación utilizado, la estructura y la organización de base de datos, etc.) ni de una mínima política de promoción.

Algunos de los productores de bases de datos españoles, citados con intención meramente orientativa, son los siguientes: Agencia EFE, Editorial Aranzadi, Banco de España, Centro de Información y Documentación Científica (Cindoc), Institut d'Estadística de Catalunya (IDESCAT), Instituto de Comercio Exterior (Icex), Instituto para la Pequeña y Mediana Empresa Industrial (Impi), Ministerio de Cultura, Ministerio de Educación, etc. Si analizamos su origen se constata el predominio del sector público. La baja presencia de la empresa privada —aunque últimamente ha aumentado- es otro factor que demuestra que la situación del mercado de las bases de datos no ha llegado aún a su pleno desarrollo. En Estados Unidos o en Gran Bretaña, dos mercados muy avanzados, el porcentaje de servicios creados por la iniciativa privada supone un $70 \%$ del total.

Respecto a la tipología de las bases de datos, España se encuentra en sintonía con las tendencias europeas al respecto. Es decir, existe un predominio de las bases de datos referenciales sobre las bases de datos fuente. No obstante, en los mercados más desarrollados esta situación se encuentra totalmente invertida, ya que predominan las bases de datos de tipo fuente.

Uno de los principales problemas de las bases de datos españolas procede del carácter marcadamente local de su contenido. Muchas de las informaciones incluidas en las bases de datos españolas se refieren exclusivamente al propio país. Son, por lo tanto, unas bases de datos de tipo local, muy determinadas geográficamente. No pueden competir de ninguna manera con las bases de datos de economía, ciencia o tecnología producidas en otros países. Por este motivo, la información que suministran difícilmente podrá ser de interés para usuarios extranjeros y no superará el mercado estrictamente estatal.

Las bases de datos de Prous Science (<http://www.prous.com>) constituyen la excepción a lo que estamos comentando. Esta empresa, con sede en Barcelona y fundada en 1958, distribuye diversos productos de información especializada en farmacología y medicina y ha logrado un reconocido prestigio internacional. Tiene clientes en todo el mundo y sus bases de datos pueden consultarse en formato ASCII, disco óptico o por el Web (fue una de las primeras del sector en apostar por Internet y el Web como plataforma de distribución). 
La difusión y comercialización de cualquier base de datos pasa necesariamente por su inclusión en una buena red de distribución. Como ya se ha explicado, los principales hosts son norteamericanos, y su potencial técnico y económico permite ofrecer sus productos en cualquier rincón del mundo. Aunque probablemente la gran mayoría de productos españoles no interesen más allá de sus fronteras, lo que sí se podría conseguir es un buen nivel de utilización por parte de los usuarios estatales. Sin embargo, para que esto sea posible, debe facilitárseles, mediante una buena distribución, el acceso a cualquier base de datos española. Como ya se ha dicho, el distribuidor es la empresa encargada de planificar una estrategia de promoción adecuada (elaboración de catálogos, confección de manuales de usuario para su consulta, facilidades y variedad de fórmulas de suscripción, política de precios, etc.) para propiciar la comercialización de las bases de datos. Hasta hoy, no podemos considerar que esto se haya llevado a cabo en España.

Una de las características del mercado español de las bases de datos reside en la existencia de muchos distribuidores en relación con el número de bases de datos. Esto indica que la mayoría de los productores son, además, distribuidores de sus propias bases de datos y que, por lo tanto, la función primordial del host, facilitar el acceso a través de un solo contrato y un único lenguaje de interrogación en muchas bases de datos, no se cumple. ${ }^{34}$ Tal vez sea éste el principal problema específico que afecta al sector de las bases de datos en España: la ausencia de un gran distribuidor multidisciplinar, con buenos equipos informáticos, personal y medios económicos que permitan una mejor comercialización de las bases de datos españolas, que contribuya a aumentar la demanda y disminuya los gastos de promoción y distribución. Tomás Baiget ha puesto en evidencia repetidamente esta carencia (Baiget, 1989).

Todas estas características apuntadas (predominio del sector público y de las bases de datos referenciales, contenidos de carácter local y los problemas en la distribución) son algunos de los rasgos que explican la situación de atraso de las bases de datos españolas respecto a los Estados Unidos o a los países pioneros de Europa Occidental. Por todo esto, podemos afirmar que este sector no constituye todavía en España un mercado mínimamente desarrollado, y que no es probable, por otra parte, que el pequeño crecimiento que se va detectando permita la equiparación, a medio plazo, a lo que podríamos llamar las locomotoras del sec-

\footnotetext{
${ }^{34}$ En Estados Unidos, p. e., existe un distribuidor por cada 60 bases de datos y no por cada cuatro, como en el caso español.
} 
tor (EUA, Gran Bretaña, Francia, etc.), al menos en lo que se refiere a lo que es producción y distribución de bases de datos.

$\mathrm{Si}$, en cambio, lo que se valora es el uso que se hace de las bases de datos, quizás podamos encontrar ciertos motivos para un mayor optimismo, ya que, en los últimos años, han aumentado sensiblemente las cifras de utilización de bases de datos. Estas consultas, no obstante, se concentran básicamente en productos extranjeros.

Ninguno de los problemas reseñados son nuevos. Ya hace muchos años que expertos y especialistas en el sector han ido poniéndolos de manifiesto. Podemos remontarnos a 1983, cuando diferentes especialistas fueron convocados por el Ministerio de Educación y Ciencia con el objetivo de analizar la situación de la información y documentación en España, y de elaborar propuestas para mejorarla. Uno de los grupos de trabajo que se constituyó fue el de creación y distribución de bases de datos, ocupado de presentar las líneas maestras de una política de información en ese sector. Las acciones concretas derivadas de estas reflexiones, no obstante, no fueron más allá de la publicación del texto que contenía las propuestas. Desde entonces, y pronto hará casi veinte años, la administración ha jugado un papel de total indiferencia respecto de este sector, no ha existido una política de potenciación de la información especializada, ni de su distribución en línea. En España no existe ninguna dependencia administrativa encargada del fomento y la promoción de la información digital especializada, al estilo, por ejemplo, de una Dirección General del Libro y Bibliotecas (Ministerio de Cultura) o del Servei de Biblioteques (Departament de Cultura), ni se han articulado programas de promoción con una asignación presupuestaria suficiente con el fin de dinamizar este incipiente sector.

\subsection{PERSPECTIVAS}

El soporte óptico fue el primer competidor del formato ASCII como sistema de distribución. Al ser independiente de las redes de telecomunicaciones, y eliminar los costes de utilización, era más atractivo para muchos usuarios. Algunos distribuidores de bases de datos reaccionaron a esta notoria competencia ofreciendo nuevas y variadas fórmulas de facturación para permitir que el uso de sus bases de datos no dependiera exclusivamente del factor tiempo. Hay que recordar aquí mismo, sin embargo, que la gran ventaja de consultar una base de 
datos en línea respecto del disco óptico consiste en el grado de actualización (los discos pueden tener una media de retraso de entre uno y seis meses) y en el hecho de poder contener mucha más información. Otros inconvenientes del disco óptico residen en el alto coste y la baja velocidad de las torres lectoras, en la necesidad de ir instalando las continuas actualizaciones de los programas de recuperación, y en los costes y retrasos en la distribución. Así pues, si durante un cierto tiempo pareció que el disco óptico superaba y superaría a la distribución en línea, ahora, en cambio, las impresiones se han invertido, y las bases de datos en línea han vuelto a adquirir un cierto protagonismo mejorando la presentación, los servicios, etc.

Si el formato ASCII resistió el envite de los discos ópticos, no ha pasado lo mismo con la competencia del Web. Las facilidades de esta nueva forma de distribución, en especial su universalidad y el hecho de disponer de un sistema de consulta estandarizado, provocaron que la totalidad de las empresas distribuidoras de bases de datos lo adoptaran rápidamente, aunque no fuera de forma exclusiva, sino complementaria al sistema tradicional. Actualmente se mantienen ambas formas de distribución, aunque ya son minoría los usuarios que siguen utilizando el formato ASCII. Las ventajas que justifican aún su vigencia se fundamentan en la rapidez y en la posibilidad de utilizar algunos recursos especializados del lenguaje de interrogación, prestaciones en las que el ASCII es superior al Web. De todas maneras, parece claro que la desaparición del formato ASCII está cantada y que el único interrogante será cuánto va a tardar.

Como hemos visto, el formato ASCII se ha tenido que ir adaptando a la aparición de nuevas formas de distribución y a la competencia que éstas suponían y, si bien remontó el primer escollo (el disco óptico), no parece que vaya a superar el segundo. En este punto, no obstante, podríamos hacer una reflexión no ya sobre la forma de distribución, sino sobre el producto, las bases de datos especializadas, que se ven actualmente amenazadas por lo que podríamos denominar la cultura Internet. La Red dispone de un sinfín de bases de datos y de una gran cantidad de información circulante que lleva asociada la idea de gratuidad ( en el Web no se paga por la información», se dice). En este contexto, es difícil hacer resaltar las ventajas de la información especializada y de los sofisticados sistemas de indización y recuperación de la misma y defender el hecho de pagar por ella. Aunque las necesidades de información especializada para las empresas y organizaciones no desaparecerán, será más difícil su comercialización y promoción en el contexto antes apuntado. 
Finalmente, también se ha de tener en cuenta que muchos de los productores de contenidos (las revistas científico-técnicas, especialmente) de los que se nutren las bases de datos disponen de modernos sistemas de recuperación de la información y ponen a disposición de los usuarios los textos completos en formato digital (pdf, html, etc.), con lo cual compiten directamente con los productores de bases de datos. 


\section{EL WEB, EL NUEVO ESTÁNDAR DE DISTRIBUCIÓN}

Nadie duda que Internet y el Web son uno de los fenómenos informativos y culturales más espectaculares de los últimos tiempos. De tanto hablar de ellos los hemos convertido en un objeto poliédrico, en una realidad con tantas caras como perspectivas se utilizan para definirlo o aproximarse a él. Los comunicólogos hablan, y no les falta razón, de un nuevo medio de comunicación, que integra y supera a la vez la prensa, la radio o la televisión. Los economistas y los empresarios han descubierto el mercado más grande y fabuloso jamás soñado: la tienda global, un bazar en el que todo puede encontrarse y venderse. Los sociólogos y politólogos presentan la red como un espacio de democracia en estado puro, un lugar en el que se puede establecer un sistema de relaciones sociales totalmente nuevo. Los bibliotecarios y documentalistas lo definen como un ámbito documental, como una gran biblioteca. Para el gran público puede ser no tan sólo un lugar de trabajo, sino también de ocio. Todos ellos revisten Internet con los atributos que mejor conocen y, de hecho, todos tienen razón, porque Internet es todo esto y mucho más. En este capítulo, que mantiene una estructura parecida a la del anterior y la del siguiente, se describirán las principales características del Web como sistema de distribución de información digital, sus antecedentes, las fuentes de información sobre la oferta, la situación en España y las perspectivas de futuro.

Internet y, más concretamente, el Web constituyen actualmente el sistema más utilizado para la distribución de información en línea. En Internet encontramos todo tipo de productos de información digital y en unas cantidades nunca vistas: miles de bases de datos especializadas o generales, cientos de miles de libros y de grabaciones sonoras, miles de cabeceras de prensa diaria, y millones de páginas de información corporativa pertenecientes a todo tipo de organizaciones. Se trata, por tanto, del sistema de distribución más utilizado. 
Por otro lado, no ofrece tan sólo información, sino que tiene especialmente desarrollados los servicios de comunicación y transacciones entre usuarios u organizaciones, con lo cual se trata del sistema de distribución más completo (el acceso en línea clásico no permitía transacciones, y el disco óptico sirve sólo para la distribución de información).

Como veremos, los orígenes de Internet (v. 5.1) se encuentran en el ámbito de la investigación (primero vinculada a la industria militar y, después, a las universidades), aunque se ha ido extendiendo en los últimos años hacia todos los públicos. Actualmente, pues, encontramos una importante oferta de servicios de un carácter muy general, junto a otros que tienen una orientación más especializada y que son de interés para sectores profesionales y de investigación.

Una de las claves del éxito en la popularización de Internet reside en el hecho de que se trata de un sistema universal, es decir, que está estandarizado y es totalmente abierto, lo que le permite llegar a usuarios de todo el mundo. Cualquier máquina (micro, mini o gran ordenador) con cualquier tipo de sistema operativo y de cualquier parte del mundo puede conectarse a la Red y hacer uso de sus servicios.

Tampoco hay que olvidar que Internet ha permitido la distribución en línea de información multimedia, es decir, la inclusión de textos, sonidos e imagen (fija y en movimiento) dentro de un mismo entorno, lo que no era posible con los servicios en línea precedentes (en formato ASCII o videotexto).

\subsection{ANTECEDENTES HISTÓRICOS}

Los orígenes de Internet se remontan a 1968, en el contexto de la guerra fría. El Departamento de Defensa de Estados Unidos encargó a la agencia ARPA (Advanced Research Project Agency, rebautizada más tarde como DARPA, al añadirse el nombre Defense) el diseño del proyecto de una red de ordenadores con una configuración que pudiera seguir en funcionamiento aunque alguna parte se averiase y que, además, permitiera una fácil conexión y desconexión de sus nodos. Esta red recibió el nombre de Arpanet y empezó con un pequeño número de ordenadores interconectados que se fue ampliando progresivamente: las universidades americanas, las europeas, las grandes empresas de informática (a partir de 1991 se empezó a permitir el acceso al sector privado), etc., hasta llegar a los millones de ordenadores que actualmente forman Internet. Así pues, no es del todo exacto definir a Internet como una red. De hecho, viene a ser como una fe- 
deración de redes - y de subredes - de telecomunicaciones de todo el mundo que se interconectan entre ellas por medio de los protocolos TCP/IP (Transmission Control Protocol / Internet Protocol). ${ }^{35}$

Para que esta transferencia de datos sea posible se hace imprescindible poder identificar cada uno de los ordenadores de la red. Esta identificación es numérica (dirección IP), pero también puede ser alfabética (DNS, Domaine Name System, o Sistema de Nombres por Dominio) con el fin de facilitar la memorización. Es decir, que para poder conectarnos con cualquier ordenador hemos de conocer su dirección, ya sea de forma numérica (IP) o alfabética (DNS). ${ }^{36}$

La estructura informática sigue el modelo cliente-servidor. Es decir, tenemos por un lado unos usuarios que solicitan información o servicios (clientes) y, por otro lado, unos ordenadores conectados en Internet (servidores) que disponen de programas y de información y que atienden a estas peticiones. El resultado acostumbra a ser una transferencia de datos desde el servidor hacia los clientes.

Si quisiéramos profundizar un poco más en la descripción de la evolución de Internet, podríamos destacar tres fases:

\section{Desarrollo (1969-1982)}

En 1969 nace Arpanet, como resultado de la interconexión de cuatro grandes ordenadores. Se establece la familia de protocolos TCP/IP (1974) para que máquinas con diversidad de arquitecturas y sistemas operativos pudieran intercambiar información en la red sin problemas. Durante la década de 1970 la red tuvo un crecimiento muy lento, y a principios de la década de 1980 ya se disponía de un centenar de ordenadores conectados.

\footnotetext{
${ }^{35}$ Un protocolo es un conjunto de instrucciones y procedimientos que rigen el intercambio de información entre ordenadores. En Internet, la transferencia de datos entre ordenadores no se hace de una sola vez, sino por paquetes. Así, en la red viajan paquetes de información provenientes de ordenadores diversos y con diferentes destinos. El protocolo TCP se ocupa de dividir la información en paquetes de la medida apropiada, los numera para que puedan volver a agruparse de forma ordenada en su destino y añade unos datos de control para evitar posibles errores. El protocolo IP, por su lado, se ocupa de etiquetar cada paquete de información con la dirección apropiada.

${ }^{36}$ La dirección o número IP está formada por cuatro grupos de números separados por puntos, p. e., 161.116.100.2 (cada grupo de cifras puede ser un número del 0 al 255). Cualquier programa o aplicación en Internet tiene que conocer el número IP del ordenador al que se quiere conectar. Asimismo, cada máquina (nodo) dentro del sistema tiene que disponer de una identificación numérica. Los nombres por dominio (Domaine Name System, DNS) son un sistema equivalente a la dirección IP que dan una orientación sobre el tipo o la situación geográfica del ordenador. Así, p. e., 161.116.100.2/biblio es la IP de la Facultat de Biblioteconomia i Documentació de la Universitat de Barcelona, a la que se puede acceder también por el DNS www.ub.es/biblio.
} 


\section{Crecimiento (1982-1992)}

Arpanet adoptó como estándar el protocolo TCP/IP (1982). Una vez establecidos y consolidados los fundamentos tecnológicos, la red se amplió al ámbito universitario (Estados Unidos y Europa) y también hacia el sector empresarial. Otras redes independientes (Csnet o Milnet) también adoptaron el protocolo TCP/IP y, en 1983, se interconectaron con Arpanet, momento que se suele considerar el nacimiento de Internet. En 1986 se amplió para el uso de universitarios e investigadores. La National Science Fundation creó una nueva red llamada NSFNED con el objetivo de facilitar el acceso de las universidades americanas a los grandes centros de computación. A partir de este momento, las conexiones aumentaron aún más. El éxito fue tan grande que debieron hacerse sucesivas ampliaciones de capacidad. Tim Berners-Lee, un investigador del CERN (Centro Europeo de Investigación Nuclear, con sede en Ginebra), puso en funcionamiento, en 1991, el WorldWide Web (www o Web, traducido con el nombre de telaraña global), un sistema que facilita la distribución de información. En 1992 se creó la Internet Society (ISOC), un organismo de ámbito internacional, sin ánimo de lucro, en el cual se encuentran representados tanto los usuarios, como proveedores, o los operadores de la red, y que tiene por objetivos fomentar y mejorar el uso de la red.

\section{Expansión (1993-)}

La consolidación del Web como estándar de consulta y distribución de información multimedia dentro de la red disparó el interés por Internet y se inició una fase de crecimiento espectacular. El Web es un servicio de transferencia de información en línea que permite distribuir texto, imagen y sonido, posibilita la comunicación, facilita la realización de transacciones o el entretenimiento. Por otro lado, ha permitido agrupar una variedad de herramientas que antes se proporcionaban de modo aislado (p. e.: ftp, telnet, gopher, news, etc.). Aunque se trate de recursos que no son hipertexto, el programa cliente del Web nos permite consultarlos como si lo fueran. Así pues, el Web permite superar los inconvenientes derivados de la incompatibilidad de formatos, la existencia de diversos protocolos en la red, etc.

El Web es, sin duda, uno de los grandes activos de la red. Se trata de un sistema normalizado de presentación, consulta y distribución de información. El secreto de su éxito radica en el establecimiento de un elevado grado de estandari- 
zación a diferentes niveles que en la actualidad está asegurada por el WWW Consortium <http://www.w3.org>, una institución en la que participan los principales protagonistas de Internet. Los ejes de esta normalización son los siguientes:

- El lenguaje para codificar la información (HTML). El lenguaje HTML (Hyper Text Markup Language) es el estándar utilizado para la edición de las páginas de los documentos que forman el Web. Se trata de un lenguaje que incluye unas determinadas marcas a los documentos para que puedan ser interpretados desde cualquier plataforma, es decir, por cualquier máquina o programa de cualquier parte del mundo.

- El protocolo de transmisión (HTTP). HTTP (HyperText Transfer Protocol) es el conjunto de reglas que controlan el intercambio de información entre los servidores web (suministradores de información) y los usuarios (peticionarios o clientes). Está estructurado de modo que no exige una conexión permanente entre cliente y servidor, sino que va transferiendo la información por bloques (cantidades discretas) a medida que el cliente la va pidiendo. Además, se puede utilizar para transferir cualquier tipo de datos. La conexión se cierra después de cada intercambio entre cliente y servidor. ${ }^{37}$

- La forma de consultarse (hipertexto).

Los documentos, las páginas web, están vinculados entre sí mediante enlaces hipertextuales que permiten que el usuario pueda moverse de un documento a otro siguiendo la libre asociación de ideas. Estos enlaces, resaltados visualmente, permiten saltar a cualquier parte de un mismo documento o ir a cualquier otro documento.

La red está llena de servidores web, es decir, de máquinas que disponen de páginas de información multimedia, elaboradas, consultadas y distribuidas según estos patrones. Este alto grado de estandarización permite que cualquier usuario pueda consultar webs desde el lugar más alejado del mundo sin ninguna formación previa. No necesita disponer, prácticamente, de ningún conocimiento previo ni de ningún tipo de convertidor. Todo ello hace que el Web se haya convertido en la estrella de Internet y en una de las claves de su éxito.

\footnotetext{
${ }^{37}$ Las consultas en línea tradicionales implicaban una conexión permanente entre el usuario y el distribuidor, con lo cual cuando se llegaba a la capacidad máxima de usuarios conectados se impedía el acceso a ningún otro mientras no se realizara ninguna desconexión.
} 
El espectacular crecimiento de los servidores en la Red está directamente relacionado con la introducción y consolidación del Web (a partir de 1991), y también con la aparición del primer visualizador gráfico, que fue Mosaic (1993). ${ }^{38}$ Así pues, si en 1993 se podían encontrar 1,5 millones de máquinas en Internet, ya eran 6 millones en 1995; 19 millones, en 1997; 56 millones, en 1999, y más de 72 millones, en el año 2000. ${ }^{39}$

En lo que se refiere a los usuarios, según NUA Internet Surveys se calcula que actualmente hay unos 360 millones de personas conectadas a Internet en el mundo. Hay que destacar América del Norte (160 millones) y Europa (95 millones) como zonas con mayor número de internautas, y, en el otro extremo, a África, que, con tres millones de usuarios, es el área geográfica con menor presencia en Internet. La media mundial de conexión a Internet está situada en el 5,5 \%, y las zonas con una mayor concentración de usuarios son los países nórdicos (un $50 \%$ de la población conectada) y Estados Unidos (48 \%).

Si comparamos estos datos de crecimiento con los experimentados por las otras dos formas de distribución de información digital analizadas, podemos comprobar que las diferencias son abismales y que el Web refleja el aumento cuantitativo más importante en un espacio de tiempo más breve.

\subsection{FUENTES DE INFORMACIÓN SOBRE EL SECTOR: LOS LOCALIZADORES DE RECURSOS}

Con el interés por la Red, se han publicado una gran variedad de directorios de servicios. El problema radica en el hecho de que ninguno de ellos puede recoger el gran dinamismo y crecimiento experimentado por Internet. Esto hace que pierdan vigencia con mucha rapidez y que sean más útiles aquellos directorios de tipo electrónico.

Los localizadores de recursos, unas voluminosas bases de datos que contienen las referencias o el texto completo de una gran cantidad de webs, son las herramientas imprescindibles para poder conocer el contenido de los miles y miles de servidores que existen en la Red. Los localizadores vienen a ser, pues, los catálogos de esta enorme biblioteca digital de alcance mundial que es el World Wide

\footnotetext{
${ }^{38}$ Se trataba del antecesor de Netscape Communicator.

${ }^{39}$ Datos del Internet Software Consortium <http://www.isc.org/ds/www-200001/report.html>.
} 
Web y sirven para ayudar a encontrar documentos en la Red (no tan sólo en la Web, sino también en las noticias, etc.).

Tabla 5.1. Tipología de localizadores según diversos criterios ${ }^{40}$

Criterio

Según estructura y funcionamiento

\section{Tipología}

- Índices temáticos (v. 5.2.1): tan sólo disponen de referencias de las webs que clasifican en categorías temáticas. P. e.: Yahoo!, Buscador-Terra, Omni.

- Buscadores (v. 5.2.2): indexan el texto completo de las webs y, por tanto, permiten recuperar la información a partir de cualquier término que esté incluido en las páginas web. P. e.: Altavista, Alltheweb o Sol.

- Metabuscadores: ejecutan una consulta en paralelo en diversos localizadores. P. e.: Metacrawler.
Según el ámbito de los contenidos
- Generales: tratan de todas las materias. P. e.: Yahoo o Altavista.

- Especializados: se centran en una disciplina o ámbito determinado. P. e.: Sosig (ciencias sociales), Omni (medicina), etc.
Según el tipo de contenido
- Recursos web. P. e.: Yahoo!, o Altavista.

- Bases de datos. P. e.: Invisible web o Internet invisible.

- Grupos de noticias. P. e.: Deja-news.

- Direcciones de correo. P. e.: Who where?

- Programas informáticos. P. e.: Tucows shareware.

- Internacionales. P. e.: Yahoo o Altavista.

- Estatales. P. e.: Buscador-Terra, Sol o Voila.

- Nacionales o regionales. P. e.: Vilaweb.

- Particulares: analizan la información de una sola web. P. e.: La Vanguardia Digital, Universitat de Barcelona o Ajuntament de Barcelona.

\footnotetext{
${ }^{40}$ Direcciones citadas, en orden alfabético: Alltheweb <http://www.alltheweb.com>; Altavista <http://www.altavista.com>; Ajuntament de Barcelona <http://www.bcn.es>; Buscador-Terra <http://buscador.terra.es >; Deja News $<$ http://www.deja.com>; Internet invisible <http://www.internetinvisible.com>; Internet Public Library $<$ http://www.ipl.org>; Invisible web <http://www.invisibleweb.com>; Metacrawler <http://www.metacrawler.com>; Omni <http://www.omni.ac.uk>; Sol <http://www.sol.es>; Sosig <http://www.sosig.ac.uk>; Tucows <http://www.tucows.com>; Universitat de Barcelona <http://www.ub.es>; La vanguardia digital <http://www.vanguardia.es >; VilaWeb <http://www.vilaweb.com>; Voila <http://www.voila.fr>, Who where <http://www.whowhere.lycos.com>; Yahoo! <http://www.yahoo.com>
} 
Con estas cuatro variables podemos caracterizar cualquier localizador. Hemos de tener presente que la primera de ellas, la estructura y el funcionamiento, es la más importante y sustancial. El contenido y el ámbito geográfico serían adjetivos que calificarían un índice temático o un buscador. P. e., Buscador-Terra es un índice temático general de ámbito estatal (o español), mientras que SOSIG es un índice temático especializado de ámbito internacional. En cambio, Altavista es un buscador general de ámbito internacional, y el motor de búsqueda de la Universitat de Barcelona es un buscador particular.

Es importante conocer estas características de los localizadores cuando hemos de plantear nuestras preguntas, ya que habrá casos en que será mejor acudir a un índice temático o a un buscador. Otras veces, no obstante, quizá tendremos la necesidad de realizar la pregunta a ambos tipos de instrumento.

Para poder disponer de un listado exhaustivo de localizadores se puede consultar algún directorio de localizadores, como Buscopio <http://www.buscopio.com>, que recopila más de 2.200 localizadores organizados geográficamente y temáticamente, o la Relación de buscadores españoles de RedIris <http://www.rediris.es/doc/buscadores.es.html>.

\subsection{1. Índices temáticos}

Este tipo de localizadores disponen de datos descriptivos de un gran número de webs (el título, la dirección y un breve resumen, normalmente), a los que clasifica según unas categorías temáticas previamente establecidas (p. e., arte, cultura, economía, deportes, etc.). Estos índices son gestionados por un equipo humano que es el responsable de asignar a cada Web la categoría adecuada. Cuando busca la información, el usuario dispone de diversas carpetas que se pueden subdividir ad infinitum y que contienen la descripción básica de las webs que tratan del tema que corresponde. Tres ejemplos paradigmáticos son Yahoo!, en el ámbito internacional; Buscador-Terra, en el español, y Vilaweb, en el catalán.

Así pues, si nuestra consulta coincide con el epígrafe de la carpeta, habremos acertado plenamente, ya que, seguramente, la gran mayoría de direcciones que constan en su interior estarán relacionadas con el tema que nos preocupa. Los problemas empezarán cuando esto no sea así. En este caso disponemos aún de una pequeña oportunidad: podemos ver si los términos de búsqueda aparecen en 
el título o en el resumen de alguna web. Es lo que se denomina buscar por palabra clave. Desgraciadamente no podemos ir más allá y no podemos preguntar, como sí hacen los buscadores (v. 5.2.2), por cualquier parte del texto completo de las webs.

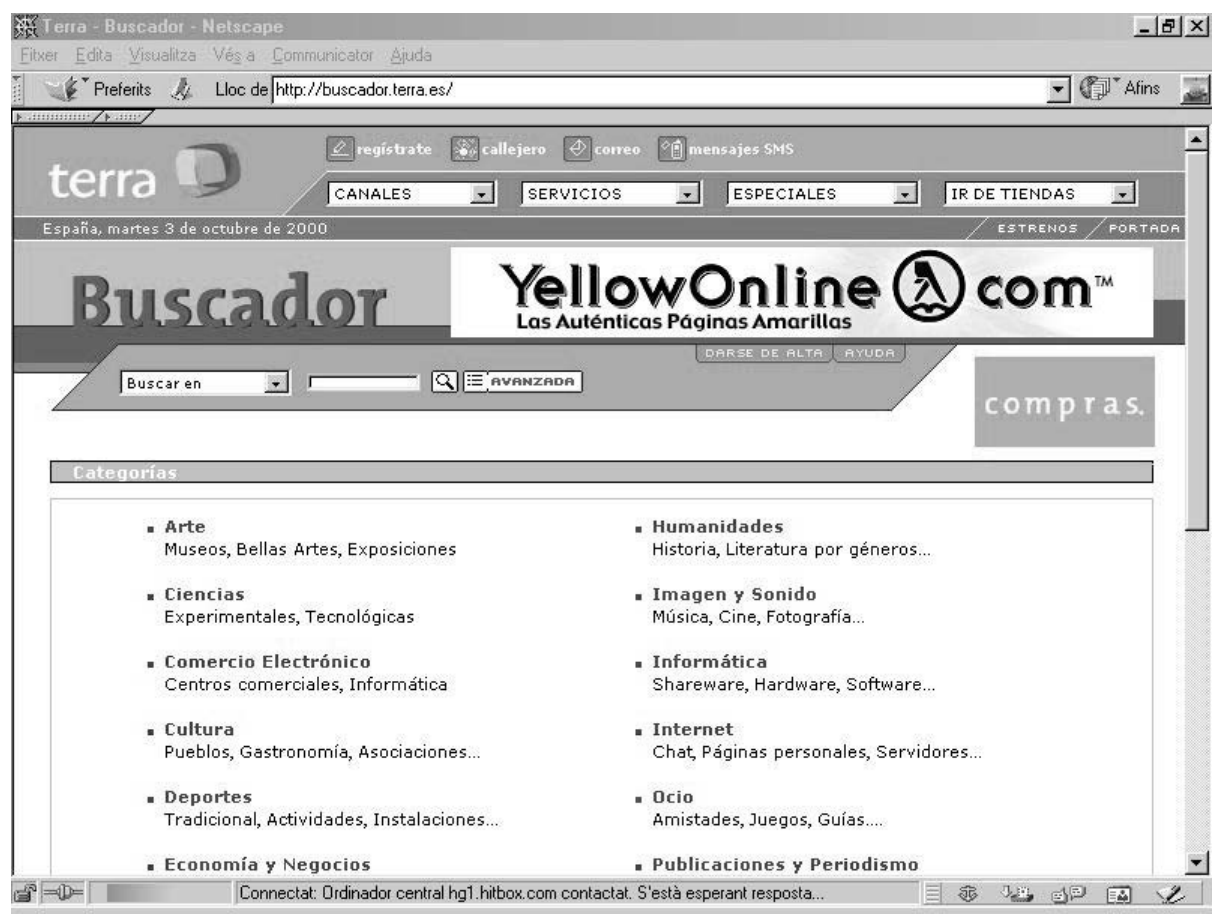

Fig. 5.1. Ejemplo de índice temático

Esta forma de trabajar y de estructurar la información provoca que los índices temáticos sean muy adecuados para ayudar a responder preguntas de carácter general (p. e., documentos sobre música pop, diarios de Gran Bretaña, turismo rural, etc.). En cada uno de los casos, es muy importante hallar la categoría correspondiente dentro de la clasificación temática que utiliza el localizador. Aquí no está de más recordar que no todos los índices temáticos utilizan el mismo tipo de clasificación. Así, puede pasar que el epígrafe que buscamos esté situado en categorías diferentes en función de cuál sea el índice que estemos utilizando. 


\subsubsection{Buscadores}

A diferencia de los índices temáticos, un buscador o robot (el más famoso es Altavista) nos permite encontrar un documento a partir de cualquier palabra de su contenido, y no únicamente a partir del texto del título y del resumen. Como es bien sabido, los buscadores crean grandes bases de datos en las que se hallan los índices que remiten al texto completo de miles y miles de páginas web. Esta indexación se realiza de forma automática, sin existir ninguna clasificación o descripción manual de los recursos web.

Esto quiere decir que cuando consultamos la base de datos del buscador no disponemos de información sobre cuáles son las principales materias de las que trata cada recurso web, y tan sólo podemos recuperarlas en el caso de que aparezcan escritas en alguna parte del documento. La recuperación de la información, por tanto, se hace mediante la utilización de lo que se llama lenguaje libre y no en base a un lenguaje controlado, que permite recuperar la información a partir de unos términos que han sido asignados de forma homogénea y que intentan representar el contenido del documento. Los principales problemas del lenguaje libre residen en la imposibilidad de asegurar que, cuando se utiliza un término (p. e., coche) se encuentre todo lo que se refiera a él (puede haber documentos que utilicen automóvil o turismo para denominar el mismo concepto) y, también, que en una gran parte de los documentos encontrados el término no será el objeto central del documento, ${ }^{41}$ ya que, al no existir indización manual, nadie decide cuáles son las principales materias de que trata un documento.

Las preguntas las hemos de formular utilizando un complejo lenguaje de interrogación que nos ayudará a concretar todas las claves de búsqueda que pueden formar parte de nuestra petición. Aunque podemos pedir cosas muy precisas, normalmente el resultado de la consulta será mucho más amplio que en el caso de los índices temáticos. El hecho de poder buscar directamente sobre el texto completo provoca que los puntos de acceso a la información se multipliquen.

Estas especiales características explican que los buscadores sean muy adecuados para ayudar a responder preguntas muy concretas. P. e.: buscamos el nombre

\footnotetext{
${ }^{41}$ De hecho, este último inconveniente los buscadores lo trampean ordenando las respuestas por ránquing de frecuencia de aparición del término y también teniendo en cuenta el lugar de la página donde aparece el término. De esta forma nos mostrarían en primer lugar aquellos documentos en los que aparece más veces el término que buscamos o aquellos documentos en los que el término aparece en las partes más significativas (el título o el primer párrafo).
} 
de una persona poco conocida, queremos información sobre una ciudad pequeña, sobre una raza de perros un poco especial, etc. En muchos casos, ni la persona, ni la ciudad ni la raza son tan importantes como para que un índice temático les dedique una categoría específica.

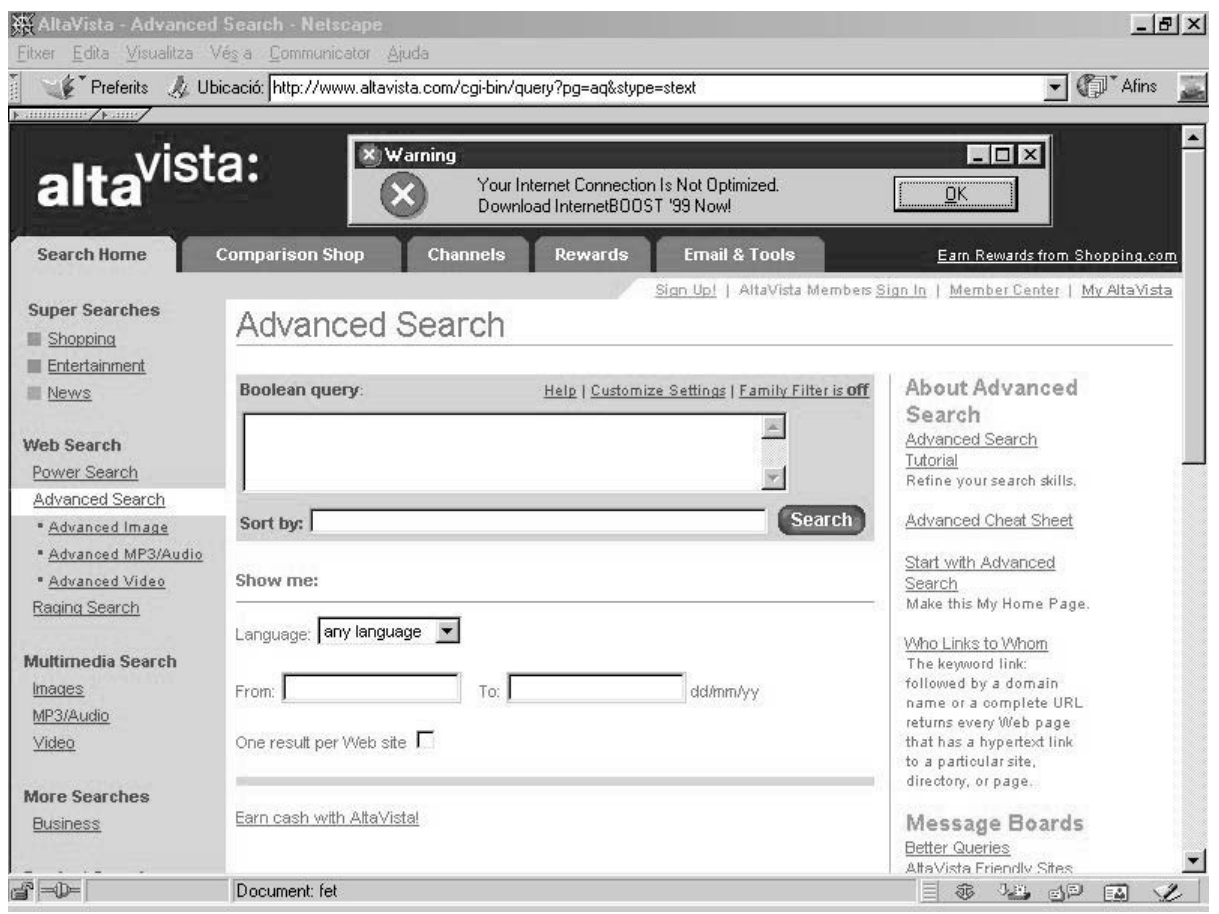

Fig. 5.2. Ejemplo de buscador: Altavista

Finalmente, hay que resaltar que cada vez son más habituales los sitios web que disponen de un buscador interno. Este instrumento es especialmente útil en el caso de webs de instituciones que disponen de miles y miles de páginas y por los cuales, muchas veces, se hace especialmente difícil navegar usando tan sólo el sumario de la página de inicio. Algunos ejemplos próximos, que ya han sido citados con anterioridad, son las webs de la Universitat de Barcelona o de La vanguardia digital, que indexan el contenido de todos los documentos que se encuentran en su servidor. 


\subsubsection{Otros criterios}

\section{ESPECIALIZACIÓN TEMÁTICA}

Además de los localizadores de tipo general, son de mucho interés los localizadores especializados que se ocupan de realizar un control y selección de los recursos web que van apareciendo en un determinado campo temático. Podríamos citar, como ejemplo, The Internet Public Library, un localizador especializado en recursos para la biblioteca pública, u Omni, que está especializado en medicina. ¿Qué aportan este tipo de localizadores? En primer lugar, realizan un control exhaustivo de los recursos informativos existentes en un ámbito temático determinado. En segundo lugar, algunos llegan a un nivel de clasificación temática más detallada que el conseguido por los índices generales. En aquellos campos o disciplinas en que nos movemos con más frecuencia, es muy importante disponer de un instrumento de estas características.

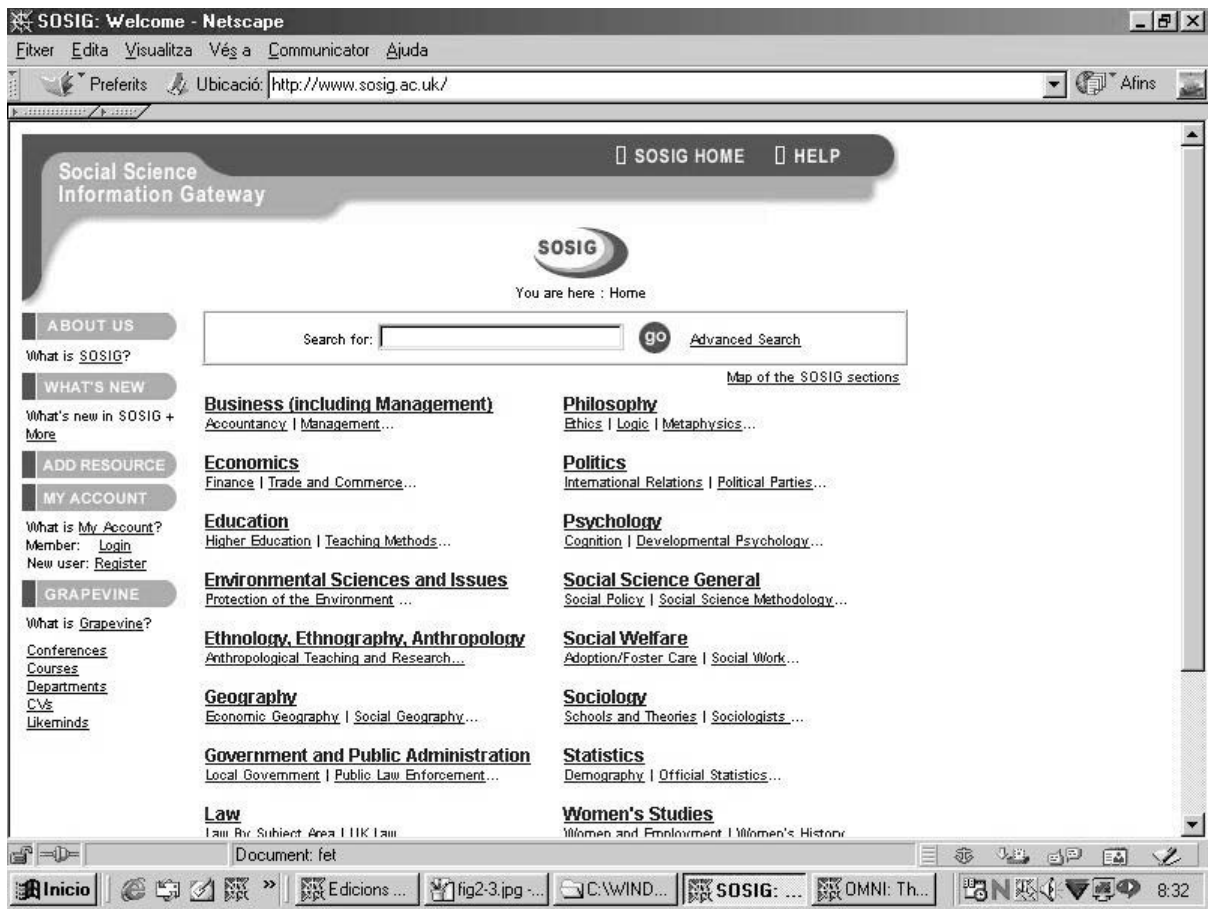

Fig. 5.3. Ejemplo de localizador temático: SosiG 
Las bibliotecas, principalmente las especializadas, cuentan con una notable experiencia en este campo y son unas grandes y eficientes productoras de este tipo de guías de recursos.

TIPO DE CONTENIDO

Los localizadores más utilizados y conocidos acostumbran a incluir todo tipo de recursos. Ahora bien, cada vez se constata más la especialización según el tipo de contenido que se incluye en el localizador. Hay que destacar los sistemas que facilitan la búsqueda de bases de datos, como puede ser el caso de Internet invisible, y también se pueden citar los que están especializados en encontrar programas informáticos, como Tucows, o direcciones de correo, como Who where.

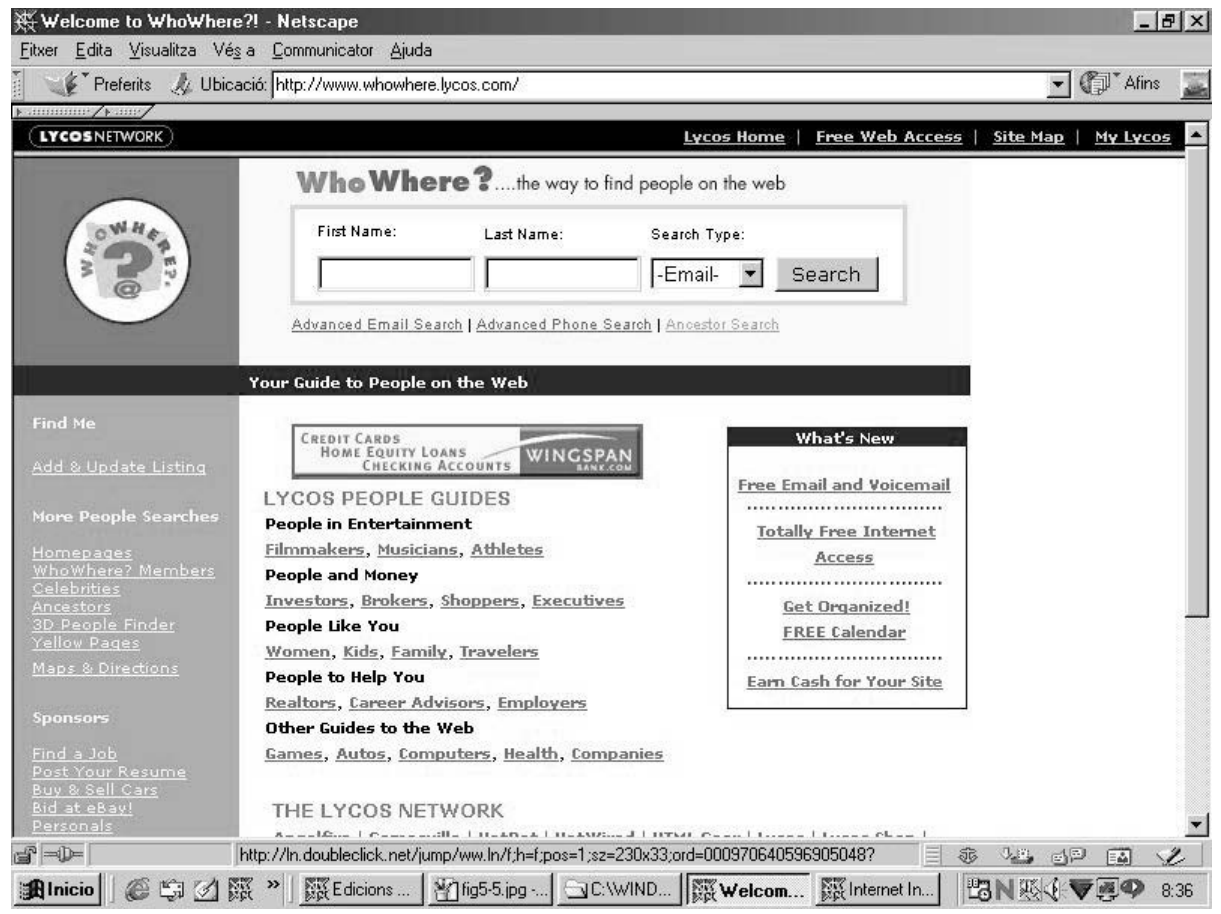

Fig. 5.4. Ejemplo de directorio de personas: Who where 


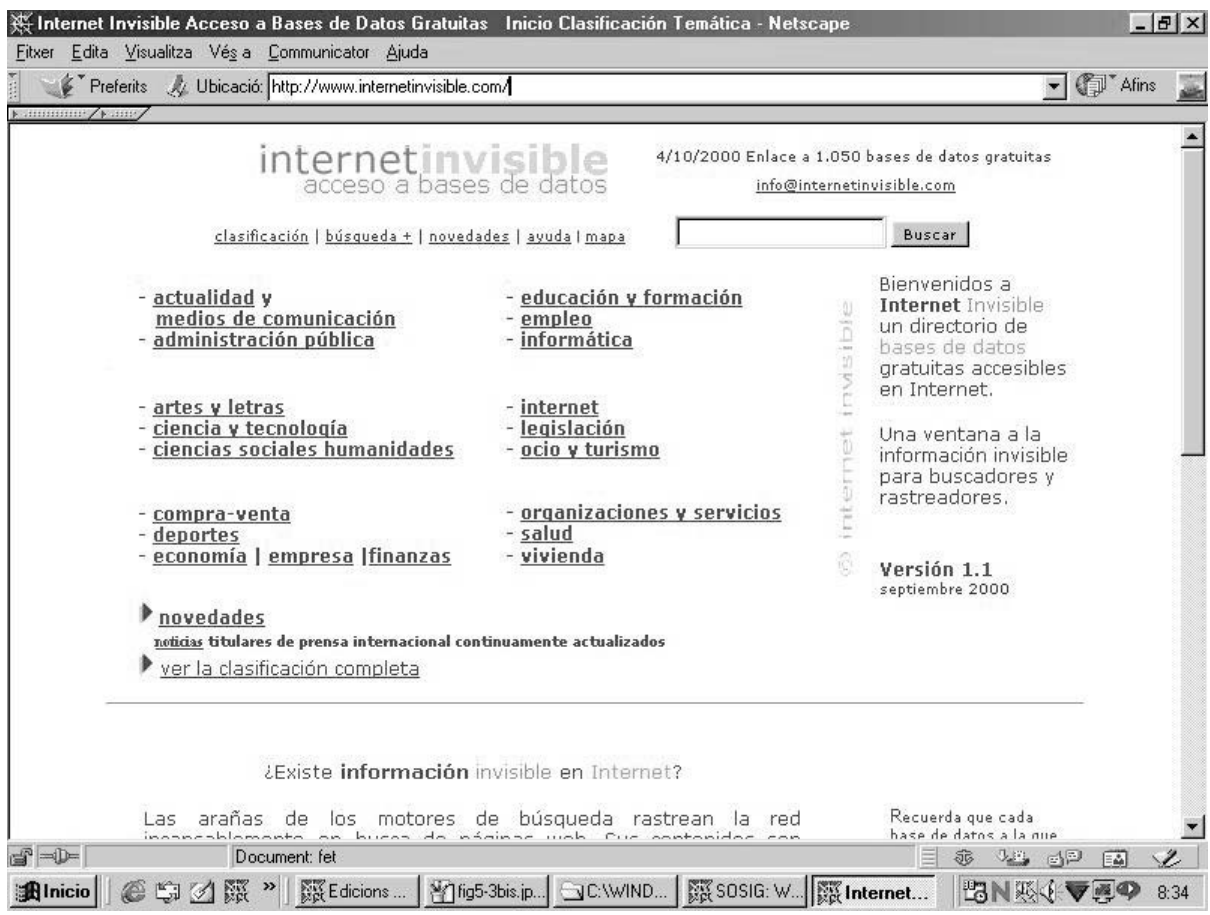

Fig. 5.5. Ejemplo de directorio de bases de datos: Internet invisible

\section{ÁMBITO GEOGRÁFICO}

Aunque existen algunos localizadores de ámbito internacional (sería el caso de Yahoo), la mayoría de ellos acostumbran a estar especializados en una área lingüística determinada (Vilaweb, en recursos catalanes; Buscador-Terra, en recursos españoles).

Un último comentario sería para traer a colación el concepto de infranet o Internet invisible (Aguillo, 2000). Con este término se quiere hacer referencia a toda aquella información existente en Internet que es opaca — no accesible- por parte de los localizadores. Sería el caso del contenido de las bases de datos, de enciclopedias y diccionairos o de los catálogos de biblioteca, que son invisibles e impenetrables para los localizadores, ya que se trata de páginas que se generan dinámicamente al rellenarse un formulario por parte de los usuarios. 


\subsection{SITUACIÓN EN ESPAÑA}

En España el punto de partida a la introducción de Internet es 1985, cuando Fundesco y la Secretaría de Estado para las Universidades elaboraron el proyecto Iris (Interconexión de Recursos Informáticos) para poder conectar los centros de cálculo de diversas universidades. De aquí nació más tarde RedIris, organismo encargado de gestionar la parte española de Internet.

A mediados de 1990 RedIris creó un servicio experimental que suponía la primera conexión española a Internet. En aquellos momentos tan sólo había cuatro centros interconectados (Fundesco, UCM, CICA y CIEMAT). En el año 1991 empezó la fase operativa del servicio de acceso a Internet y, desde ese momento, el número de máquinas conectadas no ha dejado de aumentar.

La eclosión de Internet en España es tardía y coincide con la popularización del Web. En 1993 el Departament d'Educació de la Universitat Jaume I (Castellón) creó el primer servidor web del Estado. Al año siguiente ya existían 13 servidores y, a partir de aquí, se inició un crecimiento espectacular en la línea de lo que se ha comentado en el apartado 5.1. A mediados del año 2000 ya eran unos 29.000 los dominios registrados bajo la denominación «es», de un total de seis millones de dominios nacionales y de 21 millones de dominios no nacionales (org, net, com, etc.).

En lo que se refiere al uso de Internet en España (número y caracterización de los usuarios, sistema de acceso, webs más visitadas, etc.) existen diversos estudios estadísticos, algunos de los cuales se actualizan periódicamente. Uno de los más conocidos es el EGM (Estudio General de Medios) <http://www.aimc.es>, un estudio general sobre la audiencia de los medios de comunicación (prensa, radio, televisión y, desde 1996, también Internet). Se trata de un sondeo que se realiza trimestralmente a una muestra de 14.000 personas mayores de 14 años. El cuestionario es bastante extenso y también incluye algunas preguntas relativas a los hábitos e intereses respecto a Internet. Los datos de abril-mayo de 2000 (EGM) indican que un $29,3 \%$ de la población usa el ordenador (era el 18,4 \% en 1996), el 13,4 \% tiene acceso a Internet (el 1,4\% en 1996), y el perfil de este usuario es el de una persona de sexo masculino ( $58 \%$ del total), menor de 35 años $(39 \%$ ) y de clase media-media ( $37 \%$ ) o media-alta $(28 \%) .{ }^{42}$ Las cinco webs más visitadas eran Terra, Yahoo, El País, Altavista y Marca.

\footnotetext{
${ }^{42}$ Estas cifras, aunque bajas, contrastan con el 2,3 \% de la población que tenía acceso a Internet en 1996, cuando se hizo la primera encuesta.
} 
La Asociación de Usuarios de Internet <http://www.aui.es> también ha realizado algunos sondeos sobre cuáles son las webs más visitadas, el uso de Internet en España, etc., aunque en este caso no existe una periodicidad tan establecida ni un alcance tan amplio. Lo mismo puede decirse del sondeo que se realizó para obtener datos sobre la presencia y uso de equipos informáticos y acceso a Internet en los hogares españoles (Baiget, 1999) ${ }^{43}$ y que formaba parte de un estudio más amplio para evaluar la utilización de las nuevas tecnologías de la información y de la comunicación por parte de la sociedad española.

Hasta ahora nos hemos referido fundamentalmente a cifras procedentes de sondeos que se han elaborado a partir de encuestas realizadas a una muestra de población más o menos amplia. Otro tipo de información de interés la ofrece la Oficina de Justificación de la Difusión (OJD), <http://www.ojd.es>, fundada en 1964, que se ocupa de controlar la difusión de 840 medios de prensa escrita y de 160 digitales. En este caso no se trata de un sondeo, sino que se cuantifica el número total de visitas realizadas y de páginas consultadas a los distintos servicios web que han aceptado someterse a su control.

Recientemente han comenzado a operar en España empresas extranjeras de medición de audiencias, como pueden ser ACNielsen <www.acnielsen.com > o NetValue <www.netvalue.com $>$, que utilizan un sistema parecido al que se usa para la medición de audiencias en televisión. Así pues, se escoge una muestra representativa de población y se les instala un programa en el ordenador que registra los datos relativos a las páginas visitadas, la duración de las consultas, la descarga de ficheros audio y vídeo, o el uso del correo electrónico. Dentro de poco tiempo, por tanto, será posible conocer con mucho detalle y precisión cuáles son los intereses de la población respecto a los contenidos que existen en el Web.

\subsection{PERSPECTIVAS}

La valoración general que hay que hacer sobre las posibilidades y perspectivas de Internet y del Web en general son muy positivas. Se trata, sin duda, de la forma de distribución de la información que ha llegado a disponer de la cobertura más amplia en un espacio de tiempo más corto, y también la que ha visto intro-

\footnotetext{
${ }^{43}$ Este documento complementaba un estudio global sobre el uso actual y las perspectivas de futuro de las tecnologías de la información en España que fue dirigido por Tomás Baiget y que puede consultarse en $<\mathrm{http} / / / w w w . a s e-$ die.es/msstudy>.
} 
ducir un mayor número de innovaciones tecnológicas. Nadie duda de que va a convertirse, a medio plazo, en la forma mayoritaria de distribución de información, y no sólo digital (ya lo es ahora), sino que también superará la difusión impresa.

El discurso que actualmente impera sobre Internet es extremadamente optimista, ensalza sus excelencias, y considera que Internet es la solución de (casi) todos los problemas. Los que utilizan la red con asiduidad saben que esta caracterización está aún lejos de lo que, hoy por hoy, es en realidad Internet. Por ello es importante realizar una tarea pedagógica que sitúe Internet exactamente en el punto en que se encuentra, desmitificándola y resaltando lo que ahora mismo son sus principales problemas. Esto puede ayudar a no crear falsas expectativas y a aprender a utilizar mejor esta herramienta tan fantástica. Algunos de los principales problemas pendientes de resolver, o en vías de solución, son los siguientes:

- Dificultades en la localización de la información.

La gran cantidad de información y servicios disponibles dificulta, muchas veces, la selección de aquellos documentos que nos pueden ser de interés. Los localizadores son el medio que ayuda a resolver este problema, aunque los resultados que nos ofrecen no son, la mayoría de las veces, totalmente satisfactorios para el usuario. La progresiva extensión de los metadatos, o sea, de información normalizada que describe el contenido de los recursos web, indicando quiénes son sus autores, sus editores, la fecha, unos descriptores que reflejan el contenido, etc., puede ayudar mucho a mejorar los resultados que ofrecen los localizadores.

- Lentitud del sistema.

En muchas situaciones, es fácil que el acceso a la información se realice con cierta lentitud. Esto puede llegar a desesperar al usuario y restar eficacia al sistema. Los motivos de esta lentitud son debidos, sobre todo, a tres factores:

- Equipo informático del usuario.

La utilización abundante de imágenes por parte de las webs exige que el usuario disponga de un equipo informático potente, de versiones actualizadas de los navegadores y de otros programas auxiliares y, además, que pueda recibir los datos a una velocidad mediana o alta. 
- Saturación de las redes.

Este problema no lo puede arreglar el usuario por sí solo. Las dimensiones de las redes de telecomunicaciones no han variado en la misma proporción que la gran cantidad de servicios que pueden circular en la actualidad. Esto quiere decir que, en horas de máxima utilización de las redes, la circulación será más lenta.

- Saturación o mal funcionamiento del servidor.

Sólo nos podemos conectar a los servidores que estén disponibles cuando realizamos la conexión. Los mensajes en pantalla «too busy now, try later» (ocupado), «unable to connect» o «cannot access directory» (no se puede establecer conexión) son el pan nuestro de cada día. La promesa de la siempre disponible biblioteca virtual queda defraudada per la limitación del ancho de banda, puertos y horarios de los servidores.

- La seguridad de los datos.

Aunque se están desarrollando sistemas cada vez más sofisticados, hay que ir con cuidado a la hora de enviar informaciones referidas a la intimidad de las personas (datos domiciliarios, personales, etc.) así como datos económicos (números de tarjetas de crédito, etc.).

Las normas de intercambio y transferencia de información implementadas en Internet no fueron pensadas para una utilización comercial de la Red. Es por esto que no está todavía resuelto del todo el mantenimiento de la privacidad y la integridad de los datos que se transfieren.

Se han establecido diversos acuerdos tecnológicos entre las grandes empresas de dinero electrónico (Visa, Mastercard) y las empresas de informática (Microsoft, Netscape, IBM) tendentes a diseñar un protocolo estándar para poder realizar operaciones comerciales de forma segura. Ahora bien, aparte de los tecnológicos, quedan otros obstáculos políticos y económicos que parecen todavía más difíciles de salvar. Estos se derivan, por ejemplo, de la simplicidad con que se pueden llevar a cabo operaciones de movimiento de capitales con dinero electrónico, incluyendo lavado de dinero o tráfico de divisas sin ningún tipo de control.

- El control sobre los contenidos.

Dentro de Internet no hay ningún tipo de control sobre lo que se distribuye. Por ello no es muy complicado encontrar información para fabricar bombas caseras, textos de sectas destructivas, propaganda antisemita o también imágenes porno- 
gráficas. Diversas voces claman para establecer una censura en la Red y se debate entre el mantenimiento de una libertad total o de un control selectivo. Con todo, de momento, Internet todavía sigue fiel a sus principios fundacionales.

Ahora bien, cuando hay que clamar por la limitación en la difusión de los contenidos, a cada país le duele en sitios distintos. Estados Unidos, defensor a ultranza del puritanismo, está especialmente preocupado por la decencia. Los chinos, en cambio, quieren prevenir cualquier forma de disidencia política o desviacionismo respecto de lo que son las directrices oficiales. Finalmente, los europeos quieren impedir la difusión de contenidos racistas, xenófobos o de defensa de la violencia política.

- Información de calidad.

Determinar el valor de los recursos de información es uno de los principales problemas de contenido que se han planteado. Si en el entorno impreso disponemos de una serie de criterios de evaluación que ayudan a discernir el valor e interés de una obra, hay que hacer la transición a las nuevas fuentes disponibles en red. Según diversos autores, las principales características clave que deben observarse en un recurso informativo de Internet son las siguientes: accesibilidad, autoridad, interactividad y «amigabilidad». Lluís Codina (2000), en un artículo reciente, presenta una síntesis de cuáles son los principales indicadores para la evaluación de los recursos web.

En lo que se refiere a las oportunidades, hemos de repetir aspectos que ya han sido comentados anteriormente en otros apartados: la posibilidad de llegar a usuarios de todo el mundo, la facilidad para actualizar los contenidos, la sencillez en la edición y los bajos costes de distribución, entre otros. Todos ellos constituyen la gran baza de Internet y del Web para convertirse en el medio por excelencia para la distribución de información.

Finalmente hay que destacar la tendencia cada vez más acusada de una convergencia entre Internet y la televisión, el mundo audiovisual. Cada vez son más numerosos los servicios de audio y vídeo que son accesibles por Internet. Un estudio de la consultora Multimedia Research calcula que actualmente se pueden encontrar unos 100.000 sitios web que ofrecen servicios mediáticos y que para el 2001 podrían ser tres veces más. La descarga de vídeo en Internet está despertando una inusitada expectación y está llevando a muchas empresas a ofrecer contenidos para este medio. La distribución de vídeo por Internet permite encontrar 
nuevas audiencias que, aunque son más reducidas, tienen un carácter muy especializado. Algunos ejemplos de productos que se ofrecen son los conciertos o espectáculos deportivos (fútbol en especial) en directo. Así pues, el tiempo destinado a la televisión (cultura del sofá) se irá reduciendo a favor de los ratos que se consumirán conectados a la Red (cultura de la silla) hasta que, seguramente, se pase a utilizar un mismo aparato para poder realizar funciones que ahora se encuentran separadas. 


\section{LA EDICIÓN ÓPTICA, EL PASO INTERMEDIO ENTRE EL PAPEL Y LA RED}

La distribución de los discos ópticos se realiza como cualquier otro producto cultural tradicional (un libro, un disco o una cinta de vídeo) y no hace falta, por lo tanto, ninguna conexión a las redes de telecomunicaciones. Ésta es la primera gran diferencia respecto de los dos sistemas de distribución analizados anteriormente. El aspecto positivo, en este caso, proviene del ahorro de costes en el uso de las telecomunicaciones, mientras que, por el lado negativo, se tendría que tener presente que el proceso de actualización de la información es mucho más lento. Por otro lado, esto también explica que no sea posible ni la comunicación ni la realización de transacciones.

A diferencia de las bases de datos en línea o del Web, que pueden contener, en teoría, volúmenes prácticamente ilimitados de información, el soporte óptico tiene fijado, hasta ahora, un techo (los $650 \mathrm{Mb}$ de capacidad de un cederrón o los 4,7 Gb del DVD), aunque pueda ser muy alto.

Los primeros títulos editados en disco óptico correspondían a un tipo de obras, como bases de datos o bibliografías, dirigido a sectores especializados, aunque poco a poco se fue ampliando la oferta con obras generales y de entretenimiento. Actualmente, pues, podemos encontrar obras editadas en disco óptico dirigidas a toda clase de público, ya sea especializado o con intereses más bien generales, aunque se tiene que destacar que el número de títulos dirigidos al gran público es notablemente mayor, tal y como constatamos en la tabla 6.1 .

También hay que recordar, por otro lado, que cada día tiene una mayor aceptación la edición de discos ópticos para uso interno en grandes corporaciones (muchas empresas distribuyen, entre sus departamentos, voluminosos catálogos que antes estaban impresos sobre papel y que, cada vez más, se pasan a soporte ópti- 
Tabla 6.1. Oferta de títulos editados en disco óptico según el tipo de público (1999)

\begin{tabular}{lc}
\hline Ámbito & Porcentaje \\
Gran público & $71 \%$ \\
Profesional & $20 \%$ \\
Académico & $9 \%$ \\
\hline
\end{tabular}

[Fuente: New media titles]

co), así como para la distribución entre los clientes (por ejemplo, son muchas las editoriales que editan sus catálogos de publicaciones en disco óptico).

Los productos editados en soporte óptico no disponen de una forma de consulta estandarizada. Como ya ha sido descrito, el Web ha conseguido un sistema homogéneo de consulta, lo que facilita el acceso del usuario a la información. En el caso de los discos ópticos, podemos encontrar toda clase de sistemas de consulta: uso de lenguaje de interrogación, sistema de menús, y también enlaces hipertextuales, lo que dependerá fundamentalmente del tipo de obra y del editor.

La comercialización de los discos ópticos es idéntica a la de cualquier otro producto cultural (p. e.: libros, música, etc.). Existen, por un lado, unas empresas editoras encargadas de la producción y duplicación de los discos y, por otro, otras que hacen de distribuidoras y se ocupan de hacer llegar estos discos a los puntos de venta habituales (tiendas especializadas, grandes almacenes, etc.). El precio de un disco va en función del tipo de información que contiene y de la tirada que se haga. En este sentido, la política de costes sería muy similar a la del sector editorial clásico. En algunos casos, no obstante, no se abona un precio fijo por el disco, sino que se establece una especie de suscripción y el usuario recibe con una determinada periodicidad las actualizaciones de los discos. Esto es más frecuente en el caso de bases de datos referenciales, y no tanto en lo que se refiere a documentos primarios.

En el caso de la edición óptica es importante conocer algunas características y tipología del soporte que se utiliza para la distribución, antes de entrar a ver detalles sobre los antecedentes históricos, las fuentes de información, la situación en España o las perspectivas de futuro, que son más o menos los apartados que hemos descrito en los dos sistemas de distribución analizados anteriormente. 


\subsection{SOPORTES ÓPTICOS}

Los discos ópticos aparecen a principios de la década de 1980 y constituyen, hasta el momento, la última generación de soportes documentales. La posibilidad de leer datos mediante la incidencia de un rayo láser sobre una superficie que contiene la información ha permitido un importante salto cualitativo en los sistemas de almacenaje de información.

Se trata de unos soportes que registran la información en forma de pequeñas marcas sobre una superficie sensible a la luz, y en los que la lectura se realiza a partir de la desviación que sufre el rayo láser cuando encuentra una variación en la superficie del disco. Su principal característica distintiva reside en una gran capacidad de almacenaje: el volumen de información que puede contener un disco óptico oscila entre los $650 \mathrm{Mb}$ de un cederrón hasta los $17 \mathrm{~Gb}$ de un DVD. Por otro lado, facilitan la conservación y la perdurabilidad de los datos (no les afecta el polvo, ni la humedad, ni los campos magnéticos, y la calidad del almacenaje es superior a la de cualquier otro soporte porque, al no entrar nunca el disco en contacto físico con el aparato de lectura, no se produce ningún tipo de desgaste en la superficie) y, además, pueden contener información de todo tipo (textual, sonora, gráfica, e imagen animada).

La rápida obsolescencia técnica constituye un importante problema que es compartido por los soportes digitales en general. Probablemente, mucho antes que cualquier soporte óptico resulte afectado por el paso del tiempo se volverá ilegible porque ya no existirán en el mercado máquinas que puedan leerlo. Por poner un ejemplo, actualmente ya no resulta posible, para la mayor parte de los ciudadanos y empresas, leer los datos de los disquetes de 5,25 pulgadas, que nacieron con el PC y que se utilizaron de forma masiva durante toda la década de 1980. Aunque se conserven en buen estado, no sirve de nada si ya no quedan ordenadores que contengan lectores para esa clase de discos, ni sistemas operativos o programas compatibles con los datos que contienen. Es muy cierto, pues, que la amenaza de la obsolescencia técnica es especialmente grave en lo que concierne a la conservación del patrimonio histórico. La mayor parte de los organismos encargados de la preservación de documentos recomiendan una combinación de medidas: o bien la fabricación de máquinas y software emuladores o bien el trasvase cada cierto tiempo de la información de los viejos a nuevos soportes, por ejemplo, del cederrón al DVD.

Ofrecer un panorama exhaustivo y detallado de la familia de los discos ópticos es una tarea difícil de llevar a buen puerto debido a que la aparición de nuevos 
sistemas y formatos es constante. Hace unos años existía una diferencia fundamental entre los discos ópticos dependiendo de que el sistema de codificación fuera de tipo analógico o digital. ${ }^{44}$ Actualmente todos los discos son digitales, por lo que este criterio es ya irrelevante para hacer alguna distinción.

Quizá un criterio válido para poner un poco de orden en la diversidad de sistemas y formatos sea la posibilidad de grabar, o no, la información por parte del usuario. Siguiendo esta pista, encontraríamos discos que sólo permiten la lectura (ROM, Read Only Memory), discos que pueden ser grabados una sola vez por el usuario (WORM, Write Once Read Many o también R, Recordable) y, en tercer lugar, discos regrabables (RW, Rewritable), que permiten reescribir la información tantas veces como se quiera. Dentro de cada subfamilia (lectura, grabables y regrabables, o ROM, R y RW, si utilizamos las siglas) existen múltiples variedades de formatos que se diferencian por las dimensiones del disco, por la capacidad de almacenaje o por el sistema de grabación utilizado.

Finalmente, podríamos hacer alusión al sistema de grabación, con lo que se dibujarían dos grandes familias: los discos compactos (CD) que cumplen la norma ISO 9660, y los recientemente aparecidos discos de vídeo digital (DVD), que utilizan un sistema diferente. A ambas tipologías nos vamos a referir someramente, poniendo especial énfasis en los discos de lectura (ROM), ya que constituyen el soporte ideal para la distribución de publicaciones digitales.

\subsubsection{Los discos compactos (CD)}

Las primeras investigaciones tecnológicas sobre el disco compacto empiezan a partir de 1976, como consecuencia de la colaboración entre dos empresas: Philips y Sony, verdaderos artífices de su desarrollo y posterior implantación en el mercado. En primer lugar se comercializó el compact disc audio (CD-A), alcanzando un éxito muy rápido como forma de distribución de productos musicales. Posteriormente, y aprovechando un poco este impulso, se fue diversificando la familia de los soportes ópticos.

Los fabricantes adoptaron la norma ISO 9660, que establece, entre otras cosas, cuál debe ser el diámetro del disco $(12 \mathrm{~cm})$ y también la forma en la que debe re-

\footnotetext{
${ }^{44}$ Durante la década de 1980 existieron discos ópticos de grabación analógica como los videodiscos y los discos láser.
} 
alizarse el registro de la información (secuencialmente a lo largo de $5 \mathrm{~km}$ de pista concéntrica) para que, posteriormente, cualquier reproductor la pueda leer. A partir de esta norma fueron surgiendo diferentes tipos de disco compacto pensados para diferentes tipos de información: $\mathrm{CD}-\mathrm{A}$ (sonido), cederrón (texto), foto $\mathrm{CD}$ (imagen fija), CD-I (imagen en movimiento), etc. Todos ellos con la misma apariencia externa y la misma capacidad $(650 \mathrm{Mb}$, o unos 74 minutos de sonido de alta calidad, o unos 200.000 DIN A4 de texto), diferenciándose por el tipo de información que contienen y la forma de almacenarla.

Tabla 6.2. Tipología básica de la familia $\mathrm{CD}^{45}$

\begin{tabular}{lll}
\hline Nombre & Año & Características \\
\hline CD-A & 1982 & $\begin{array}{l}\text { Información sonora (estándar desarrollado por Philips y } \\
\text { Sony). 74 minutos de sonido de alta calidad. }\end{array}$ \\
\hline cederrón & 1985 & $\begin{array}{l}\text { Información textual y gráfica (imagen fija). 200.000 DIN } \\
\text { A4 de texto. }\end{array}$ \\
\hline $\begin{array}{l}\text { cederrón XA } \\
\text { Architecture })\end{array}$ & 1988 & $\begin{array}{l}\text { Información textual, sonido, imagen fija y fragmentos de } \\
\text { imagen animada, que pueden reproducirse de forma } \\
\text { sincronizada (máximo 35 minutos). Se trata de una } \\
\text { mejora del anterior. }\end{array}$ \\
\hline $\begin{array}{l}\text { CD-I (Compact Disc } \\
\text { Interactive) }\end{array}$ & $(1986$, & $\begin{array}{l}\text { Información multimedia (estándar desarrollado por } \\
\text { Philips). Lectura desde un ordenador o desde un monitor } \\
\text { de televisión. Soporta formatos de compresión de video. }\end{array}$ \\
\hline Capacidad: 72 minutos de vídeo.
\end{tabular}

\footnotetext{
${ }^{45}$ Además de los discos que constan en la tabla, existen otros estándares que se han perdido por el camino, y que han tenido un impacto más bien bajo. Sería el caso del CDTV (Commodore Dynamic Total Vision), un disco multimedia comercializado a partir de 1991 por la casa Commodore; del Tandy VIS (Video Information System), de características similares y presentado en 1992 por Tandy, o del Data Discman, un primer modelo de «libro electrónico", de $8 \mathrm{~cm}$ de diámetro, comercializado por Sony en 1991, que tenía que ser leído en un lector de bolsillo específico. De todos ellos se editaron diversos títulos, aunque ya en la edición de 1995 del directorio TFPL (v. 6.2) prácticamente no constaba ningún ejemplo bajo estas plataformas.
} 
El CD-I constituyó la gran apuesta de penetración hacia el gran público. No en vano puede ser leído desde un monitor de televisión y, además, está pensado para contener imagen en movimiento. A pesar de ello, ha tenido un impacto y grado de difusión más bien modesto.

El CD-R (recordable, grabable) ha de ser reseñado de forma destacada porque facilitó la introducción del concepto de autoedición en el ámbito de los $\mathrm{CD}$, hecho que está impulsando todavía más la utilización de los soportes ópticos, porque se simplifican muchísimo los procesos de elaboración de los másteres para la duplicación. Los CD-R son discos funcionalmente idénticos a los cederrones, pero que pueden ser codificados por usuarios personales mediante grabadoras domésticas y visualizados, posteriormente, con un lector estándar. Las diferencias con los cederrones provienen de la estructura física del disco: el cederrón tiene tres capas (policarbonato, aleación de aluminio y laca), mientras que el CD-R tiene cuatro (policarbonato, pigmento verdoso, aleación de oro y laca). La información digital del CD-R se codifica mediante la decoloración del pigmento verdoso. Estas diferencias estructurales son perceptibles a simple vista. En la cara que se utiliza para etiquetar el contenido los $\mathrm{CD}-\mathrm{R}$ tienen una coloración verdosa-oro, mientras que el cederrón es plateado.

\subsubsection{Los DVD}

El disco de vídeo digital, también llamado disco versátil digital (DVD), empezó a desarrollarse para superar las deficiencias y limitaciones de los cederrones en lo que respecta al almacenamiento de información multimedia y, en especial, de imágenes en movimiento. Los expertos pronostican que desplazará al cederrón, al CDI, y también a la cinta de vídeo. Los motivos son claros: se trata de un sistema que permite distribuir productos de entretenimiento para el gran público y que combina prestaciones repartidas actualmente en soportes diversos, ya que tiene la calidad de sonido del CD-A, la capacidad de cinta de vídeo, etc.

La investigación en este soporte es reciente y se gestó inicialmente por caminos separados. En diciembre de 1994 la industria estaba desarrollando dos propuestas distintas. Por un lado, existía un consorcio liderado por Toshiba y las grandes productoras norteamericanas del sector audiovisual (Warner, MCA, MGM, etc.) y, por otro, Philips y Sony. Cada uno de los grupos reclamó el apoyo de las grandes empresas de informática (IBM, Apple, HP, etc.) las cuales, en lugar de decantarse por unos u otros, forzaron un acuerdo. El 15 de setiembre de 1995, aprovechan- 
do que se celebraba en Berlín la feria de la electrónica más grande de Europa, se llegó a un compromiso de acuerdo con el propósito de evitar la repetición de antiguas luchas por estándares (como fue el caso, p. e., del vHS, Beta y V2000).

El formato acordado sigue las especificaciones básicas y la estructura de datos defendida por Toshiba y el sistema de modulación de señal del otro consorcio. En cualquier caso, se garantiza la compatibilidad con los actuales CD. Es decir, los reproductores de DVD pueden leer sin problemas cualquier tipo de CD.

La cantidad de memoria que pueden almacenar está cifrada en 4,7 Gb (siete veces más que los actuales cederrones). Contado de forma más ilustrativa: unos 133 minutos de vídeo de alta calidad, con una velocidad de transmisión de datos de 3,5 Mb/segundo y un estándar de compresión MPEG-2. Se ha previsto una gama de seis discos que difieren en su capacidad de memoria, ya que algunos de ellos están grabados a doble cara y a doble capa (en este caso, la capacidad puede llegar a los $17 \mathrm{~Gb}$ ).

Sin duda una de las primeras aplicaciones está siendo la grabación de películas con un alto grado de definición. La capacidad del soporte permite, además, doblar una película en cinco idiomas y subtitularla en otros 30. A diferencia de la actual cinta de vídeo analógica, este nuevo soporte elimina cualquier tipo de problema de compatibilidad entre las tres normas de emisión televisiva: NTSC (Estados Unidos y Japón), Secam (Francia) y Pal (Alemania y España).

El DVD ha tenido muchos problemas comerciales en su lanzamiento y promoción porque han existido muchos recelos por parte de los grandes distribuidores audiovisuales hacia la facilidad para poder copiar el contenido sin pagar los derechos.

Tabla 6.3. Tipología básica de los DVD

\begin{tabular}{lll}
\hline Nombre & Año & Características \\
\hline DVD-ROM & 1997 & $\begin{array}{l}\text { Información multimedia. Capacidad de memoria de 4,7 } \\
\text { hasta } 17 \mathrm{~Gb} \text { (según se grabe a una sola cara o a doble } \\
\text { cara y doble capa). Se lee desde un PC. }\end{array}$ \\
\hline DVD-vídeo & 1997 & $\begin{array}{l}\text { Las imágenes se ven desde un monitor de televisión. } \\
\text { Constituyen el sustituto potencial de la cinta de vídeo y, } \\
\text { por tanto, los lectores de DVD-vídeo serán el } \\
\text { magnetoscopio digital. }\end{array}$ \\
& & $\begin{array}{l}\text { Permite grabar 2,6 Gb por cara (5,2 Gb). Los discos } \\
\text { grabados pueden ser visionados, indistintamente, por un } \\
\text { lector DVD-ROM o DVD-vídeo. }\end{array}$ \\
\hline DVD-RAM & 2000 &
\end{tabular}


Por el momento, Hollywood está invirtiendo de forma muy lenta y cautelosa y, de hecho, durante los dos primeros años en el mercado se podían encontrar pocos títulos. Sin embargo, su implantación en el mercado es imparable, porque las actuales tendencias en edición multimedia exigen un soporte como el DVD. Por poner un ejemplo, la mayoría de las últimas ediciones en cederrón de las principales enciclopedias digitales del mercado, como las de Microsoft, Grolier o Enciclopedia Británica, han necesitado entre dos y cuatro discos, con la consiguiente antiergonomía en su utilización, mientras que con un solo DVD podrían incluir sus contenidos (así, p. e., podemos comprar Encarta 2000 en un DVD o en cuatro cederrones).

A finales del año 2000 salieron al mercado los primeros DVD regrabables, tecnología que ha de sustituir las aplicaciones del vídeo doméstico, un formato desfasado. El recambio no será inmediato, porque existe un importante problema de compatibilidad por solventar. Actualmente se están comercializando tres sistemas de DVD diferentes: el DVD-RAM (Panasonic, Toshiba, etc.), el DVD-RW (Pioneer y Sharp) y el DVD+RW (Sony, Philips, RCA, etc.). Aunque se han dado pasos para intentar armonizar las tendencias en este ámbito, por el momento esta incompatibilidad confunde y perjudica al usuario.

Hay compatibilidad de lectura descendente entre la mayoría de los soportes comentados. Esto quiere decir que desde un mismo aparato se puede descodificar cualquier tipo de CD anterior. Por ejemplo, un lector de cederrón no podrá leer aparatos de DVD, pero este último sí puede leer discos cederrón. Estos aparatos lectores han ido aumentando su velocidad de acceso a la información, y también ha ido mejorando la velocidad de transferencia de los datos del disco al ordenador. Esto hace que cada vez sea más sencillo consultar documentos con muchos gráficos, imágenes en movimiento, etc. También hay que destacar que la tendencia actual es que los lectores de discos ópticos que van incorporados a los nuevos equipos informáticos sean DVD-ROM, y no cederrón debido, además de a las razones técnicas, a que el margen comercial de beneficio que tienen los distribuidores es superior en el caso del DVD. ${ }^{46}$

En este apartado se han descrito los actuales sistemas que permiten el almacenamiento y la distribución fuera de línea de publicaciones digitales. En el capítulo 3, por otra parte, se ha hecho referencia a los nuevos soportes que se están preparando para la visualización de publicaciones digitales. Su lectura complementa lo que se ha descrito aquí.

\footnotetext{
${ }^{46}$ En 1999 se vendieron 1,4 millones de lectores de DVD en Europa y 4 millones de unidades en Estados Unidos.
} 


\subsection{FUENTES DE INFORMACIÓN SOBRE EL SECTOR}

La bibliografía sobre los discos ópticos es cada vez más extensa, tanto en lo que se refiere a monografías especializadas como en lo que respecta a publicaciones periódicas, amén de secciones fijas en diversas revistas. Evidentemente, esto se corresponde con la creciente importancia que están adquiriendo los discos ópticos en el ámbito editorial.

Ahora bien, en lo que se refiere a la función más coyuntural y descriptiva de repertoriar o inventariar las continuas novedades y productos que van saliendo al mercado (en el ámbito mundial), se podrían mencionar los siguientes directorios:

— New media titles. Londres: Waterlow, 1999-. <http://www.waterlow.com>.

Esta obra, que se puede consultar en papel, en el Web y también en disco óptico, está estructurada en dos partes (que corresponden a volúmenes separados en la edición impresa). En el primero, titulado The market, se incluye información sobre miles de compañías comerciales de la industria de la edición óptica (editores, estampadores, productores de hardware y software, empresas de desarrollo, etc.), junto con la descripción de los principales eventos y conferencias internacionales, publicaciones especializadas, informes de mercado, etc.

El segundo volumen, The titles, contiene la descripción de más de 30.000 títulos de obras editadas en disco óptico relacionadas alfabéticamente, de las cuales se indica: ISBN/ISSN, editor, país, materia, lengua, precio, año de edición y descripción del contenido.

Este directorio, que es el más prestigioso del sector, ha ido cambiando su denominación adoptando diversos títulos que son un fiel reflejo de la evolución que ha ido experimentado el sector en estos últimos años: en un primer momento el nombre utilizado fue The CD-ROM directory; poco después incorporó el subtítulo with multimedia discs. En 1996 ya se denominaba The multimedia and CD-ROM directory para pasar, en 1999, a adoptar el título que encabeza este epígrafe. El anterior editor fue TFPL (hasta 1997).

— Gale directory of databases. Detroit [etc.] : Gale Research Inc., 1993-. Semestral. v. 2: CD-ROM, diskette, magnetic tape, handheld, and batch access database products.

Presenta la descripción de aquellas bases de datos que son transportables, es decir, que pueden ser consultadas de forma local sin necesidad de conexión con un 
terminal remoto. La tipología de productos considerada es triple y tiene en cuenta el soporte: en cederrón, en disquete y en cinta magnética. De cada uno de los títulos incluidos presenta, entre otras informaciones, nombre, productor, distribuidor, formato, requerimientos informáticos, precio, tipo de información, materia, contenido, lengua, cobertura temporal y geográfica, actualización, etc. Además pueden encontrarse anexos unos índices suplementarios de materias, de productores, de distribuidores y de bases de datos. Este directorio es muy exhaustivo por lo que se refiere a las bases de datos distribuidas en cederrón, pero no es tan completo en lo que se refiere a productos de tipo editorial (obras de referencia básicamente). Aunque incluye alguna enciclopedia y diccionario especializado, no permite hacerse una idea de los productos existentes en el ámbito editorial.

En la edición de 1999 incluía la descripción de casi 8.000 títulos (4.600 de ellos en formato cederrón).

\section{- ISBN.}

La consulta por Internet de Libros españoles en venta, <http://www.mcu.es/bases/spa/isbn/isbn.html>, nos permite localizar cuáles son los documentos editados en formato electrónico, ya que es posible restringir la consulta del campo «Clase de registro» a la opción «Edición electrónica», ${ }^{47}$ y también se pueden realizar consultas por tipo de soporte (cederrón, DVD, etc.).

Ahora bien, utilizar el ISBN implica asumir las carencias e imprecisiones ya puestas de manifesto por los bibliógrafos y que derivan del mismo procedimento que se utiliza para recoger los datos. Como es bien sabido, los datos descriptivos son facilitados por los editores antes de que los libros estén terminados, con lo cual hay elementos que pueden variar y otros que son desconocidos (en el caso del libro impreso, las páginas, por ejemplo). También hay que considerar que normalmente quien tramita las peticiones no es personal experimentado en descripción de documentos (no es una tarea trivial la de tener que determinar quién es el autor, o la materia de una monografía). Estos problemas quizá son más acentuados en el caso de documentos electrónicos: encontramos datos incompletos, informaciones inexactas, también constan discos que ya han pedido el número de registro pero que aún no se han publicado o que nunca se publicarán. Finalmente, no tenemos ninguna garantía, a diferencia de lo que pasa con los documentos impresos, de que consten todos los títulos que se encuentran efectiva-

\footnotetext{
${ }^{47}$ No hay que olvidar que bajo este término, además de las obras en disco óptico, también se incluyen documentos editados en disquete.
} 
mente a la venta, ${ }^{48}$ aunque hay que suponer que a medio plazo esto ya no será así, y su fiabilidad aumentará.

\subsection{LA EDICIÓN ÓPTICA EN EL MUNDO}

En la Feria del Libro de Fránkfort de 1985 se dio a conocer uno de los primeros productos en cederrón. La Biblioteca Británica, en colaboración con BRS y Philips, presentó un disco compacto que contenía 500.000 referencias de su base de datos Blaise. A partir de este momento, el número de títulos de discos ópticos publicados no ha cesado de crecer, y sigue en constante aumento, como puede comprobarse si se observa la tabla 6.4. La última edición del directorio New media titles contiene más de 30.000 títulos en soporte óptico, entre los que no se incluyen las ediciones internas, que cada vez son más numerosas. Como sucede con todos los directorios, la cifra que se ofrece queda muy superada por la oferta real que puede encontrarse en el mercado.

Tabla 6.4. Producción mundial de títulos en disco óptico

\begin{tabular}{rr} 
Año & Títulos \\
1987 & 48 \\
1988 & 189 \\
1989 & 390 \\
1990 & 817 \\
1991 & 1.522 \\
1992 & 2.212 \\
1993 & 3.597 \\
1994 & 5.379 \\
1995 & 9.691 \\
1996 & 17.000 \\
1997 & 19.000 \\
1998 & 28.000 \\
1999 & 31.048 \\
\hline
\end{tabular}

[Fuente: TFPL y New Media Titles]

${ }^{48}$ En un estudio realizado recientemente sobre la edición óptica en Cataluña (Abadal, 1998) se elaboró una relación bibliográfica de 317 títulos, de los cuales tan sólo 136 (un 43 \% del total) aparecían en el IsBN. 
En la edición de discos ópticos conviven productos especializados, como pueden ser muchas de las ediciones de bases de datos o bibliografías especializadas que no sobrepasan unos pocos centenares de ejemplares de tirada, junto con títulos dirigidos al gran público, como algunas enciclopedias que han llegado a vender miles y miles de copias en diversos idiomas.

En los inicios de la edición óptica tuvieron un papel muy destacado empresas que, curiosamente, no procedían del sector editorial. Si se analizan quiénes son los editores de los primeros títulos se pueden encontrar empresas del sector informático (sería el caso de Microsoft, en el ámbito internacional, o Micronet, en España, ambas con un catálogo notable de títulos dentro del mercado al que concurren), de la electrónica de consumo (Philips, Sony, etc.), o del audiovisual, y no es sino hasta pasados unos cuantos años (a principios de la década de 1990) cuando las editoriales tradicionales irrumpen con fuerza en el sector y se hacen con la iniciativa. Actualmente la composición de los principales editores se asemeja más a lo que es el sector de la edición impresa.

En lo que se refiere a la distribución geográfica de los títulos (v. tabla 6.5), hay que destacar a Estados Unidos y Canadá, que disponen de una producción que representa un $60 \%$ del total y que ha ido experimentando un progresivo y leve descenso en el curso de los años. ${ }^{49}$ Por otro lado, la presencia europea en este sector se ha mantenido en torno al $30 \%$ del total mundial, haciendo un salto en 1995 hasta casi el $40 \%$. Estas dos áreas geográficas concentran la práctica totalidad de los títulos editados. La tercera zona, a mucha distancia, sería Japón (incluido en la tabla dentro de Asia). África y Oriente Medio tendrían una presencia próxima a cero, y por tanto, ya no los hemos incluido en la tabla.

Tabla 6.5. Distribución de títulos de cederrón por áreas geográficas (1990-1995)

\begin{tabular}{lrrrrrr}
\hline Área geográfica & 1990 & 1991 & 1992 & 1993 & 1994 & 1995 \\
\hline América & $62 \%$ & $63 \%$ & $62 \%$ & $63 \%$ & $61 \%$ & $56 \%$ \\
\hline Europa & $29 \%$ & $32 \%$ & $32 \%$ & $28 \%$ & $29 \%$ & $38 \%$ \\
\hline Asia & $5 \%$ & $4 \%$ & $7 \%$ & $6 \%$ & $6 \%$ & $5 \%$ \\
\hline Australia-Oceanía & $4 \%$ & $3 \%$ & $3 \%$ & $2 \%$ & $2 \%$ & $1 \%$ \\
\hline
\end{tabular}

[Fuente: TFPL]

\footnotetext{
${ }^{49}$ Aunque en la tabla consten los países latinoamericanos, su contribución es prácticamente testimonial.
} 


\subsection{SITUACIÓN EN ESPAÑA}

El mercado de la edición óptica en España se encuentra en una fase muy dinámica, con una oferta de títulos cada vez más amplia, lo cual hace difícil controlar de forma exhaustiva las novedades que van apareciendo. Pese a que existieron diversas fuentes para conocer la oferta, ${ }^{50}$ actualmente sólo se puede recorrer al catálogo ISBN, aunque, como ya se ha comentado (v.6.2), presenta algunas lagunas.

Al Diccionario Marín de Medicina le corresponde el mérito de haber sido el primer producto estatal (1986), y uno de los primeros de Europa en publicarse, aunque esto no le ahorró constituir un auténtico fracaso comercial. Para Micronet, una de las empresas del sector, el semi-fracaso de estos primeros productos se debía, por un lado, al bajo número de lectores cederrón instalados entonces en España y, por otro, al mismo carácter de los títulos publicados, que no tenían las características propias de un catalizador de mercado. Con el descenso continuado de los precios de los lectores y su considerable difusión y utilización, han ido apareciendo nuevos productos con mayor penetración (p. e., en el campo de la legislación, o los dirigidos al gran público), que se han ido abriendo paso en el mercado.

Hasta 1994 los principales editores españoles de cederrón (Micronet, en primer lugar y, a continuación, La Ley, BSI Multimedia, entre otros) no procedían del sector editorial, sino que, en la mayoría de los casos, se habían incorporado a esta nueva área a partir del sector informático. El panorama de la edición española se complementaba, como muy bien apuntan Pedro Hípola y Félix Moya (Hípola, 1993), con una notable fragmentación del sector, en el que participaban muchos pequeños editores que colocaban en el mercado un gran número de títulos a unos precios cada vez más competitivos.

A partir de este momento, no obstante, las grandes editoriales tradicionales españolas empezaron a desarrollar sus primeros productos. Anaya Multimedia fue una de las pioneras estrenándose con libros interactivos de la colección extranjera La aventura del conocimiento. Zeta Multimedia fue otra de las primeras: llegó a un acuerdo con la editorial Dorling Kindersley (Gran Bretaña) para publicar en español diversos títulos de su catálogo. Planeta también ha realizado notables

\footnotetext{
${ }^{50}$ Hasta 1997 el directorio Fuinca (v. nota 32) y la Guía CD-ROM (v. nota 53) incluían la lista de títulos editados en España.
} 
inversiones para desarrollar y promocionar un amplio abanico de títulos (una historia del arte español multimedia en CD-I, enciclopedias generales, enciclopedias temáticas, atlas, etc.).

Panorámica de la edición española es una memoria anual que publica la Dirección General del Libro, Archivos y Bibliotecas que ofrece estadísticas sobre el sector del libro en España a partir del análisis de la base de datos del ISBN. Este estudio dispone, desde 1994, de un epígrafe que analiza la edición electrónica y que incluye los títulos publicados en disco óptico (cederrón, CD-I, DVD, etc.) y también en disquete. En diferentes tablas se describe cuál ha sido la evolución cuantitativa del sector, el tipo de editor, los principales editores, la edición por comunidades autónomas, y la edición por subsectores temáticos. A partir de aquí se puede tener una visión general de cuál es la situación del sector, aunque los datos de los que parte no son del todo fiables ni, por ahora, exhaustivos, como se ha comentado anteriormente.

Los últimos datos publicados hasta el momento corresponden a 1998 (Panorámica, 1999) y permiten conocer, además del número de ISBN asignado, el sistema de distribución, ya sea cederrón, DVD o disquete. Estos datos han sido complementados con la consulta a la base de datos del ISBN (en Internet y en disco óptico) para conocer las cifras correspondientes a 1999 y el número de títulos acumulado del 2000.

Tabla 6.6. Publicación de títulos en soporte digital en España

\begin{tabular}{lccccc}
\hline Año & ISBN & Acumulado & Disco óptico & Disquetes & DVD \\
\hline 1994 & 220 & & 97 & 123 & \\
\hline 1995 & 525 & 745 & 300 & 201 & \\
\hline 1996 & 749 & 1.494 & 598 & 120 & 101 \\
\hline 1997 & 809 & 2.225 & 580 & 150 & 51 \\
\hline 1998 & 1.513 & 2.395 & 1.290 & 30 & \\
\hline 1999 & 1.030 & 3.427 & 832 & & \\
\hline 2000 & & 4.573 & &
\end{tabular}

[Fuente: ISBN]

Como podemos comprobar a partir del análisis de la tabla 6.6, la oferta de títulos digitales editados en España crece de forma importante desde 1994, y en 
muchos de ellos se puede encontrar un notable grado de profesionalidad, tanto en lo que se refiere a la presentación como a los contenidos. Algunas de las principales áreas de edición son las obras de consulta (enciclopedias generales y temáticas, diccionarios, etc.), el libro didáctico o de conocimientos, el libro infantil de ficción (que empieza a abrirse camino), la legislación (con una presencia muy notable en España desde los inicios de la edición óptica), la prensa, las bibliografías, etc. Las editoriales que disponen de un catálogo de obras más importante son: Anaya, Zeta, ${ }^{51}$ Planeta, Micronet, Aranzadi, Enciclopèdia Catalana, etc.

\subsection{PERSPECTIVAS}

Se hace difícil resumir de forma general cuál ha sido la evolución de las ventas y la implantación de los discos ópticos. Todo depende del mercado al cual hagamos referencia. Si hablamos del mercado profesional podemos afirmar que los discos ópticos han experimentado un crecimiento lento, pero sostenido. Si, por el contrario, nos centramos exclusivamente en el mercado doméstico, se puede comprobar cómo este crecimiento ha empezado más tarde, pero de forma mucha más rápida. A pesar de todo, la edición óptica no ha obtenido, ni por asomo, el éxito rotundo del CD-A, que se consolidó muy rápidamente como el número uno entre el gran público.

En el apartado anterior se han descrito las líneas generales de un sector que hace pocos años que ha empezado a despuntar, y que está en proceso de perfilar su público y de configurar una oferta de títulos. Para poder conseguir una posición aún más relevante como medio de distribución de productos culturales hará falta haber superado diversos inconvenientes, pero también tendrán que tenerse presentes toda una serie de ventajas que plantea la edición digital. Sobre todo ello, y sobre las perspectivas de futuro, vamos a realizar algunos comentarios.

\subsubsection{Amenazas}

A continuación se señalan algunos de los problemas que constituyen hoy por hoy una traba para el crecimiento del sector:

\footnotetext{
${ }^{51}$ Estas dos editoriales son las que han traducido más obras extranjeras.
} 
- Instalación y consulta de los discos.

Existe un conjunto de problemas de tipo técnico relacionados con las pre-instalaciones (la gran mayoría de los títulos necesitan instalar una parte de información en el disco duro del microordenador), la utilización de diversas interfaces y sistemas de consulta (p. e., todas las enciclopedias tienen diferentes programas de recuperación de la información y esto es extensible a todos los tipos de documento), o los requerimentos de configuración (algunas obras necesitan una determinada resolución y número de colores a veces incompatibles con otras), que constituyen un enojoso problema.

- Precios poco competitivos, comparados con la edición impresa.

Editar un disco óptico tiene unos costes muy elevados que se pueden situar fácilmente en unas cuantas decenas de millones de pesetas. Los conceptos incluidos en los gastos de desarrollo de un título se pueden parecer más a un producto audiovisual que a uno impreso (doblaje, vídeo, música, creación de animación, etc.); por otro lado no se puede olvidar el coste de una buena campaña de márquetin de lanzamiento, ni los gastos de embalaje (funda, carátula, caja de cartón, etc.) y de distribución. Todo esto explica que, al no tratarse de ventas masivas, los precios de los títulos sean más altos que los de las ediciones impresas. Ahora bien, últimamente se han ido produciendo continuados descensos de precios que permiten intuir una mejora progresiva de la competitividad.

- Dificultades en la distribución y la venta al detalle.

En un primer momento las ventas (sobre todo para el gran público) se realizaban por catálogo. La mayoría de empresas de este estilo se concentraban en Gran Bretaña y Estados Unidos, aunque se podían encontrar varias en España (p. e., Silver Disc sería una de las primeras). Las empresas de venta a sectores especializados (p. e., DOC6, en Barcelona o LUA, en Madrid) funcionan desde hace más años. Posteriormente, al aumentar la popularidad de los discos ópticos, ha sido más fácil encontrarlos en puntos de venta al detalle. Uno de los problemas que asaltaban al comprador profesional era dónde dirigirse. ¿A una tienda de informática? $¿$ A una tienda de discos compactos musicales? Los grandes supermercados culturales (tipo FNAC, Crisol o Abacus) han sido los primeros en incorporarlos a sus expositores. Algunas librerías les están siguiendo e incorporan secciones específicas. Poco a poco, pues, los discos ópticos ya habrán encontrado su espacio en la 
cadena del consumo. A pesar de ello, no se trata de un fenómeno generalizado y al consumidor se le hace difícil poder contactar con la oferta.

- Poca información sobre los contenidos.

Si, como decíamos antes, encontrar los títulos constituye un problema, ¿qué no será desconocer lo que se puede comprar? No existen revistas especializadas dirigidas al gran público que presenten y analicen la oferta de documentos electrónicos en disco óptico (el equivalente al Qué leer, ${ }^{52}$ por ejemplo). Guía CD-ROM, ${ }^{53}$ una revista muy interesante que cumplía bien este papel, dejó de publicarse en abril de 1997. Al lector le faltan instrumentos para ayudarlo a escoger entre los títulos existentes. Algunos periódicos disponen de pequeñas secciones semanales donde se recogen informaciones sobre las novedades editoriales, y también algunas librerías realizan un importante papel orientador con los compradores.

- La existencia de un amplio número de aparatos de lectura, pero aún no masivo.

En este punto hay que destacar dos tendencias muy claras. Por un lado, prácticamente todos los ordenadores que se venden actualmente ya incorporan el lector de discos ópticos y, por otro lado, no para de crecer el número de hogares que ya disponen de este equipo. El tipo de lector en muchos casos ya es DVD, porque, como ya se ha dicho, los márgenes comerciales para el vendedor son mayores.

Aparte de todo esto, los editores también se quejan de que el libro digital, al no ser considerado por la Administración pública como un producto editorial, se queda al margen de las ayudas que existen actualmente para fomentar la edición de publicaciones.

\subsubsection{Oportunidades}

Pasemos a mirar ahora la situación desde el otro lado. ¿Cuáles son los puntos fuertes de la edición óptica? ¿Cuáles son los motivos que impulsan a los editores a introducirse en el campo de la edición electrónica?

En primer lugar, los editores han constatado un cierto estancamiento en el mercado tradicional del libro que se produce en los países más desarrollados. Esto va

${ }^{52}$ Qué leer. Año 1, n. ${ }^{\circ} 1$ (1996, junio)-. Barcelona, Comunicación y Publicaciones, 1996-. Mensual.

${ }^{53}$ Guía CD-ROM. N. ${ }^{\circ} 1$ (1994) - n. 28 (1997, abril). Barcelona, Zinco Multimedia, 1994-1997. Mensual. 
relacionado con un cierto descenso en los hábitos de lectura entre la juventud, un público que se siente mucho más atraído por los mensajes audiovisuales que por el texto. La edición digital, con sus posibilidades para ofrecer contenidos multimedia, permite que el editor se ajuste a los hábitos y gustos de los lectores más jóvenes. Podemos relacionar este hecho directamente con la orientación temática de la oferta. Si repasamos alguna lista de obras podremos comprobar rápidamente cómo la mayor parte de los títulos se dirigen claramente al público infantil y juvenil. De hecho, los consumidores actuales de este tipo de obras son prácticamente este segmento de población. Los adultos normalmente compran para regalar, no para su uso.

Por otro lado, la edición electrónica propicia el establecimiento de una relación muy directa con los clientes. Sus productos (en disco óptico y, especialmente, en Internet) generan la necesidad de atender consultas y observaciones de los usuarios. (Así, p. e., los compradores de los Juegotes pueden enviar a sus editores, Barcelona Multimèdia, los resultados que han conseguido para que los tabulen, así como hacerles preguntas y consultas diversas).

Finalmente, los editores de discos ópticos pueden huir de este modo un poco de la dependencia casi exclusiva respecto del papel, una materia prima que podría convertirse en un bien escaso a medio plazo, lo cual implicaría que aumentase todavía más su impacto sobre el precio final del libro.

Un indicador positivo de esta progresiva popularización de los discos ópticos y su ampliación hacia el gran público lo constituye la creación de las primeras ferias internacionales dedicadas exclusivamente al libro electrónico. Los editores han visto la necesidad de separar este tipo de celebraciones de las ferias tradicionales para conectar mejor con los usuarios de la edición digital. Así, por ejemplo, en enero de 1994 se celebró en Cannes el I Salón Internacional del Libro Ilustrado y de las Nuevas Tecnologías (MILIA), en el que se realizaron diversos debates sobre la situación del libro digital y su relación con el papel, y también se presentaron las últimas novedades en el campo de la edición óptica. Desde entonces se ha seguido convocando anualmente de forma ininterrumpida. También se ha de destacar la inclusión de salones propios en las ferias del libro tradicionales.

\subsubsection{Futuro}

Los expertos del sector coinciden en señalar que la edición en disco óptico es un estadio transitorio y que seguramente dentro pocos años la distribución de pu- 
blicaciones electrónicas se realizará básicamente en línea (Internet o cable). Los motivos son claros, ya que el Web dispone de muchas ventajas: facilidad para llegar a muchos usuarios de todo el mundo, sencillez de edición, costes de distribución muy pequeños, facilidad de actualización de los contenidos, etc. Mike Shatzkin $^{54}$ es muy contundente en las recomendaciones que dirige a los editores: ignorar el disco óptico, porque los costes de desarrollo y comercialización son altísimos y muy difíciles de recuperar, y centrarse, en cambio, en Internet. En el informe de Andersen Consulting ${ }^{55}$ van un poco más allá y consideran que, a medio plazo, la difusión digital por cable y satélite será una alternativa o un complemento muy importante a la distribución en línea (a través de las redes de telecomunicaciones). También recomiendan a los editores ópticos que se vayan preparando para este futuro próximo en que el cederrón será superado por la distribución en línea o por la difusión por cable y que sean capaces de trasladar sus productos a la Red. Ahora bien, no podemos olvidar algunos de los principales problemas pendientes de resolver en Internet y que harían referencia a la lentitud del sistema (ya se está experimentando en Internet2, una red preparada para la distribución de contenidos multimedia), y también al establecimiento de pagos que permitan la recuperación de la inversión de los editores, entre otras cosas.

Por ahora, los editores más experimentados en la utilización de las redes son los científico-técnicos, los cuales ya ofrecen la consulta en línea a centenares de publicaciones en serie de mucha calidad (v. 3.3), y que están desarrollando diversos sistemas para poder asegurarse el pago de los derechos de autor. ${ }^{56}$ También disponen de una gran experiencia los editores de prensa de masas, quienes, de momento, distribuyen gratuitamente sus cabeceras. Ahora bien, el resto de productos editoriales aún no están en la Red, y los editores prefieren distribuirlos mediante soporte óptico, a pesar de todos los inconvenientes que éstos puedan tener respecto de la difusión en línea (que es más barata, más rápida, con las máximas posibilidades de actualización, etc.).

\footnotetext{
${ }^{54}$ Mike, Shatzkin: «Las editoriales y las nuevas tecnologías», Delibros. abril 1997, pp. 38-41.

${ }_{55}^{5}$ Strategic developments for the european publishing industry towards the year 2000: executive summary. Andersen Consulting. Bruselas; Luxemburgo, ESCS-EEC-EAEC, 1996. 56 pp. <http://www2.echo.lu/elpub2/en/exengl.pdf>. (Consultado en febrero de 1998.)

${ }^{56}$ El DoI, identificador de objeto digital, en traducción castellana, sería un buen ejemplo. Su función es la de permitir controlar el uso que se hace de la publicación electrónica (las partes que se consultan, se copian o se imprimen, etc.).
} 



\section{ECONOMÍA Y CULTURA EN UN MUNDO GLOBAL}

La reproducibilidad técnica de los documentos ha facilitado su introducción en la dinámica del mercado. Actualmente podemos ir a comprar libros y, justo al lado, encontrar chocolatinas, $o$ ir a escoger cintas de casete y tener que separarlas de los accesorios del automóvil, lo que nos recuerda a cada momento que los documentos no dejan de ser también objetos de consumo como cualquier otro.

Esta vertiente más prosaica y menos poética de los soportes documentales y de su contenido nos permite verlos como productos culturales que se ofrecen para ser vendidos en el mercado, y que han sido producidos o fabricados en serie por empresas e industrias diversas. Como bien indican Bustamante y Zallo (1988), de un tiempo para acá han aparecido una serie de análisis y estudios que han abordado el ámbito de la cultura y de los productos culturales desde el punto de vista económico. Estos teóricos son los que han acuñado el término industrias de la cultura, para hacer referencia, en especial, a los medios de comunicación, a la edición, al audiovisual y a la industria cinematográfica. Fijémonos, sin embargo, en que este sector económico, como cualquier otro, se fundamenta en la difusión masiva de productos culturales registrados sobre un soporte documental, que puede ser un libro (empresas editoriales), un diario (prensa), una película (cine), una cinta de vídeo (televisión, vídeo), o de casete (sector audio).

Como vemos, las industrias de la cultura no pueden rehuir la estructura económica de su entorno sociopolítico y, en este sentido, en una sociedad de libre mercado como la que impera en la mayor parte del mundo, dos son las características que condicionan actualmente la actividad económica: concentración, es decir, la tendencia a reducir el número de agentes económicos que actúan en un sector, y globalización o transnacionalización, a saber, la expansión internacional de los agentes y de sus actividades económicas. 
Ahora bien, a pesar del énfasis que ponemos al referirnos a los productos culturales como objetos de consumo inmersos en la lógica del mercado, no podemos olvidar que también tienen un contenido simbólico, una capacidad para transmitir valores y referentes culturales que, de momento, no tienen ni los yogures, ni las sillas ni los cepillos de dientes. No se puede dejar de lado esta singularidad porque de su existencia, precisamente, se ha derivado una serie de largas discusiones y enconados debates que no se hubieran producido si los productos culturales fueran considerados como cualquier otro objeto de consumo.

\subsection{CONCENTRACIÓN}

La existencia de procesos de concentración empresarial es una tendencia irrefrenable que, en sí misma, no se puede considerar ni buena ni mala, y que los economistas justifican para que las empresas puedan operar con más efectividad y competencia en un sector económico y en el contexto de globalización de mercados en que vivimos. Esta concentración puede adoptar, sobre todo, dos formas. En primer lugar, la integración vertical, término que se utiliza cuando una misma empresa opera en las diversas fases de un mismo producto (en la producción, la distribución y la comercialización), de manera que así puede controlar total o parcialmente la cadena; en segundo lugar, la diversificación horizontal, denominación que se aplica cuando la expansión se orienta hacia la adquisición de empresas que se dedican al mismo tipo de negocio, por ejemplo, una editorial que compra otra u otras empresas editoras, o una cadena radiofónica que adquiere un periódico para constituir un grupo multimedia.

Aunque se trate de una tendencia irrefrenable, hay que controlar la concentración, porque, de otra forma, podría conducir a una situación de monopolio. Imaginemos que en un sector económico sólo operara, sin competencia, una única empresa. Podría hacer pagar lo que quisiera por sus productos, perjudicando a los eventuales consumidores, que se encontrarían indefensos frente su actuación. Con el fin de evitar estos efectos negativos, la mayoría de países dispone de leyes antimonopolio, que limitan hasta cierto punto los procesos de concentración. Actualmente estamos asistiendo al fin del proceso judicial que se está llevando a cabo en Estados Unidos, un país con una legislación antimonopolio muy estricta, contra Microsoft, y que va a provocar la segregación de este gigante del software en diversas empresas (sistemas operativos e Internet, como mínimo). El funda- 
mento legal en el que se ha basado esta sentencia casi sin precedentes no es otro sino el supuesto abuso de la posición de predominio en el mercado de que gozaba Microsoft.

En el ámbito de las industrias de la cultura hay que hilar aún más fino para poder controlar estos procesos. Hay que recordar que se trata de un sector que se utiliza como plataforma para disponer de presencia pública por parte de grupos organizados y así poder influir en las conductas, creencias y opiniones de la sociedad (en especial, los medios de comunicación). Por eso, es muy importante determinar cuál es el grado óptimo de concentración para que no se atente contra el pluralismo y los valores democráticos. ¿Podríamos imaginar un país en el que la mayoría de periódicos, radios o emisoras de televisión perteneciesen a un mismo grupo empresarial? ¿En qué situación quedarían sus ciudadanos? ¿Se podría hablar de libertad de prensa y de opinión? Sobre todas estas cuestiones se ha generado un largo e intenso debate teórico, y continuamente aparecen nuevas disputas prácticas. Sin ir más lejos, se ha criticado mucho el hecho de que Fininvest, empresa propiedad de Silvio Berlusconi, antiguo primer ministro italiano, disponga de la concesión de diversos canales de televisión que, en teoría, se tendrían que hacer la competencia. En España también generó una notable polémica la unión entre las cadenas Ser y Antena 3-Radio, que fue calificada por las emisoras de la competencia (Cope, Onda Cero, etc.) como un atentado contra el pluralismo.

Los defensores de la concentración alegan, por su parte, que con empresas pequeñas no se puede ir a ningún sitio, que sólo con grupos de medianas y grandes dimensiones es posible invertir en el extranjero y afrontar la globalización, ser competitivos, racionalizar recursos, etc., unos razonamientos que también parecen bastante lógicos y sensatos. Por ello es necesario encontrar el punto medio de equilibrio entre las dos tendencias.

La estructura del sector de la información digital también se caracteriza por un alto índice de fusiones y adquisiciones a todos los niveles: producción de bases de datos, distribución y gestión de redes. De esta forma se avanza hacia una mayor concentración de los servicios, que pasan a manos de un menor número de actores. Algunos ejemplos de esta concentración los podemos encontrar en la compra del host suizo Data-Star por parte de Knight-Ridder, el antiguo propietario de Dialog, que luego ha pasado a formar parte de dos grandes corporaciones, Maid y, actualmente, Thomson; así como en las adquisiciones de distribuidores de bases de datos que llevó a cabo el grupo Maxwell (eran BRS y Orbit, en Estados Unidos, y Pergamon, en Gran Bretaña) para constituir Maxwell Online. Esta última cor- 
poración, sin embargo, duró poquísimo, ya que en febrero de 1994 desmembró el grupo vendiendo la cartera de clientes de Pergamon a Data-Star; Orbit, a Questel (Francia), y BRS-Online, a CD-Plus (Estados Unidos), un productor de cederrones. Internet y el mundo de las telecomunicaciones son también un pozo sin fondo de fusiones: AOL compra Netscape y se fusiona con Time-Warner; Terra, el portal español de Telefónica, ha comprado el buscador Lycos.

\subsection{GLOBALIZACIÓN}

La globalización, la expansión internacional de las empresas, anteriormente denominada transnacionalización, es otra tendencia de la actividad empresarial que, normalmente, no provoca excesivas polémicas excepto en aquellos ámbitos que son considerados de interés estratégico (defensa, seguridad, etc.). Las industrias de la cultura también son consideradas, por muchos países, como un sector estratégico que hay que defender de una excesiva transnacionalización, por el hecho de que ésta desemboca en una nueva suerte de colonización cultural de los países invadidos por los productos de las potencias culturales. Esto es especialmente claro en el sector del audiovisual (programación de televisión, cine, audio, etc.), donde existe un absoluto predominio de la oferta norteamericana, y, también, a menor escala, en el ámbito de los servicios de información digital (bases de datos en línea, edición óptica, etc.).

\section{La excepción cultural}

Estos temores y prevenciones han generado una polémica entre los defensores del máximo liberalismo (no hay que poner ninguna limitación a la lógica del mercado) y los proteccionistas (hay que articular medidas legales para controlar la excesiva penetración de productos culturales extranjeros y defender así la cultura propia). Esta polémica estuvo presente en las negociaciones finales del GATT (Ronda Uruguay), ${ }^{57}$ donde se discutió la liberalización del comercio mundial. Francia y Es-

${ }^{57}$ El GATT (General Agreement on Tarifs and Trade, Acuerdo General sobre Aranceles y Comercio) era un organismo intergubernamerntal que pretendía, desde su fundación en 1948, favorecer el libre comercio entre los países reduciendo las trabas arancelarias. La última ronda de negociaciones, Ronda de Uruguay, acabó en diciembre de 1993, después de más de ocho años de conversaciones. El GATT, como tal, se disolvió y dio paso a la Organización Mundial del Comercio (OMC), que tiene por objetivo impulsar medidas para favorecer el comercio mundial. 
tados Unidos oficiaron de líderes de una y otra posturas, y el punto de discusión se centró en la industria audiovisual, sobre la cual los americanos querían que se eliminara cualquier barrera arancelaria o proteccionismo legal, mientras que los franceses defendían justo lo contrario. España y la mayoría de países de la Unión europea (excepto Gran Bretaña) estaban de acuerdo con los franceses en esta cuestión. El origen de la polémica hay que buscarlo, en 1989, cuando se aprobó una directiva europea, conocida popularmente como «Televisión sin fronteras», que recomendaba a los países europeos que reservasen la mayor parte del tiempo de emisión televisiva para producciones europeas. La aprobación de esta directiva fue denunciada dentro del GATT como un antentado contra los principios que regían en este organismo y que habían sido también suscritos por la Unión Europea.

Las conocidas y polémicas cuotas de pantalla que afectan la exhibición cinematográfica en muchos países europeos (es obligado exhibir una determinada proporción de cine europeo en todas las salas) eran el caballo de batalla de los americanos, que lo consideraban una medida proteccionista atentatoria contra los principios de liberalización del comercio mundial, es decir, contra la filosofía de la Ronda Uruguay. El argumento de los franceses se basaba en la especificidad de la industria de la cultura, que no tiene el resto de sectores productivos. La discusión no está cerrada y, de hecho, muchos países europeos mantienen todavía las cláusulas de protección para defenderse de la penetración de productos culturales extranjeros (especialmente norteamericanos). Después de muchas controversias y negociaciones dentro del GATT, se excluyeron temporalmente las «creaciones del espíritu» de las normas vigentes para otras mercancías.

\section{El NOMIC}

De hecho, la polémica no es nueva. Haciendo un poco de historia podemos ver cómo se repiten aquí, con pequeñas variaciones, las discusiones que se sostuvieron a mediados de la década de 1970 en torno a los medios de comunicación. En aquel momento los países del Tercer Mundo intentaron defenderse del monopolio informativo del que gozaban, en su opinión, las agencias de noticias occidentales (en especial las norteamericanas). Los medios de comunicación, con la selección y jerarquización que hacen de las noticias y con la forma de explicarlas, ofrecen sutilmente una determinada visión del mundo en la que predominan los valores occidentales. Los países con pocos recursos para disponer de medios de información 
de alcance supranacional se quejaban de la invasión informativa. La Unesco, entonces dirigida por el senegalés Amadou Mahtar M’Bow, propició la realización de diversos estudios para intentar corregir estos desequilibrios. Era lo que se denominó NOMIC (Nuevo Orden Mundial de la Información y de la Comunicación), una propuesta, presentada dentro del ámbito de la Unesco, que pretendía reducir el colonialismo informativo de los países occidentales y favorecer la difusión de la cultura de los países del Tercer Mundo en los medios de comunicación.

El comunicólogo irlandés Sean Mac Bride fue nombrado por la Unesco en 1977 presidente de una comisión encargada de analizar los problemas de la comunicación en el ámbito internacional. El famoso informe que elaboraron, presentado en Belgrado en 1980, denunciaba un desequilibrio informativo entre norte y sur que podía llegar a afectar la diversidad cultural. Una de sus recomendaciones era la creación de una agencia de noticias internacional independiente gestionada por la Unesco para contrapesar el poder de las grandes agencias comerciales.

Estados Unidos y la mayoría de países occidentales se opusieron frontalmente a lo que consideraban una forma de atentar contra el libre mercado y la libre competencia y, como consecuencia de las discusiones, forzaron la salida de los Estados Unidos de la Unesco (1984), a la que consideraban como un foro de propaganda antioccidental. Posteriormente, Gran Bretaña siguió el mismo camino. La crisis que sufrió este organismo dependiente de las Naciones Unidas fue profunda, y no sólo tuvo repercusiones institucionales, sino también económicas (hay que recordar que Estados Unidos sufragaba una cuarta parte del presupuesto total de la Unesco). El período en que Federico Mayor Zaragoza dirigió la Secretaría General (19872000) tuvo como objetivo prioritario ir cerrando poco a poco la crisis —olvidando el proyecto- y establecer las condiciones para facilitar el retorno de Estados Unidos y Gran Bretaña a la Unesco, aunque finalmente no lo consiguiera.

A pesar de que actualmente el debate sobre el nuevo orden mundial de la comunicación está apagado, la discusión sobre los efectos de la libre circulación de la información o de los productos culturales — como si fueran una mercancía más- vuelve a renacer a menudo y no está, ni mucho menos, resuelta. Sin ir más lejos, el creciente proceso de globalización que está afectando a todos los ámbitos —y no sólo al económico— también está generando un ferviente rechazo en muchos sectores que ven amenazada su singularidad, desde los agricultores del sur de Francia, defensores del camembert y de los productos autóctonos frente al fast-food y los cultivos transgénicos, a los indígenas de América Latina, celosos de sus costumbres y modus vivendi. 


\subsection{LA CUESTIÓN DEL IDIOMA}

Los productos culturales suelen traducirse a múltiples idiomas cuando su difusión masiva permite una rentabilización. El ejemplo más claro son las grandes producciones cinematográficas, o los best-séller editoriales. Descontando estos casos, acostumbran a ser distribuidos en un solo idioma. Analicemos, por ejemplo, la edición científico-técnica, un ámbito que se caracteriza por unas tiradas bajas, dirigidos a un público especializado, y que se tienen que amortizar buscando un público global (toda la comunidad científica mundial). Esto comporta la utilización de lenguas de amplia difusión (es decir, del inglés, el idioma científico por excelencia) para buscar una mayor rentabilidad.

Los productos y servicios de información digital se encuentran en este mismo contexto. Esta tendencia a la homogeneización lingüística afecta especialmente a los productos especializados (las bases de datos en línea, los discos ópticos y los servicios de información en Internet), que son productos dirigidos a mercados mundiales y que, por lo tanto, se trasmiten en idiomas de amplia comprensión (especialmente, y como es bien sabido, el inglés), y no tanto a los productos orientados al mercado doméstico. En este caso, las informaciones que suministran se presentan en el idioma o idiomas de uso corriente en los diferentes países en los cuales se distribuyen, y no están afectados por esta inclinación en torno a la difusión exclusiva en inglés. ${ }^{58}$

Harry Collier, especialista británico en el campo de la información electrónica, se muestra muy contundente respecto a los problemas relacionados con la lengua. Este autor considera que una de las razones de la supremacía de Estados Unidos en la industria de las bases de datos reside en su unidad, no sólo política, sino, especialmente, lingüística. Europa, por su parte, ve disminuida su capacidad de competencia a causa de su disgregación política y lingüística. Esta opinión la podríamos poner como ejemplo de lo que piensa un sector amplio de teóricos y políticos.

Collier no hace otra cosa que constatar cuáles son las exigencias del mercado actual. La industria de la información digital, como cualquier otro sector económico, se debe fundamentalmente a un mercado, desarrollado únicamente en los países occidentales y caracterizado por el predominio casi absoluto de la lengua inglesa. A su entender «no existe evidencia, teórica o real, sobre la existencia de

\footnotetext{
${ }^{58}$ Algunos de los productos dirigidos al gran público disponen de versiones en distintos idiomas. Sería el caso, por ejemplo, de diversos títulos de Microsoft (la enciclopedia Encarta, los atlas, etc.) o de otras grandes editoriales digitales.
} 
un mercado nacional viable en Europa, ni sobre la demanda de bases de datos en un idioma que no sea ampliamente utilizado o extendido» (Collier, 1985, 99). Esta afirmación no la presenta a modo de hipótesis, sino que constituye una simple descripción de lo que es la realidad. Las características y tipos de usuarios de las bases de datos en línea impiden la rentabilidad si sólo se distribuyen en un país o Estado, o si se utiliza un idioma que no sea mayoritario.

Las tablas que vienen a continuación ilustran con mucha claridad esta cuestión. En 1988 casi el 90 \% de los títulos publicados en cederrón se encontraban en inglés, y la presencia del resto de los idiomas era prácticamente insignificante. Con los años, el inglés ha bajado hasta un $70 \%$ mientras que el resto de lenguas ha ido aumentando lentamente. El francés, con una notable área de influencia, o el alemán, con un peso importante en la producción científica, por ejemplo, sólo se sitúan en 1995 alrededor del 10 \% de la oferta de títulos. El castellano también tiene unos porcentajes muy bajos (sobre el $6 \%$ ), aunque es una de las lenguas más habladas en el mundo.

Tabla 7.1. Distribución de los discos ópticos por lenguas ${ }^{59}$

\begin{tabular}{lcccc}
\hline Idioma & 1988 & 1992 & 1994 & 1995 \\
\hline Inglés & $88 \%$ & $62,5 \%$ & $72,9 \%$ & $68 \%$ \\
\hline Alemán & $2,5 \%$ & $8,2 \%$ & $8,3 \%$ & $13 \%$ \\
\hline Francés & $2,5 \%$ & $9,5 \%$ & $8,2 \%$ & $8 \%$ \\
\hline Español & & $4,7 \%$ & $6 \%$ & $6 \%$ \\
\hline Japonés & $5,8 \%$ & $5,7 \%$ & $6 \%$ \\
\hline Italiano & $4,8 \%$ & $4,6 \%$ & $5 \%$ \\
\hline$\ldots$ /... & & & \\
\hline
\end{tabular}

[Fuente: TFPL]

Si analizamos el caso de las bases de datos en línea (v. la tabla 7.2), encontramos unas cifras bastante similares, pero con unos desequilibrios todavía más acusados. Fijémonos, si no, en el caso del castellano, que dispone de un $6 \%$ de los títulos en disco óptico, pero que no supera el $2 \%$ en lo que respecta a las bases de datos en línea. Lo mismo se puede decir del alemán o del francés, que también disponen de cuotas de producción inferiores a las mostradas en la tabla anterior.

\footnotetext{
${ }^{59}$ En el caso del cederrón no se puede olvidar que una buena parte de los títulos son multilingües. Esto hace que haya discos que contienen más de un idioma y que los porcentajes sumen más de cien.
} 
Actualmente el directorio Gale recoge la descripción de bases de datos registradas en 38 idiomas diferentes (incluidos catalán, vasco y gallego), pero en unas proporciones muy bajas, como podemos ver en la tabla siguiente.

Tabla 7.2. El idioma de las bases de datos en línea

\begin{tabular}{lccc}
\hline Idioma & 1988 & 1996 & 2000 \\
\hline Inglés & $3.171(84,7 \%)$ & $4.626(79,9 \%)$ & $4.728(78 \%)$ \\
\hline Francés & $205(5,5 \%)$ & $366(6,3 \%)$ & $332(5,5 \%)$ \\
\hline Alemán & $135(3,7 \%)$ & $325(5,5 \%)$ & $428(7,13 \%)$ \\
\hline Español & $47(1,25 \%)$ & $137(2,3 \%)$ & $118(2 \%)$ \\
\hline Otros & $178(4,68 \%)$ & $338(5,9 \%)$ & - \\
\hline
\end{tabular}

[Fuente: Gale directory of databases]

La utilización de lenguas en la Red ofrece un cuadro bastante similar a los dos anteriores. Así pues, en Internet se constata también esta tendencia hacia la homogeneización cultural, que reduce a la mayoría de los idiomas a un uso cada vez más local y doméstico, e impone de hecho el inglés como la lengua propia del ciberespacio o de las autopistas de la información. Consecuentemente, los proyectos editoriales planteados en lengua inglesa disponen de un amplio mercado, mientras que el resto quedan confinadas a su territorio nacional. Si esto ya es un problema para lenguas con amplias bases demográficas, como el castellano o el francés, parece un problema durísimo para idiomas con un número reducido de hablantes, como pueden ser el sueco, el holandés o el catalán.

Tabla 7.3. El idioma en Internet (distribución de lenguas por número de páginas) ${ }^{60}$

\begin{tabular}{lc|lc}
\hline Idioma & Porcentaje & Idioma & Porcentaje \\
\hline Inglés & 68,3 & Ruso & 1,88 \\
\hline Japonés & 5,85 & $\ldots / \ldots$ & \\
\hline Alemán & 5,77 & Portugués & 1,37 \\
\hline Chino & 3,97 & Catalán & 0,14 \\
\hline Francés & 2,86 & Euskera & 0,01 \\
\hline Español & 2,42 & & \\
\hline
\end{tabular}

[Fuente: Vilaweb, citado por AUI]

${ }^{60} \mathrm{El}$ número total de páginas que se consideran en la tabla es de unos 313 millones. 
Ahora bien, se hace un poco difícil claudicar frente a estas crudas constataciones y renunciar a la defensa de un patrimonio cultural y lingüístico diverso. Por fortuna no son únicamente las leyes del mercado las que imperan $\mathrm{y}$, aunque muchos se quejen del proteccionismo, se hace necesario un cierto grado de intervención de los poderes públicos para apoyar la diversidad, buscando soluciones imaginativas que conjuguen universalismo con particularidad.

Quizá el multilingüismo, que empieza a ser cada día más habitual en bases de datos, productos en disco óptico y, en especial, en el Web, sea una solución intermedia que ayude a superar la tensión entre universalidad y particularidad, la forma de conjugar los dos polos de la alternativa: aspirar a un amplio mercado de distribución sin renunciar a la utilización del propio idioma. Evidentemente, esta opción hace aumentar los costes de producción, aunque los continuos avances tecnológicos, en campos como, por ejemplo, la traducción automática, ${ }^{61}$ son buenos recursos para contribuir a la presencia de las lenguas minoritarias en el mercado de la información digital. La Unión Europea dispuso del programa MLIS (Multilingual Information Society), que tenía por objetivo favorecer e impulsar el multilingüismo en la sociedad de la información.

Como cualquier otra industria cultural, el sector de la información digital también está afectado por los procesos de concentración y globalización y por sus efectos. Sobre la forma de actuar no hay, como es de prever, unanimidad. Diversos autores defienden la intervención de la administración con el fin de preservar la identidad cultural o lingüística:

«Las minorías lingüísticas resultan especialmente vulnerables en un mundo en el que la comunicación se efectúa cada vez más en inglés. Es, pues, extremadamente importante para los países no anglófonos o biblingües dotarse de políticas culturales sólidas» (Lynch, 1997, 316).

Otros, sin embargo, han criticado precisamente esto, la excesiva presencia pública y las ayudas a fondo perdido que, en muchos casos, se ofrecen a productores y distribuidores de información digital (el ejemplo más claro podría ser la promoción, por parte de la Administración pública francesa, del videotexto).

«No existe evidencia, teórica o real, sobre la existencia de un mercado nacional viable en Europa, ni sobre la demanda de bases de datos en un idioma que no sea ampliamente utilizado o extendido» (Collier, 1985,99).

${ }^{61}$ Podríamos citar el caso de El Periódico de Catalunya, un diario publicado en español desde sus inicios y que a partir de 1998 saca otra edición en catalán utilizando un programa de traducción automática (junto con un buen equipo de correctores). 
Lo que está claro es que hay que encontrar el justo equilibrio entre lo global y lo local, entre la homogeneidad lingüística y cultural que permite un diálogo entre todos y la heterogeneidad que singulariza los individuos y las comunidades. Sólo de esta forma se podrá preservar la riqueza cultural y lingüística que existe en la actualidad y se dispondrá de plataformas universales de comunicación. 



\section{LAS PUBLICACIONES DEL FUTURO Y EL FUTURO DE LAS PUBLICACIONES}

La discusión sobre las publicaciones del futuro mezcla, sin demasiados miramientos, aspectos diversos que se funden y confunden entre sí. En primer lugar, la polémica sobre el soporte documental: ¿sustituirá la publicación digital a la publicación impresa sobre papel? En segundo lugar, la discusión sobre el modelo de publicación: ¿`seguiremos teniendo libros, periódicos y revistas estructurados y organizados de la misma manera que los actuales o se podrá crear un nuevo tipo de publicación? Finalmente, el tipo de información: ¿nos encontramos ante la desaparición de la cultura textual en beneficio de una cultura centrada casi exclusivamente en la imagen?

Como muy bien detalla Lluís Codina (1996), muchos de los críticos de la información digital ponen en un mismo saco la primera y la tercera de las polémicas como si se tratara de la misma cosa. Para ellos un triunfo de la publicación digital significa, a la vez, la desaparición de la información textual. Esto no es así. Por un lado, es plausible pensar en un futuro con una presencia escasa o mínima de los documentos sobre papel. Por otro lado, está bastante claro que el texto seguirá siendo la forma básica de transmisión de cultura y conocimiento. En los siguientes apartados vamos a analizar de forma separada las tres cuestiones planteadas.

\section{1. ¿DOCUMENTO IMPRESO O DIGITAL? LA DISCUSIÓN SOBRE EL SOPORTE}

El futuro de la publicación tradicional sobre papel es un tema recurrente que siempre sale a la luz cuando se habla de los nuevos medios digitales. Para analizar la cuestión con desasosiego, vamos a realizar una valoración general de las 
ventajas e inconvenientes del documento digital con relación al documento impreso. ${ }^{62}$ Con tal propósito, elaboraremos una tabla evaluativa ${ }^{63}$ para, a continuación, repasar aquellos aspectos positivos de la publicación digital, aquellas prestaciones que ofrece a un nivel muy superior al documento impreso.

Tabla 8.1. Evaluación de la publicación digital

Puntos fuertes

- Recuperación de información.

- Interactividad.

- Información multimedia.

- Actualización.

- Densidad.

- Accesibilidad.

\section{Puntos débiles}

- Mediatización (se necesita un equipo intermediario para acceder al contenido).

- Ergonomía de lectura.

- Diversos sistemas de consulta.

Una de las grandes ventajas de la publicación digital consiste en permitir un acceso selectivo de la información. Gracias a la existencia de un sistema de recuperación de la información (lenguaje de interrogación, enlaces hipertextuales o menús) el usuario se puede mover dentro de grandes volúmenes de documentos almacenados y seleccionar sólo aquella pequeña parte que, en un momento determinado, le puede interesar. La localización de información en un libro impreso se basa en los índices analíticos, que son de costosa elaboración, disponen de entradas limitadas, no permiten la combinación de términos, ni tampoco la formulación de preguntas complejas. Cualquier parte de la publicación digital, en cambio, puede ser recuperable. Este interés es especialmente manifiesto en el caso de obras generales (enciclopedias, diccionarios, etc.) y, sobre todo, en prensa escrita. Tiene, también, posibilidades de consulta hipertextual. El papel, en cambio, está pensado básicamente para la lectura secuencial, aunque pueda haber prestigiosos intentos de obviarlo, com podría ser el conocido caso de Rayuela.

La interactividad puede entenderse como la posibilidad de establecer un «diálogo», una relación entre el usuario y el sistema de información de tal manera que cada uno de ellos responda a los estímulos del otro. Las posibilidades de interac-

${ }^{62}$ Lluís Codina, en su texto sobre el libro digital (1996), entra a valorar con un cierto detalle cuáles son los puntos fuertes y débiles de la publicación electrónica.

${ }^{63}$ Si miramos la tabla desde un punto de vista meramente cuantitativo, veremos que los aspectos positivos de la publicación digital superan en número a sus debilidades, aunque éstas constituyen escollos difíciles de superar, al menos a corto plazo. 
ción del usuario con la publicación son diversas y van desde la información que envía el sistema en respuesta a consultas formuladas por el usuario hasta procesos mucho más complejos que permiten que el usuario se convierta en protagonista de una historia singular (sería el caso de los libros interactivos en los que el lector es el protagonista de una historia que se va adaptando a las decisiones que va tomando). ${ }^{64}$

Puede decirse que la posibilidad de integrar texto, sonido e imagen en un mismo documento se forja con la publicación digital. Con los sistemas tradicionales de impresión esto no era posible. El multimedia nace, pues, en el entorno digital.

También se ha de hacer referencia a la actualización, a la facilidad con la que los contenidos pueden renovarse y ponerse al día de forma constante y permanente, si fuera necesario; a la densidad (la cantidad de información por unidad de volumen es infinitamente superior utilizando un soporte digital que sobre papel), y a la accesibilidad a los contenidos (la Red nos permite encontrar y consultar títulos de todas partes del mundo de forma inmediata). ${ }^{65}$

Pasemos ahora a comentar el bloque de los problemas. Una de las principales bazas del libro impreso reside en el hecho de que el acceso a la información es prácticamente directo: sólo es necesario abrirlo e irlo hojeando para enterarse de su contenido. Además, se destaca su transportabilidad, la facilidad de llevarlo y leerlo en cualquier parte. Las publicaciones digitales, en cambio, están mediatizadas, requieren el concurso de diversos instrumentos que se han de conectar a la red eléctrica o disponer de energía acumulada. Estos aparatos actúan de intermediarios entre el lector y la información y, sin su presencia, ésta deviene indescifrable. ¿Quién puede leer un disquete o un cederrón sin un ordenador o un lector de discos ópticos enchufados a la corriente o con las baterías bien cargadas? La transportabilidad, en este caso, también es más problemática, porque no sólo nos hemos de llevar con nosotros la publicación digital, sino también el aparato de lectura.

\footnotetext{
${ }^{64}$ Toni Matas, en un excelente texto presentado en las jornadas sobre «La lectura multimedia y los nuevos lectores» (Matas, 1996), presenta unas interesantes reflexiones sobre los distintos grados de interactividad que puede contener un producto digital: interacción inmediata, que se produce cuando una acción del usuario tiene como consecuencia una reacción inmediata de la aplicación; interacción diferida, que se produce cuando una acción realizada ahora por el usuario tendrá consecuencias posteriores, y la interacción desestructurada, presente en algunos juegos de aventuras que no explicitan sus reglas de funcionamiento.

${ }^{65}$ Lluís Codina también alude a la virtualidad (una propiedad que no se ha incluido en la tabla), a la facilidad de la publicación digital para ser reproducida, transmitida y almacenada que supera, con mucho, cualquier forma de reproducción, almacenamiento o transmisión de documentos analógicos. Esta característica, precisamente, no es vista con excesivo agrado por parte de los editores.
} 
Como consecuencia de la aparición de elementos intermediarios, la interacción entre el lector y el documento también pasa a ser diferente. El hábito de la lectu$\mathrm{ra}$, aunque sigue siendo necesario, pierde alguna de sus características anteriores. No es lo mismo leer o pasar las páginas tradicionales que hacer lo mismo a través de un monitor de ordenador. El grado de definición y contraste que permite la tinta impresa sobre una hoja en blanco no está todavía presente en ningún sistema electrónico de visualización. Por otro lado, un reciente estudio ha indicado que perdemos casi un $40 \%$ de la información que aparece en pantalla a causa de la atracción que el parpadeo ejerce sobre nuestros ojos, y que la lectura es más lenta (entre un 25 y un $30 \%$ ) sobre pantalla que sobre papel. Todo esto explica que podamos estar cómodos y relajados un montón de horas leyendo libros y que, probablemente, nos cansemos más rápidamente de hacer lo mismo sentados frente a un monitor.

Finalmente, también hay que recordar que es necesario utilizar y conocer distintos sistemas de consulta. Aunque se parte de unos patrones comunes, se constata la existencia de una notable diversidad de interfaces de consulta y de programas de recuperación de la información. Esto obliga al usuario a aprender distintos sistemas si quiere consultar una variedad de títulos. Este factor es más acusado en el caso de la edición óptica que en Internet.

Como decíamos al principio, aunque las ventajas de la publicación digital son muchas, los puntos débiles pesan aún bastante y constituyen una traba difícil de superar. Ahora bien, si hemos de hacer caso a los actuales gurús, con Negroponte al frente, no es nada descabellado pensar en la sustitución del papel. ¿Cuándo se producirá? Pues cuando la publicación digital supere los puntos fuertes del papel como soporte de distribución de información. Como muy bien dice Codina (1996), esto pasará cuando, para poder superar los problemas de accesibilidad y mediatización, se reduzcan las dimensiones de los ordenadores hasta conseguir un lector de bolsillo, y se aumente su autonomía al disponer de baterías de larga duración para depender lo menos posible de la electricidad. Y, en segundo lugar, y con el fin de mejorar ergonómicamente, cuando los monitores ofrezcan una calidad de visualización idéntica a la de la tinta sobre el papel. Esto lo conseguirán, entre otras formas, mejorando el contraste de la visualización, para lo cual los monitores tendrán que aumentar su definición, y evitando el parpadeo, lo que se podrá obtener aumentando la velocidad del refresco y evitando que la renovación de la imagen en pantalla se perciba como un parpadeo.

El futuro libro electrónico que describió Jerome S. Rubin, presidente de los edi- 
tores norteamericanos, recogía estas dos exigencias. Tendrá un aspecto externo parecido al libro impreso tradicional (portátil) y dispondrá de un sistema de visualización muy avanzado (las páginas se iluminarán con un sistema parecido al de los monitores de ordenador), y, además, los títulos serán recargables (se podrá ir variando la información cambiando unos chips de memoria que se introducirán a los tomos del libro). Actualmente ya se han mostrado diversos prototipos y existen varias iniciativas que están a punto de comercializarse. ${ }^{66}$

\subsection{EL LENGUAJE DE LA PUBLICACIÓN DIGITAL}

Otra cuestión hace referencia al tipo de publicación. ¿Los libros, revistas y periódicos serán como los que conocemos ahora? O, por el contrario, ¿se podrá diseñar un nuevo modelo de publicación, una nueva forma de presentación y consulta de la información que tenga poco que ver con las experiencias previas?

La publicación digital y, en especial, la de carácter multimedia bebe directamente de las publicaciones tradicionales escritas (el libro en cualquiera de sus formas), de las audiovisuales (cine, vídeo, televisión) y, en menor medida, de las técnicas de desarrollo de juegos por ordenador. Así pues, encontramos títulos que tienen por referente una obra impresa anteriormente (p. e., la prensa diaria, algunos diccionarios electrónicos, etc.) y otras que, en cambio, tienen su referente en el lenguaje del cine o de la televisión. En medio podemos encontrar todas las mezclas imaginables, así como los intentos por encontrar un lenguaje propio que singularice la publicación digital multimedia respecto de lo que es el libro o el producto audiovisual tradicionales.

Lancaster (1995) estableció diversas fases que mostrarían la evolución en el campo de la edición. En la página siguiente hacemos una adaptación y las presentamos de forma simplificada en la tabla 8.2.

En el mercado coexisten todavía títulos y servicios editoriales de todas estas fases. Así pues, podemos ver la evolución de la publicación digital como el camino hacia el encuentro de una nueva forma de expresión, como un ejercicio de elaboración de un lenguaje propio que la singularice y la distinga del libro y del audiovisual. No es suficiente, entonces, disponer de un nuevo soporte para distribuir las publicaciones. Debemos aprovechar las posibilidades que brin-

\footnotetext{
${ }^{66}$ Se trata de Soft-Book y Rocket-e-Book, que ya han sido descritos en el apartado 3.2.
} 
Tabla 8.2. Las fases evolutivas de la edición digital

\section{Fase Descripción}

1. En un primer momento, se utilizan los recursos informáticos como un método asistido para generar publicaciones convencionales en papel.

2. Distribución de documentos de forma electrónica, pero con una correspondencia directa a publicaciones impresas previamente sobre papel.

3. Utilización de nuevos recursos aplicados a publicaciones tradicionales. Se crean publicaciones que aprovechan textos y gráficos ya existentes y los presentan de forma innovadora con nuevos sistemas de consulta, interfaces interactivas, etc.

4. Nuevo concepto de publicación. Se generan publicaciones totalmente nuevas, diseñadas desde el primer momento con los nuevos recursos.

\section{Ejemplos}

Boletines de resúmenes, cualquier libro hecho con autoedición, etc.

Revistas académicas especializadas, documentos de información corporativa, etc.

Muchos títulos editados en soporte óptico o en Internet, p. e., prensa, libro infantil, libro de conocimientos, enciclopedias, diccionarios, etc. Todos ellos incorporan diversas prestaciones que no aparecían en las versiones impresas.

De esta fase sólo se pueden citar pequeñas experiencias porque no se trata, ni mucho menos, de una situación generalizada. Sería el caso de algunos títulos multimedia de carácter experimental (de momento distribuidos en disco óptico) y de algunos medios digitales presentes en Internet.

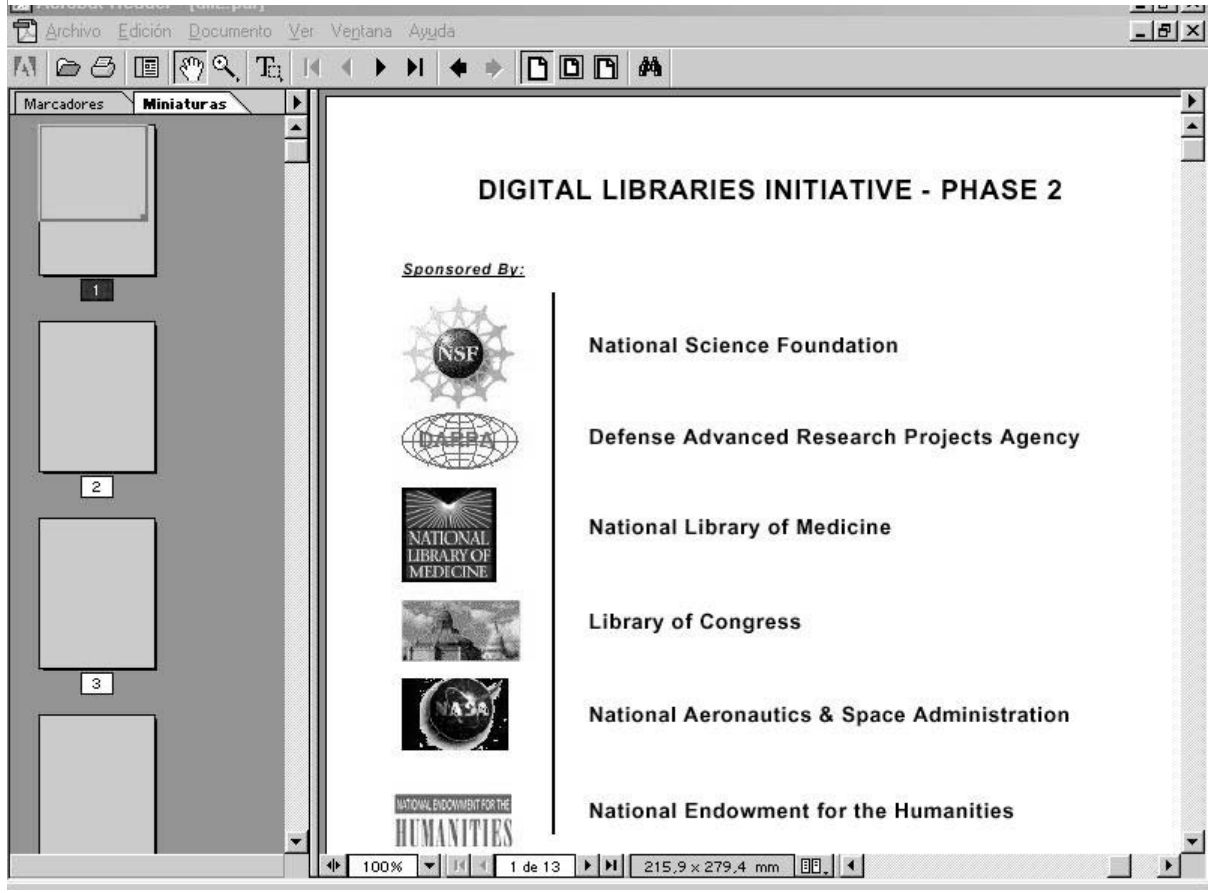

Fig. 8.1. Ejemplo de distribución de documentos impresos en formato digital (fase 2): manual de descripción del proyecto Digital Libraries Initiative 


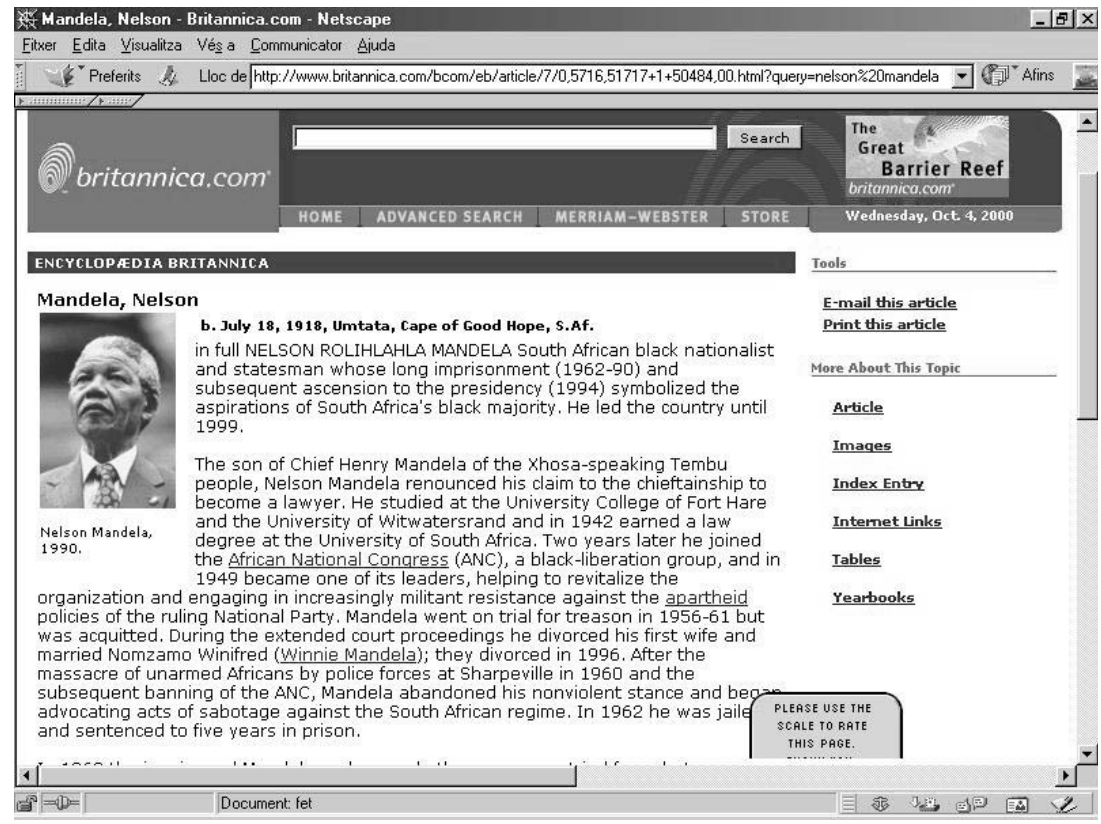

Fig. 8.2. Ejemplo de publicación digital (fase 3): artículo de la versión web de la Enciclopedia Británica

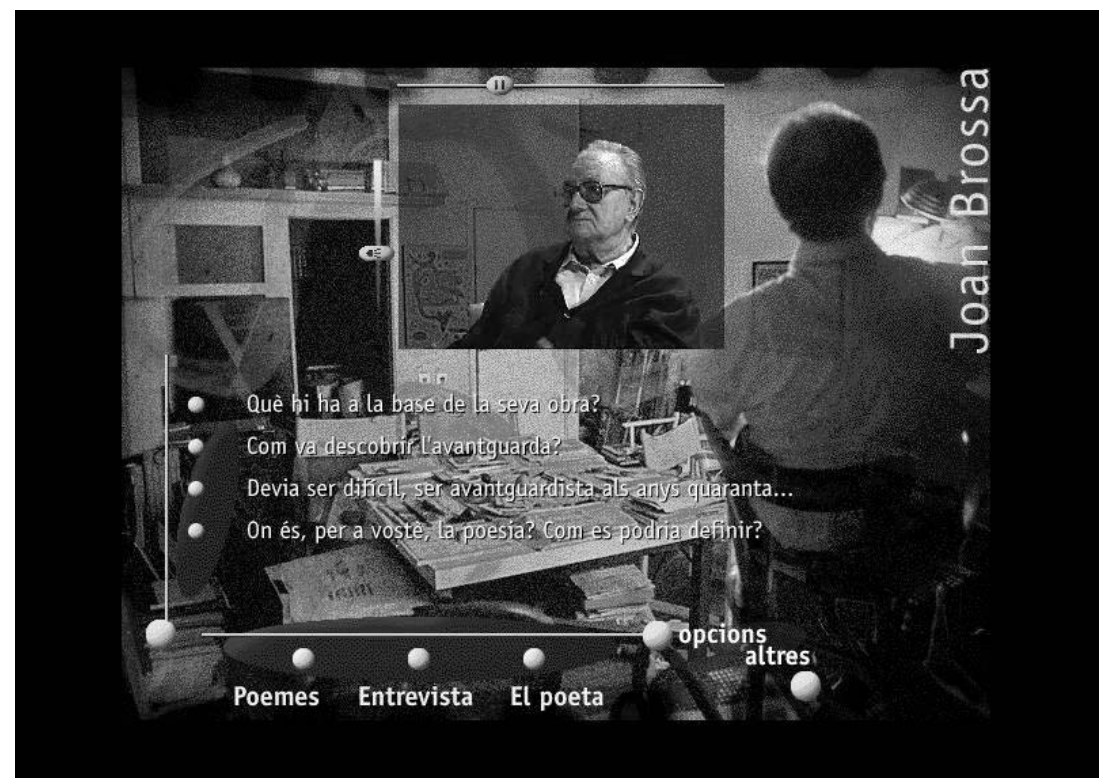

Fig. 8.3. Ejemplo de publicación digital (fase 4): Dotze sentits: poesia catalana d'avui, obra editada en disco óptico que incluye información textual sobre doce poetas catalanes, junto con la filmación de entrevistas, recital de poemas, etc. 
dan los nuevos recursos informáticos con el fin de avanzar hacia un nuevo modelo de publicación que ofrezca nuevas formas de acceso y consulta a su contenido.

\subsection{EL TIPO DE INFORMACIÓN}

Hay otro interrogante que sobrevuela el futuro de las publicaciones y que es de más calado. Se refiere a la disyuntiva entre cultura del texto y cultura de la imagen, y plantea la posibilidad de que la información icónica y multimedia acabe imponiéndose y desplazando a la información textual. El texto ha sido hasta ahora la base para la transmisión del conocimiento. Como muy bien indican los filósofos del lenguaje, tan sólo conocemos aquello que podemos explicar o expresar con el lenguaje. La imagen, ya sea estática o en movimiento, tiene otras características o potencialidades, entre las cuales, no obstante, no se cuenta la posibilidad de difundir conocimiento. No se puede elaborar ningún tratado de metafísica, ni explicar el último avance científico tan sólo con imágenes.

Mientras que no es descartable que, en un futuro no lejano, el soporte digital desplace al papel, y que la publicación digital encuentre un nuevo lenguaje de expresión, es difícil que la información textual deje de constituir la principal forma de difusión del conocimiento. El escritor Stephen Vizinczey (Budapest, 1933) argumentaba muy bien el porqué en unas declaraciones a La vanguardia publicadas con motivo del día del libro:

«La palabra impresa seguirá siendo el medio fundamental de comunicación de masas en el siglo XXI y más allá de él; nunca será desbancada por ningún otro medio. Puede que la mayoría de las personas mire la televisión en lugar de leer, pero eso no rebate la supremacía de lo impreso. Incluso cuando el $99 \%$ de la población era analfabeta, la palabra impresa era el medio más importante y eficaz de transmitir y recibir información, por la sencilla razón de que sólo las palabras pueden comunicar los pensamientos en toda su complejidad, y la forma más fiable de transmitir y conservar las palabras es imprimirlas sobre papel [...].

»Como consecuencia de la creciente influencia de los medios visuales en la atención de las personas, se ha afirmado que ahora la gente aprende de las imágenes todo lo que antes aprendía de los libros. Sin embargo, lo que podemos aprender de las imágenes es lo que puede aprender un perro inteligente: conocimiento no verbal, impresiones sin comprensión. Para comprender tenemos que pensar y, pa- 
ra pensar necesitamos palabras, porque sólo podemos pensar aquello para lo que disponemos de una palabra». (Vizinczey, 1996, 2.)

Ahora bien, su acérrima defensa de la información textual (él la llama «palabra impresa») incurre en una falsa asimilación realizando un salto teórico no explicitado: no se puede confundir la hipotética desaparición del libro impreso con el fin de la cultura del texto. Repetimos aquí un fragmento de su argumentación: «[...] la palabra impresa era el medio más importante y eficaz de transmitir y recibir información, por la sencilla razón de que sólo las palabras pueden comunicar los pensamientos en toda su complejidad, y la forma más fiable de transmitir y conservar las palabras es imprimirlas sobre papel [...].» (Vizinczey, 1996, 2) ¿Por qué la impresión sobre papel es la forma más fiable? ¿Qué diferencia sustancial hay en un texto cuando se imprime en papel o se distribuye por Internet? No se puede identificar el libro digital con la cultura de la imagen y el libro impreso con la cultura textual. Hay que remarcar que se trata de dos temas diferentes y que defender la publicación digital no implica, ni mucho menos, apostar exclusivamente por la cultura de la imagen. La capacidad para distribuir un determinado tipo de información (texto o imagen) no depende, de ninguna manera, del soporte utilizado.

Esta discusión nos lleva a subrayar lo que consideramos que tiene que constituir el mensaje fundamental cuando se habla de los nuevos medios de información: hay que velar por el contenido y por su calidad.

En muchas ocasiones los creadores de servicios de información digital se preocupan en exceso por cuestiones tecnológicas, por presentar la información en el último soporte y con los más variados recursos técnicos aparecidos en el mercado, en detrimento de la calidad de los contenidos. Esto implica que se inviertan considerables sumas en la adquisición de equipos y programas para asegurar la viabilidad técnica de proyectos muy avanzados tecnológicamente, y se destine muy poco a la preparación y estructuración de la información que se quiere suministrar.

«Guión, guión...», claman los expertos de Hollywood para indicar cuál es la llave mágica que abre todas las puertas del éxito en la industria cinematográfica y del audiovisual. Las grandes producciones no tienen el triunfo asegurado tan sólo por el hecho de haber realizado una gran inversión, utilizado los mejores efectos especiales o la última innovación en aspectos de sonido. Lo que será determinante - la mayoría de las veces_ - provendrá de la estructura y riqueza de la historia que se explique. En el caso de los servicios y productos de información digital 
sucede exactamente lo mismo: lo importante es poder disponer de unos contenidos de interés, actualizarlos y estructurarlos correctamente y, posteriormente, prepararlos para ser distribuidos de forma electrónica. Nunca al revés, a pesar de que, lamentablemente, sea lo más frecuente. Sería ilusorio pensar que sólo por el hecho de tratarse de información electrónica podremos aumentar el consumo o la utilización. Se trata de crear buenos productos de información y, a partir de aquí, si se pueden distribuir por vía digital, mucho mejor. 


\section{BIBLIOGRAFÍA}

ABADAL, Ernest: «El futuro de la edición, ¿es electrónico?", Cuartas Jornadas Españolas de Documentación Automatizada, Gijón, Fesabid, 1994, pp. 371-391.

— «'edició òptica a Catalunya», Item, n. ${ }^{\circ} 21$ (julio-diciembre 1997), pp. 8-43.

— «La publicación electrónica: situación actual y perspectivas a medio plazo", Puertas a la lectura, Universidad de Extremadura, n. ${ }^{\circ}$ (diciembre 1998), pp. 37-48.

Abadal, Ernest, y Mei PerpinYÀ: «Trobar informació a Internet: alguns consells pràctics», en Jaume Baró (ed.): Cercar i col locar informació en el World Wide Web, Barcelona, Llibres de l'Índex, 1998, pp. 109-137.

Aguillo, Isidro: «Indicadores hacia una evaluación no objetiva (cuantitativa) de sedes web", VII Jornadas Españolas de Documentación. La gestión del conocimiento: retos y soluciones de los profesionales de la información, Bilbao, Universidad del País Vasco, 2000, pp. 233-248.

— «Internet invisible o infranet: definición, clasificación y evaluación", en VII Jornadas Españolas de Documentación. La gestión del conocimiento: retos y soluciones de los profesionales de la información, Bilbao, Universidad del País Vasco, 2000.

ADAMS, Roy: Comunicaciones y acceso a la información en la biblioteca. Traducción del inglés, David Torra Ferrer. Madrid, Fundación
Germán Sánchez Ruipérez, Pirámide, DL 1994, 319 pp. (Biblioteca del libro, 59).

Alonso, Lluís: «La impresión sobre papel pierde cuota pero aún seguirá creciendo", Ciberpaís, 1 de junio de 2000, p. 6.

ARMENTIA, J. I., y otros: El diario digital: análisis de los contenidos textuales, aspectos formales y publicitarios, Barcelona. Bosch, 2000, 240 pp. Aspectos fundamentales de la liberalización de las telecomunicaciones, Madrid, Ministerio de Obras Públicas, Transportes y Medio Ambiente, DL 1994, 47 pp., ISBN 84-7433-965-0.

BAIGET, T.: «La distribució de bases de dades a Espanya", 3.es Jornades Catalanes de Documentació, Barcelona, SOCADI; COBDC, 1989, pp. 101-141.

— «El giro copernicano de los hosts», Information world en español, n. 36 (julio-agosto 1995), pp. 5-6.

— «El mercado de la información electrónica para uso profesional en España», Anuari SOCADI de Documentació i Informació, Barcelona, SOCADI, 1997, pp. 19-28.

— «Available sources of online information", $T e$ lephassa seminar on information, communication and networking: how to make full use of available information resources: proceedings, Tilburg, Tilburg University Library, 1993, pp. 11-30.

BAIGET, Tomàs: «25 años de teledocumentación en España", Revista Española de Documen- 
tación Científica, vol. 21, n. ${ }^{\circ} 4$ (1998), pp. 373-387.

- Penetración de las tecnologías de la información y la comunicación en la sociedad, Barcelona, 1999.

BARÓ Queralt, Jaume (ed.): Cercar i colllocar informació en el World Wide Web, Francesc Mañà... [y otros], Barcelona, Llibres de l'Índex, 1998, 180 pp. (Quaderns de comunicació, 7).

Barrueco, José Manuel, y Cristina García TesTAL: «Panorama actual y posibilidades futuras en revistas electrónicas", Information world en español, vol. 6, n. ${ }^{\circ} 3$ (marzo 1997), pp. 19-22.

BRADLEY, Phil: Going online, CD-ROM and the Internet, 10. ${ }^{a}$ ed., Londres, Aslib, 1997.

Bustamante, E., y R. ZALlo (eds.): Las industrias culturales en España: grupos multimedia y transnacionales, Madrid, Akal, 1988 (Akal comunicación, 2).

CARRAL, Juan Antonio: «Internet, origen, presente ¿y futuro?», en Ignacio RAMONET (ed): Internet, el mundo que llega, Madrid, Alianza, 1998, pp. 49-60.

CASTElls, Manuel: La era de la información: economía, sociedad y cultura, Madrid, Alianza, 1998, vol. 1: La sociedad red.

Catálogo de servicios españoles de información electrónica ASCI: 1994, edición de Beatriz Ruiz, 7. a ed., Madrid, Fuinca, 1994, 408 pp.

CD-ROM facts and figures'95: from the publishers of The CD-ROM directory, Londres, TFPL, 1995, $24 \mathrm{pp}$.

CHAN, Liza: "Electronic journals and academic libraries», Library Hi Tech, vol. 17, n. 1 (1999), pp. 10-16.

Chen, C. C: «Los soportes ópticos", Informe mundial sobre la información: 1997-98, Madrid, Unesco; Cindoc, 1997.

CODINA, Lluís: Sistemes d'informació documental: concepció, anàlisi i disseny de sistemes de gestió documental amb microordinadors, Barcelona: Pòrtic, 1993, 220 pp. (Mèdia, 9).

- El llibre digital: una exploració sobre la informació electrònica i el futur de l'edició, Bar- celona, Centre d'Investigació de la Comunicació, 1996.

— «Evaluación de recursos digitales en línea: conceptos, indicadores y métodos", Revista española de documentación científica, vol. 23, n. ${ }^{\circ}$ 1, (enero-marzo 2000), pp. 9-44.

— «Parámetros e indicadores de calidad para la evaluación de recursos digitales", en VII Jornadas Españolas de Documentación. La gestión del conocimiento: retos y soluciones de los profesionales de la información, Bilbao, Universidad del País Vasco, 2000, pp. 135-144.

COLLIER, Harry: «Bases de datos europeas: los problemas de un enfoque nacionalista", en J. M. Berenguer (ed.): Bases de datos: retos, oportunidades y esperanzas, Madrid, Fuinca, 1985, pp. 95-102.

Converses a la Pedrera (4. as: 1993: Barcelona): Concentració i internacionalització dels mitjans de comunicació: repercussions socials $i$ culturals, Barcelona, Centre d'Investigació de la Comunicació, 1994, 95 pp. (Monografies i documents, 11).

CoRnella, Alfons: Información digital para la empresa: una introducción a los servicios de información electrónica, Barcelona, Marcombo Boixareu Editores, 1996, XIII, 180 pp.

Derfler, Frank J., y Les Freed: Así funcionan las comunicaciones, ilustraciones de Michael Troller, Madrid, Anaya Multimedia, 1994, IX, 216 pp.

Europa y la sociedad global de la información, Bruselas, 1994, 35 pp.

FEATHER, John: The Information society: a study of continuity and change, 2. ${ }^{\text {a }}$ ed., Londres, Library Association Publishing, 1998, 218 pp.

FuENTES, M. ${ }^{a}$ Eulàlia: La información en Internet, Barcelona, CIMs, 1997, 240 pp.

FolCH, Albert: Atrapats a Internet, Barcelona, Empúries, 1997, 172 pp.

Gale directory of databases, enero 1993-. Detroit, [etc.], Gale Research Inc., 1993-, semestral, 2 vols.

García Moreno, M. Antonia: De la teledocumentación a Internet: la industria española 
de las bases de datos, Madrid, Fragua, 1999, $335 \mathrm{pp}$.

HAWKINS, Donald T: «Electronic books: a major publishing revolution», Online (julio-agosto 2000), pp. 14-28.

Hípola, P., y F. MOYA: «El CD-ROM en España: luces y sombras de nueve años de producción», Revista española de documentación científica, vol. 16, n. ${ }^{\circ}$ 4, (1993), pp. 360-373.

Infonomics, http://www.infonomics.com.

Informe mundial sobre la información: 1997-98, Madrid, Unesco; Cindoc, 1997.

JimÉNEZ, Àngels, Alfons GonZÀLEZ y M. ${ }^{a}$ Eulàlia FUENTES: «Las hemerotecas digitales de prensa en Internet», El profesional de la información, vol. 9, n. 5 (mayo 2000), pp. 15-24.

LANCASTER, F. W.: La publicació electrònica en xarxa dels resultats de la recerca acadèmica, Barcelona, Escola Universitària Jordi Rubió i Balaguer, 1995, 34 pp.

Landoni, Monica, y Forbes GIBB: «The role of visual rethoric in the design and production of electronic books: the visual book", The electronic library, vol. 18, n. 3 (2000), pp. 190-201.

LÉVY, Pierre: ¿Qué es lo virtual?, Barcelona, Paidós, 1998, $142 \mathrm{pp}$.

- La cibercultura, el segon diluvi?, Barcelona, Edicions de la UOC; Proa, 1998, 205 pp.

Libros españoles [fichero informático] Agencia Española ISBN, Madrid, Micronet, 1992-.

LÓPEZ YEPES, Alfonso: Documentación multimedia: el tratamiento automatizado de la información periodística, audiovisual y publicitaria, Salamanca, Universidad Pontificia, 1993, 178 pp. (Manuales, 8).

LYNCH, Mary Dykstra: "Las autopistas de la información", Informe mundial sobre la información: 1997-98, Madrid, Unesco; Cindoc, 1997, pp. 301-321.

MARCos, Mari-Carmen: «La revista electrónica y su aceptación en la comunidad científica", El profesional de la información, vol. 9 , n. ${ }^{\circ} 5$ (mayo 2000), pp. 4-14.

MARTIN, William J.: The Global information society, Londres, Aslib [etc.], 1995, 233 pp.
MATAS, Toni: «Los lenguajes del producto multimedia", en IV Jornadas sobre bibliotecas infantiles: la lectura multimedia y los nuevos lectores, Salamanca, Fundación Germán Sánchez Ruipérez, 1996, [20] pp. [Toni Matas: «Productes multimèdia: disseny i anàlisi conceptual», Anuari SOCADI de Documentació $i$ Informació: 1997, Barcelona, soCADI, 1997, pp. 101-112.]

Mattelart, Armand: «Excepción o especificidad cultural: los desafíos del GATT», Telos, 42, pp. 15-27.

— «Lo que está en juego en la globalización de las redes», en Ignacio RAMONET (ed.): Internet, el mundo que llega, Madrid, Alianza, 1998. pp. 19-31.

Millán, José A.: «La edición electrónica y sus metamorfosis", Delibros (junio 1997), pp. 46-49.

— «Página personal de José Antonio Millán», 1999-2000, <http://jamillan.com> [consulta: 02/10/2000].

MOORE, Nick: «La sociedad de la información», Informe mundial sobre la información: $1997-$ 1998, Madrid, Unesco; Cindoc, 1997, pp. 287300.

MuXaCH, Santiago: «El Web», Item, n. ${ }^{\circ} 16$ (1995), pp. 4-33.

Negroponte, N.: El mundo digital, Barcelona, Ediciones B, 1995.

Nieto, A., Y A. SÁncheZ-TABernero: Servicios comerciales de información, Barcelona, Ariel, 1996, 190 pp. (Ariel comunicación).

NorA, Simon, y Alain Minc: La informatización de la sociedad, 1. ${ }^{a}$ reimp., México [etc.], FCE, 1982, 244 pp. (Colección popular, 204).

Ortega y Gasset, J.: Misión del bibliotecario, Madrid, Austral, 1985.

Panorámica de la edición española de libros: 1998, Madrid, Ministerio de Educación y Cultura, Dir. Gral. del Libro, Archivos y Bibliotecas, 1999.

Platón: «Fedro», Obras completas, 2. ${ }^{a}$ ed., 5. ${ }^{a}$ reimp., Madrid, Aguilar, 1981.

PrICE, Derek de Solla: Hacia una ciencia de la ciencia, Barcelona, Ariel, 1973, 181 pp. 
RAMONET, Ignacio (ed). Internet, el mundo que llega. Madrid, Alianza, 1998, 303 pp.

Recoder, M. J., E. Abadal, y L. Codina: Información electrónica y nuevas tecnologías, Barcelona, PPU; ESRP, 1991, 168 pp.

«Revistas-e: estado del arte», reseña de Tomàs Baiget, El profesional de la información, vol. 9, n. 9 (sept. 2000), pp. 26-35.

Rowley, Jennifer. «The question of electronic journals», Library Hi Tech, vol. 18, n. 1 (2000), pp. 46-54.

SHATZKIN, Mike: «Las editoriales y las nuevas tecnologías», Delibros (abril 1997), pp. 38-41.

Strategic developments for the European publishing industry towards de year 2000: Europe's multimedia challenge, Bruselas; Luxemburgo, ECSC-EEC-EAEC, 1996.

Tecnologías documentales: memorias ópticas. Por María Blanca Espinosa, José María Izquierdo, Juan C. Pérez Espinosa y José L. del Río; coordinador, Félix Sagredo. Madrid, Tecnidoc, [1994], 317 pp.
TerCeIro, José B.: Sociedad digital: del homo sapiens al homo digitalis, Madrid, Alianza, 1996, 245 pp.

TORRÈs, Asdrad: «¿Hay que quemar Internet?», en: Ignacio RAMONET (ed): Internet, el mundo que llega, Madrid, Alianza, 1998, pp. 165173.

Tremblay, Gaëtan: «Las autopistas electrónicas: modelos y desafíos", en Converses a la Pedrera (5..$^{\text {as: }}$ 1995: Barcelona), Autopistes de la informació, Barcelona, Centre d'Investigació de la Comunicació, 1995, pp. 11-24.

Ulrich's international periodicals directory. Nueva York, Bowker, 1932-, <http://www.ulrichsweb.com>.

VIZINCZEY, S.: «La comunicación exige imprenta", La vanguardia (Especial Sant Jordi), 23 de abril de 1996, p. 2.

Williams, Martha. "The state of databases today: 1999", en: Gale directory of databases, Detroit [etc.], The Gale Group, 1999, pp. XVIIXXIX. 


\section{ÍNDICE ANALÍTICO}

A

acceso a la información, 132

ACNielsen, 94

actualización, 133

Administración pública., 24

Adonis, 56

America Online (aol), 20, 52

Anaya Multimedia, 111

Arpanet, 81-82

ASCII, véase formato ASCII

Asociación de Usuarios de Internet, 94

audiotex, 22

autopistas de la información, 18

autor, 22

B

bases de datos, 44

consulta, 31

definición, 44

tipología, 45

bases de datos científico-técnicas, 48-49

bases de datos económicas, 50-51

bases de datos en línea

distribución, 75

España, 73-76

EUA, 69

Europa, 71

orígenes, 68-71

bases de datos fuente, 44,74 bases de datos gran público, 51-52

bases de datos referenciales, 44, 74

broker, véase documentalista

buscadores, 88

Buscopio, 86

Bush, Vannevar, 30

búsqueda por patrones, 30

búsquedas semánticas, 30

\section{C}

castellano, 125-129

CD-A, 103

CD-I, 103-104

CD-R, 103-104

CD-ROM, 102-103

CERN, 82

Chemical Abstracts, 68

Clinton, bill, 86

Comunicación, 25

comunicación oral, 13

concentración, 120-122

control de contenidos, 96-97

cultura de la imagen, 138-140

cultura del texto, 138-140

D

derechos de autor, 64, 117

Dialog, 49

discos ópticos, 99-100 
distribución, 32-33

distribuidor, 26-27

DNS, 81

documentalista, 36

DOI, 117

DVD, 104-106

comercialización, 106

E

ecuación de búsqueda, 30, 37

edición digital, 42-43

edición óptica

España, 111-113

oportunidades, 115-116

orígenes, 109-110

problemas, 113-115

Efe, 24

EGM (Estudio General de Medios), 93

empresas de telecomunicaciones, véase

operadores de telecomunicaciones

Enciclopedia Británica, 24

Enciclopedia Catalana, 24

entretenimiento, 26

explosión de la información, 15

\section{$\mathrm{F}$}

formato ASCII, 67, 77

G

Gale directory of databases (portable), 107-108

Gale directory of databases, 72

GATT, 122-123

globalización, 122

$\mathrm{H}$

hipertexto, 29-30, 83

HTML, 83

HTTP, 83

idioma, 125-129 índices temáticos, 86

Industria editorial, 24

industrias de la cultura, 119-120

información corporativa digital, 63-64

información digital

sector, 21

Informe Bangemann, 18

Informe Delors, 18

infranet, 92

inglés, 125-129

interactividad, 132-133

Internet, 79

España, 93-94

lentitud, 95

orígenes, 80

seguridad, 96

servidores, 83

usuarios, 84, 93

Internet Public Library, 90

Internet Society (ISOC), 82

ISBN, 108

ISDN, véase RDSI

$\mathrm{L}$

La Vanguardia Digital, 26, 60

lengua, véase idioma

lenguaje de interrogación, 30

Lévy, Pierre, 13, 14

liberalismo, 123

liberalización de telecomunicaciones, 34

Libro verde de las telecomunicaciones, 34

libros digitales, 52-55

localizadores de recursos, 84-86

localizadores especializados, 90

\section{M}

Mac Bride, Sean, 124

Micronet, 110-111

microordenador, 38-39

Microsoft, 20, 120

Minc, Alain, 17

módem, 35 
monopolio, 120-121

multilingüismo, 128

multimedia, 41

$\mathrm{N}$

National Science Fundation, 82

navegación de tipo jerárquico, 28

navegación hipertextual, 29-30

navegador, 84

New media titles, 107

NOMIC, 123-125

Nora, Simon, 17

$\mathrm{O}$

Oficina de Justificación de la Difusión (OJD), 94

operadores de telecomunicaciones, 34

Ortega y Gasset, José, 15

\section{P}

PC, véase microordenador

pago por visión, 59, 65

Panorámica de la edición española, 112

Planeta, 111

Platón, 13

Plutarco, 14

prensa digital, 59-63

Price, Derek S., 15

proteccionismo, 123

Prous Science, 74

proveedor de servicios, 23

PTT, véase operador de telecomunicaciones

R

RDSI, 35

recuperación de información, 27-32

redes de telecomunicaciones, 18 , 19, 3436,69
RedIris, 93

Reuters, 50-51

revistas digitales, 55-59

Rocket eBook, 54

RTB (Red Telefónica Básica), 35

RTD (Red de Transmisión de Datos), 35

\section{$S$}

sistema de gestión de bases de datos, 44

SoftBook, 54

SOSIG, 86

$\mathrm{T}$

TCP/IP, 81

telemática, 16,17

televisión, 97

Televisión sin fronteras, 123

Tena, 26, 86

Transacciones, 134

transportabilidad, 80

$\mathrm{U}$

Unesco, 124

usuario, $37-38$

V

videotexto, 17, 32

W

WAP (Wireless Application Protocol), 39 web, 79, 82-84

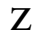

Zeta Multimedia, 111

Yahoo!, 26, 28 




